\title{
Integrating Bioinformatics and Computational Biology: Perspectives and Possibilities for In Silico Network Reconstruction in Molecular Systems Biology
}

\author{
Rui Alves ${ }^{*}, 1,2$, Ester Vilaprinyo ${ }^{1,2,3}$ and Albert Sorribas ${ }^{1,2}$ \\ ${ }^{I}$ Departament Ciències Mèdiques Bàsiques; ${ }^{2}$ Institut de Recerca Biomèdica de IRBLLEIDA; ${ }^{3}$ Institut d'Investigació \\ Biomèdica de Bellvitge (IDIBELL), Spain
}

\begin{abstract}
There is a flood of molecular data about many aspects of cellular functioning. This data ranges from sequence and structural data to gene and protein regulation data, including time dependent changes in the concentration. Integration of the different datasets through computational methods is required to extract biological information that is relevant from a systems biology perspective.

In this paper we discuss how different computational tools and methods can be made to work together integrating different types of data, mining these data for biological information, and assisting in pathway reconstruction and biological hypotheses generation. We review the recent body of literature where such integrative approaches are used and discuss automation of data integration and model building to generate testable biological hypotheses. We analyze issues regarding the design of such automated tools and discuss what limitations and pitfalls can be foreseen for the automation and what solutions can computer science and biologists provide to overcome them.
\end{abstract}

\section{INTRODUCTION}

Molecular systems biology is a broad discipline in which computational methods play a central role. Most researchers will agree that molecular systems biology ultimately aims at understanding how molecular systems function when they are assembled. Thus, pathway and circuit reconstruction and mathematical modeling of the corresponding networks, are central issues in this research area. Because of its inherent diversity, different "origins" are acknowledged for the field $[1,2]$.

From an historical point of view, the use of mathematical models and computer simulations in molecular biology can be traced at least to the early fifties. Its use appears to have been introduced by Britton Chance, Benno Hess, Joe Higgins, David Garfinkel and their colleagues [3-7]. They used modeling to achieve a more systemic understanding of the processes they were studying experimentally. Such processes ranged from the kinetics and mechanism of catalase action to glycolytic oscillations [3-7]. In the sixties and seventies a few other research groups entered the field, and applied engineering control theory to the study of biological systems [8-16]. Also in the sixties, researchers started taking advantage of the computer capabilities for data organization and analysis. The work of Fitsch [17-19], and its further development by Needleman and Wunsch in 1970 [20] and by Smith and Waterman in their seminal 1981 paper [21], would set the stage for the bioinformatics revolution that took place during the last decade in the twentieth century.

This revolution was in all likelihood prompted by an accumulation of gene sequences and protein sequences and

\footnotetext{
*Address correspondence to this autor at the Departament Ciències Mèdiques Bàsiques, Universitat de Lleida, Montserrat Roig 2, 25008 Lleida, Spain; E-mail: ralves@cmb.udl.es
}

structures. The accumulated data required the development of advanced computational tools for their analysis and organization, leading to the bioinformatics burst. As a consequence of the working capacity of the post-genomic high throughput (HTP) techniques and of the capabilities of computer tools, the old reductionism paradigm shifted towards an integrative view of the molecular biology problems. Albeit not new, this integrative view shifts attention from bioinformatics into (molecular) systems biology, which is sensed as a new frontier in biology. This shift was predicted by Bertalanffy and others as early as in 1940 [22]. The current recognition of this new paradigm has been fueled, among others, by Horishi Kitano and John Doyle [22-28].

The size and scope of the accumulated HTP data sets have made it impossible for any one person to analyze and integrate them all, even if one is only interested in a specific molecular biology process on a given organism. However, such integration is fundamental to reconstruct the molecular networks involved in cellular processes and to obtain a systemic perspective of how those networks function. Thus, researchers need tools that assist with processing, filtering, organizing, and appropriately displaying the complex information that is available. Furthermore, automation of analysis and integration is also fundamental for an effective use of that information.

The increasing availability of computational power and storage capabilities, described for example by Moore's law [29], facilitates the creation of CPU-demanding algorithms. These algorithms can be used to build software applications that can manipulate the different available datasets, integrate the information they contain, and display the end result of the analysis in a user friendly format. Web based applications play an important role in making all these software tools available to most scientists. Efficient information mining and integration, and an appropriate display of the results facilitates in silico reconstruction of the molecular networks 
that regulate and execute relevant molecular biology processes.

In silico pathway and circuit reconstruction is an important area within systems biology, and it has consequences for molecular biology, genetics, biotechnology and others. The reconstruction ultimately generates hypotheses regarding the connectivity and dynamic behavior of pathways and circuits that must be validated against experimental predictions data. Different types of in silico reconstruction problems exist:

(1) Identifying the pathways, genes and processes/functions that are encoded in the entire genome of an organism. This provides information regarding possible qualitative systemic responses of the cell. As a first approach to this reconstruction problem, one may map the annotated genes onto pre-existing charts of metabolism, gene circuits and signal transduction. This action may reveal limitations in adaptive responses of that organism. For example, if no amino acid biosynthetic pathways are found, then this organism is not likely to survive in a medium without and external amino acid source.

(2) Reconstructing the detailed reaction network that exists within specific pathways or circuits (see for example [53-59]). An important aspect in this type of research is the reconstruction of novel pathways and the identification of new components in classical pathways. This is a relevant problem because, either in well characterized organisms or with the sequencing of metagenomes [60], many genes of unknown function exist and several previously unknown pathways are being discovered. This type of reconstruction may allow for more precise predictions regarding how specific parts of the cellular response are regulated and executed, facilitating the creation of mutated organisms with biotechnological interest.

Reconstructing regulatory networks in gene expression and signal transduction. For example, identifying regulatory motifs in DNA will provide indication of what transcription factors may regulate the expression of different proteins and genes that are involved in specific processes (e. g. [61-63]). At the metabolic and signal transduction level, reconstruction of the detailed regulatory networks for the enzymes in a pathway is a requirement for accurate and quantitative prediction of the dynamic cellular behavior in response to environmental challenges.

In this paper we focus on and review the use of HTP datasets for the in silico reconstruction of metabolic pathways, signal transduction pathways, and gene circuits.We frame the reconstruction in the context of computational molecular systems biology, an emerging field that merges bioinformatics, and computational biology. Within this context, we shall discuss the data sets and computational approaches that can facilitate that reconstruction. Then, we review the literature for work that uses an integrative computational approach for this reconstruction and discuss automating the integration process. Finally, we discuss the various problems that hinder automation of integration and analysis of the data sets. We discuss in more details some of the technical aspects of the research reviewed in the main paper and provide further references to other sources of information in a supplementary appendix.

\section{WHAT IS OUT THERE? AUTOMATED DATA ANA- LYSIS IN THE AGE OF OMICS}

Pathway reconstruction requires integration of knowledge at many different levels. Before discussing this integration, we briefly characterize each of the various types of datasets that are available for in silico reconstruction of molecular biology pathways. Also, we shall discuss the different methods and tools that are more commonly used a) to mine these datasets, and b) to extract network information and facilitate pathway reconstruction.

\section{Bibliomic Data}

Bibliographic data has been accumulating for more than a century. Databases such as MEDLINE [64] or the Web of Science Citation Index [65] collect and organize data from this published literature. Through automated keyword analysis, search engines can identify relevant documents in these databases. These documents can be mined for information on genes, pathways, and networks of interest. Most of these documents concern specific, detailed studies about small sets of genes, proteins, RNAs or metabolites within specific organisms. In many cases, this data provides a detailed functional analysis of many individual genes, using methods that are more accurate than those used to obtain HTP data.

Manual and electronic literature analysis has been used for metabolic reconstruction since researchers started creating mathematical models for molecular biology processes [4]. Currently, literature searches are limited at automatically generating a possible network structure for a given molecular process, although they can easily identify papers containing information that is relevant for the reconstruction of that network. In fact, most mathematical models of molecular pathways and circuits are based upon information that was manually retrieved from literature (for example [66] or [67]).

The recent development of tools such as iHOP [68-71] or biobibliometrics [71] allows researchers to automatically reconstruct networks of genes and proteins from automated literature analysis [68-71]. The underlying assumption of these methods is that identifying gene and protein names that co-occur in the same document(s) generates a network of genes/proteins that are functionally related among them. These network reconstruction methods have been used as a starting point to reconstruct pathways such as the Iron Sulfur Cluster (ISC) biogenesis in Saccharomyces cerevisiae [55] or to identify genes involved in some types of cancer [72]. However, such a network should be viewed as a low level reconstruction of the molecular pathways that are involved in the processes for which those specific genes are important. Further analysis is advisable before one claims that the automatically generated network is a complete conceptual model of the processes of interest.

The largest fraction of the textual scientific information contained in a paper is unavailable if one mines Medline 
exclusively, because the full text of the papers is not included in this database. The PubMed, SCOPUS, PLOS, and BioMedCentral initiatives are crucial in making full text of scientific papers publicly available [73-76]. The ongoing efforts from scientific journal to make their contents fully available on line also contribute to this effort. There is strong awareness that molecular systems biology research will greatly benefit if information mining from text can be automated to a higher degree than it currently is $[61,69,77]$.

\section{Sequence Data, Functional Data, and Structural Data}

Databases of annotated gene and protein sequences facilitate the subsequent functional annotation of new genomes, through the use of homology comparisons. Gene or protein sequences from different organisms that have very high similarity (homology) are likely to have the same function. Sequence data can also be mined to predict a) regulatory regions and open reading frames of genes, b) RNA genes, and c) targets for regulation by these RNA genes (see supplementary appendix). The accumulated functional knowledge about genes and proteins facilitates the creation of charts for metabolism, signal transduction and gene circuit for the different organisms with fully sequenced and annotated genomes (see for example [78-81]). In such charts, the individual function of a protein is superimposed onto the particular steps where that protein is active. An example where genome annotation has been used to reconstruct the full complement of metabolic pathways for Lactobacillus plantarum can be found in $[45,49]$. Sequence based annotation is not possible when a new gene is not homologous to any gene of known function. However, if structural information can be gathered for the protein coded by that gene, structural homology comparisons may also facilitate attributing general or specific functions to individual genes, for example using classifications such as SCOP or CATH [82-92]. Knowing the structure of a protein (or RNA gene) can elucidate the mechanism by which these molecules perform their function. Furthermore, having structural templates allows the prediction of structures for other homologous proteins.

Even when homology is not useful for functional annotation, sequence information can still be used to infer some functional information. For example, one can use phylogenetic conservation to investigate possible functions of the genes. The logic behind phylogenetic conservation analysis is as follows. If a set of homologous genes with unknown function is present (absent) with other genes of known function in the same set of genomes, then it is possible that evolution acted simultaneously on that set of genes because somehow they share a function. This may with other genes of known function allow the researcher to predict that some genes are involved in the same processes, although their individual function may remain uncertain. Such an approach has been combined with other lines of evidence, to identify the proteins Yfh1 [93] and Grx5 [58] as being involved in ISC biogenesis. Another example is the application of phylogenetic analysis to the reconstruction of the Coenzyme A biosynthesis pathway in different archaeal genomes [94] and for the reconstruction of parasite nucleotide biosynthesis [95]. A similar method for inferring function is that of finding gene fusion events. Such events imply that two genes share common function $[96,97]$ and maybe even common regulation, as appears to be the case for example in the biosynthesis of aromatic amino acids in low GC Gram-positive bacteria [98].

Sequence based reconstruction of gene circuits can be more complex than sequence based reconstruction of metabolic and signal transduction pathways. The reason for this is that regulatory sequences in DNA are shorter than coding sequences. This creates a lower signal to noise ratio in their detection, when compared to identifying a full gene. Identification of gene circuits units within a genome can be done for example by searching for regulatory motifs or sequence patterns upstream of gene promoters. Confidence in the accuracy of the regulatory units predicted by this method is increased by finding that such motifs are phylogenetically conserved in different organisms [99-108]. This type of analysis has been used for example to identify novel targets of the Eyeless transcription factor in Drosophila [109], to identify transcription factors that regulate human gene expression [110], to identify novel gene circuits for amino acid transport and glucose in $S$. cerevisiae $[111,112]$ or to predict operons in Pyrococcus furiosus [113]. An intense research effort to understand RNA gene circuits is also under way [114-121]. Only when this new layer of regulation is fully understood and integrated into the reconstruction efforts, can one have full reconstruction of gene circuits. Progress in this area is fast and different groups are already reconstructing RNA gene circuits in bacteria and other organisms by integrating the distinct types of information discussed in this section of the review [122-127].

\section{Gene Expression Data}

Different types of mathematical analysis allow researchers to infer functional genetic modules and circuits from the analysis of high and low throughput gene expression data [128-136]. Statistical theory and information theory is extensively used to infer regulatory network structures from gene expression data [137-147]. For example, if a gene/protein of unknown function is differentially regulated during some cellular response, then one might infer that this gene is involved in that response. The set of genes responsive to human interferon beta [148, 149] or that of genes involved in the development of rat central nervous system [150] have been reconstituted from microarray data. However, one must always keep in mind that post-translational regulation and fine tuning of enzyme activities may work to modify the importance of changes in gene expression. This may complicate the interpretation of gene expression profiles.

Available gene expression data is often static, in the sense that it is measured at a specific time during the response and no other previous or subsequent measurements are available. Static gene expression data, in general, do not provide significant information about the specific function of a gene in the response. Exceptions might be for example situations where only one protein is missing in a circuit or pathway that is well known. In such cases, if only one gene of unknown function is identified in the expression data, its function is likely to be the one that is missing. Alternatively, it may be possible to infer sequential action of transcription factors in the gene circuit, by using time series data from microarray experiments [151-153]. For example, the network of gene activation in macrophage response [154], the p53 
network in human leukemia cell lines [155] and the regulation of galactose biosynthesis [156] have been studied using this type of analysis.

\section{Proteomics Data}

Proteomics experiments in which measurements of protein levels and activity are made can also assist in network reconstruction. Having such data is important and complementary to the gene expression data. In fact, proteomic data is required to ultimately refine the network structure of circuits and pathways and assess their functionality in vivo. This is so because there are cases in which the levels of the protein that is coded by a gene can change in response to some stimulus, even though expression of that gene is unchanged and no interaction with other proteins has been previously reported. In addition, proteomics analysis may reveal changes in the activity of proteins in responses to challenges that were previously unknown to affect their activity. This kind of information is still lacking for most organisms and cell types.

Proteomics studies are in their infancy, when compared to gene expression studies. Nevertheless, they have been used for pathway reconstruction in various cases. HTP proteomic experiments led to the discovery of networks of direct physical interaction between proteins in different organisms [157-172]. Finding which proteins interact physically with those of unknown function sheds light upon the processes in which the later proteins may be involved in, thus facilitating the reconstruction of their role in the cell. However, one should keep in mind that these experiments may detect false positive interactions and fail to detect real interactions, due to the experiments being made under inappropriate physiological conditions. In addition to detection of protein interactions, proteomic approaches have been used to a) identify the kinases that are necessary for cell cycle progression in Drosophila [173], b) reconstruct human phosphorylation networks [174], c) reconstruct the network of growth factor signaling in cancer cells [175], d) study the pheromone response in yeast [176], and e) study signal transduction in plants [177, 178].

It is still unfeasible to use large scale proteomic assays to measure changes in the activity of the full protein complement of an organism. However, the development of protein chips that identify binding of protein to DNA [179] and allow measuring of enzyme activity for whole pathways [180, 181] suggests that such a goal may be attainable in the future.

\section{Metabolomic Data}

Metabolomics data can also, in principle, be used to reveal information about pathway and circuit connectivity $[182,183]$, to estimate parameter values, and to validate and refine models of specific cellular processes [184, 185]. These very important points would justify a wide program of metabolomic experiments. Without this kind of measurements, validation of mathematical models for specific metabolic processes may be difficult. Furthermore, one can infer which reactions and which steps causally precede others in a metabolic or signal transduction network, by measuring the changes in the concentration of metabolites or signaling molecules over time. Such an analysis has been performed to predict the sequence of glycolytic reactions [186] and to further refine the regulatory network of glycolysis in Lactococcus lactis [184].

\section{USING MOLECULAR DATA TO PREDICT SYS- TEMIC BEHAVIOR}

In the previous section we presented a selection of the data that are available for in silico inference and reconstruction of network and pathway topology. A given network topology should be able to explain the experimental behavior of a system, if that topology underlies the process that regulates the biological response being measured. However it is often impossible to use common sense for judging how well a given network explains some dynamic response, because the dynamic behavior of biological systems is non-linear. To overcome such a limitation, topological schemas can be used to create mathematical models whose dynamical behavior can be rigorously analyzed and compared to what is experimentally observed. This validation process is fundamental in testing the correctness of in silico pathway reconstruction.

\section{Building Mathematical Models}

Mathematical models can be created for networks of different scales. Some researchers are interested in modeling the entire metabolic network found in a genome (e.g. [3152]. Such models have been analyzed to predict both, growth characteristics, and essentiality of genes in different organisms using flux balance analysis (FBA) [35, 38, 39, 46]. Although in mathematical terms FBA models are linear, the qualitative predictions of phenotype have so far held for between $60 \%$ and $80 \%$ of the genes [39, 46, 187]. These models inappropriately represent dynamic regulatory effects, which could account for some of the erroneous predictions (see [188] for details).

Smaller scale models that accurately account for dynamic regulation are important for testing more detailed hypotheses about the functioning of specific processes. For example, the regulatory structure of the Iron-Sulfur Cluster biogenesis pathway in $S$. cerevisiae has been validated by comparing the dynamic behavior of mathematical models for alternative regulatory topologies to experimental results [55]. Similarly, models of cell cycle have been validated by comparing its dynamic behavior to experimental results [189-191], and models of the pentose phosphate pathway have been validated by predicting the best targets for treatment of metabolic diseases [192-195].

Statistical methods can be used how well alternative networks can reproduce experimental behavior, if sufficient information is available. For example, one can use optimization algorithms to determine which network more accurately fits the known quantitative behavior of a system [196-198]. Qualitative statistical methods should be used for this evaluation, if the available experimental data is not quantitative. For example tree decision algorithms have been used to analyze the qualitative behavior of signal transduction modeling [199, 200].

Different types of mathematical modeling can be used to study the same biological problem. The choice of a particular type depends on the level of complexity and details one wishes to consider, on the available data, on personal prefer- 
ence, etc. Differential equations, either ordinary (for well stirred systems) or partial (for systems with spatial differentiation), are used to define mathematical models that can quantitatively simulate the dynamics of a molecular system $[4,201]$. This type of mathematical approach is still the most prevalent choice as a modeling tool, although stochastic approaches are becoming popular. Alternative approaches are further discussed in the supplementary appendix.

\section{Bottlenecks in Model Building}

One limitation to the creation of mathematical models is that, for many processes, the parameter values are unknown. Even when parameter values are available, locating them and evaluating if the experimental conditions under which they have been measured are appropriate for our modeling purposes is not easy. Furthermore, automatically identifying documents from the literature in which such information is available is still a task that is hard to automate. Another limitation in creating a mathematical model is when the knowledge about the actual mechanism that underlies many biological processes is lacking. This makes it impossible to derive classical Michaelis-Menten like expressions for the kinetics of those processes. Mathematical representations based on approximate formalisms, such as power-law models, help side-step this lack of information (see supplementary appendix and [202]). Creating a mathematical model is a very work intensive task that is prone to human error. As the dimension of a model increases, automated model building becomes important in decreasing modeling errors. General automated model building is possible only by using structured and systematic formalisms.

Most of these formalisms are mathematical approximations that simplify the exact kinetic expressions representing the dynamical behavior of individual molecular biology processes and reduce the dimension of the system of equations to be solved (for example [203]). Using structured formalisms that are based in approximation theory also sidesteps the lack of knowledge regarding mechanism while building a mathematical model [204]. These approximate representations are accurate over a varying range of values about their operating point [205] and they can be invaluable as canonical formalisms that facilitate automated generation, analysis, and exchange of mathematical models [204]. For a review of these ideas see [202].

\section{INTEGRATION OF BIOINFORMATICS AND COM- PUTATIONAL BIOLOGY FOR AUTOMATED NET- WORK EXTRACTION AND MODEL BUILDING}

Automatic model building that is based on the topological representation of a network requires integration of information at different levels. Fig. 1 outlines in a flow chart how one can integrate the bioinformatics data mining process to the model building process in order to complete the in silico reconstruction of networks. In general, the integration needs to be highly parallelized, allowing for flexible exclusion of one or more types of datasets and for an appropriate interaction with the user.

\section{Outline of the Integration}

A first layer of information (sequence data, structural data, literature data, gene expression data, proteomics data and metabolomics data) available in HTP data sets and published material can be integrated to derive a second layer of processed data. This second data layer contains information about a) gene/protein function and interactions, b) pathway and gene circuit topology, and c) parameter values. The second layer of data also receives direct experimental inputs at different levels. For example, experimentally determined parameter values can be directly integrated into this layer. The data from the second layer can in turn be integrated to generate alternative topological schemas that describe how the pathways and circuits of interest may function. Statistical algorithms, such as decision tree methods or Bayesian analysis, can be used at different stages of the reconstruction to rank the relevance of the information and give users an objective means of deciding what is the most appropriate information to include in the reconstruction.

The topological schemas can be used either to refine preexisting mathematical models or to generate new ones. The dynamical behavior of alternative models can then be compared to the experimental behavior of the system. By using statistical methods to analyze these comparisons, one may objectively rank which schema are more likely to correctly describe the topology that underlies the observed behavior. (Fig. 2) details how the analysis and integration of the different datasets can be accomplished and used for pathway and circuit reconstruction.

\section{The Role of Text-Mining}

Fig. 2A suggests how literature analysis (bibliomics) can be used to generate conceptual models for pathway and circuit reconstruction. Web crawling robots, using Artificial Intelligence (AI) algorithms, can perform automated keyword and contextual analysis of information contained either in literature databases or in live web documents. They can also identify lists of genes that appear to be relevant for the process of interest and generate a tentative topological network by suggesting functions for those genes.

Automated and contextual text analysis may be extremely important to locate information about parameter values and enzyme kinetics and in automatically integrating such information into models. However, human intervention is still the most accurate way for mining this type of information from the literature, which suggests that the need for human curation should always be kept in mind during the different stages of the reconstruction process.

If appropriate standards of model and parameter reporting are defined, automated text mining of parameter values from the literature may be possible. One must be cautious regarding these standards. Many may be tempted to use parameter values and models that are automatically found, without considering the appropriateness of the models for the goals one has and the compatibility between different parameter determinations.

\section{The Role of Mining “omics"}

Fig. 2B suggests how functional information, sequence information and gene expression information (genomics) can be used within a global strategy for pathway reconstruction. By processing sequence information one can automatically identify genes and proteins that participate in a given process 


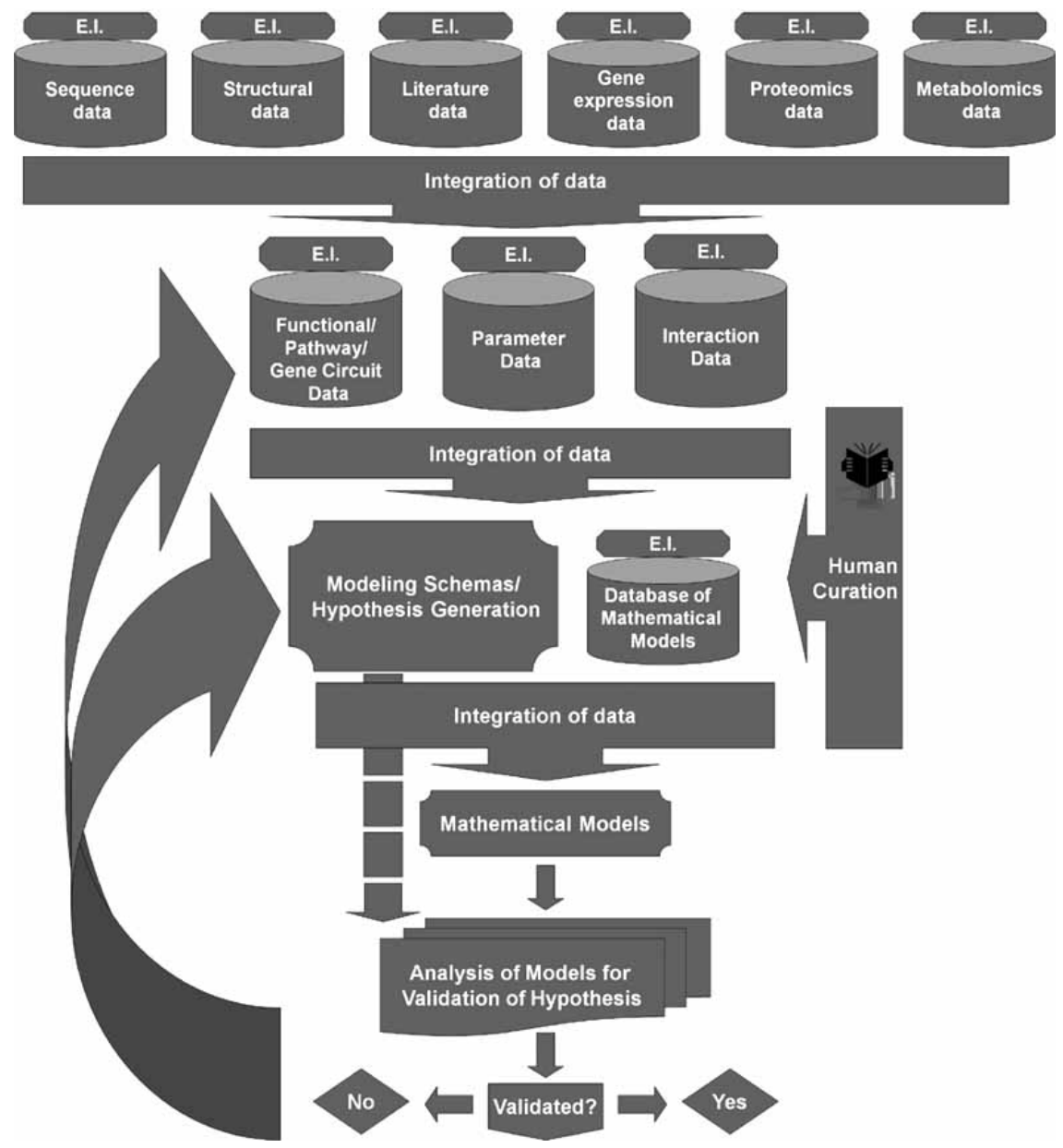

Fig. (1). Integrating the different datasets for pathway reconstruction: An overview. E.I. stands for direct experimental input to a given class of data. Different types of primary data can be used and integrated to infer functional information. Functional information can also be experimentally generated. All the relevant information can be integrated, thus generating conceptual schemas that can be used to generate and test hypotheses regarding the behavior of the molecular system of interest.See text for details.

and generate functional information for those molecules. In parallel, gene expression data can, in principle, also be used to derive some form of causal relationship between changes in the expression of the different genes. Besides identifying/confirming genes involved in the processes of interest, the information processing shown in Fig. 2B can also be used to generate alternative architectures for the topology of gene circuits and pathways.

Fig. 2C suggests that proteomics and interaction data can be used to derive a network of protein and gene interactions. In addition to identifying or confirming previously identified proteins, the interaction data can provide additional hypotheses regarding the previously unknown connectivity in a pathway.

Proteomics and metabolomics data can also be used to infer the sequence in which different proteins act in a pathway and how the activity of the different steps is regulated. "Omics" data may also contain essential information for identifying appropriate parameters for the mathematical models [2], as long as structured formalisms are used to write the model equations and sufficiently dense time series are available in the data. For more information on this subject see the supplementary appendix and references therein.

\section{From Bioinformatics to Computational Systems Biology Through Model Building}

Fig. 2D details the final stage of the integration between bioinformatics and computational systems biology. The user can attribute alternative roles in the network to genes even if they have not been automatically assigned to specific reaction steps or regulatory interactions. Once a final set of alternative schemas for the pathways and circuits of interest are created, the users must decide upon the level of detail that is necessary for their research. Automated search of databases with pre-existing models can find previously build mathematical models of the reconstructed network, if they exist. Once the models are created, they can then be analyzed, validated, and refined. The process of model validation, described in previous sections, can stimulate new research, assisting in the design of experiments that clarify unsolved questions and allowing for rational testing of hypotheses about the systemic behavior of the network.

\section{Examples of Bioinformatics and Computational Biology Integration in Molecular Biology}

It is consensual that the use and integration of different datasets, combined with mathematical modeling is important 
A

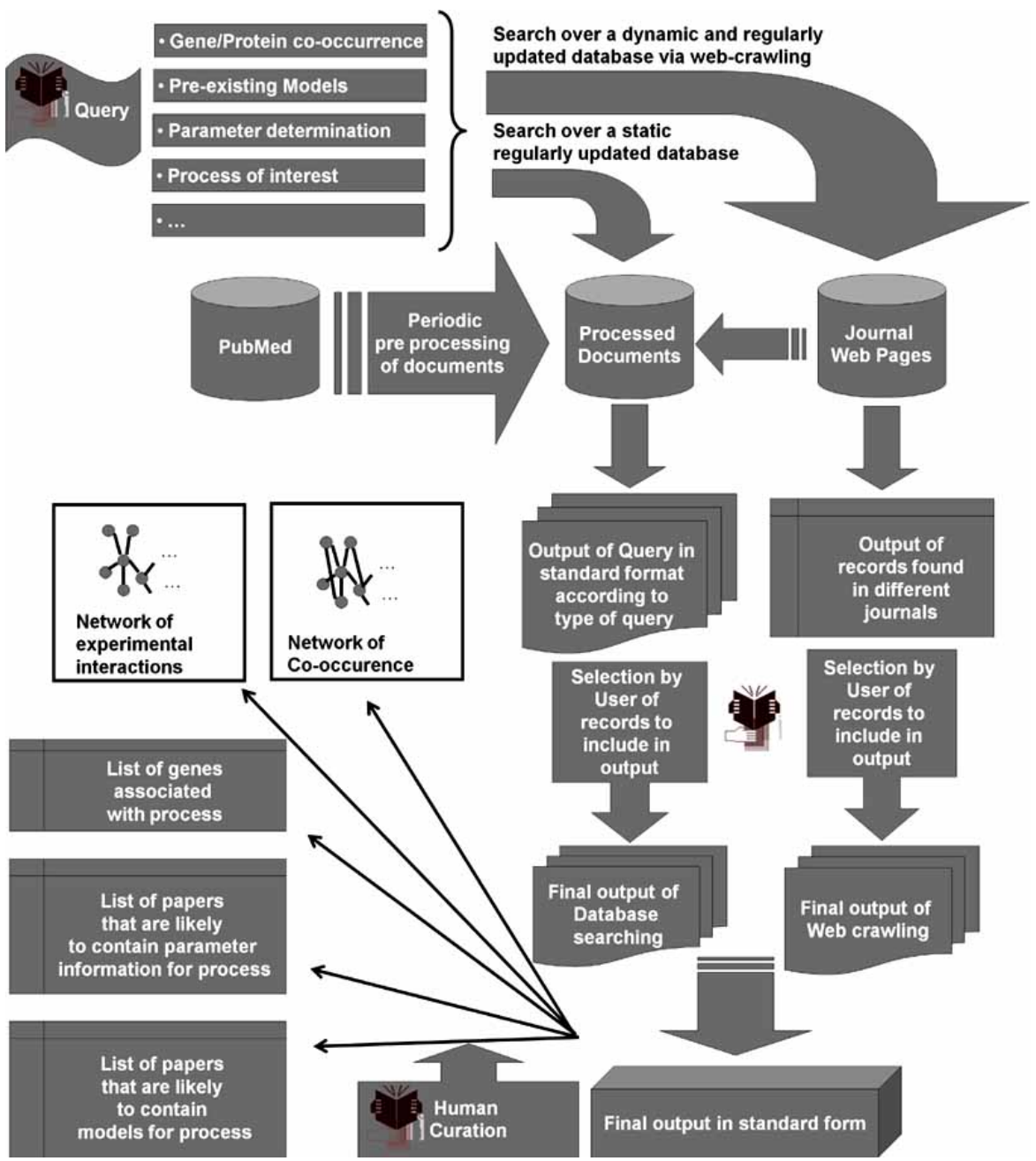

B

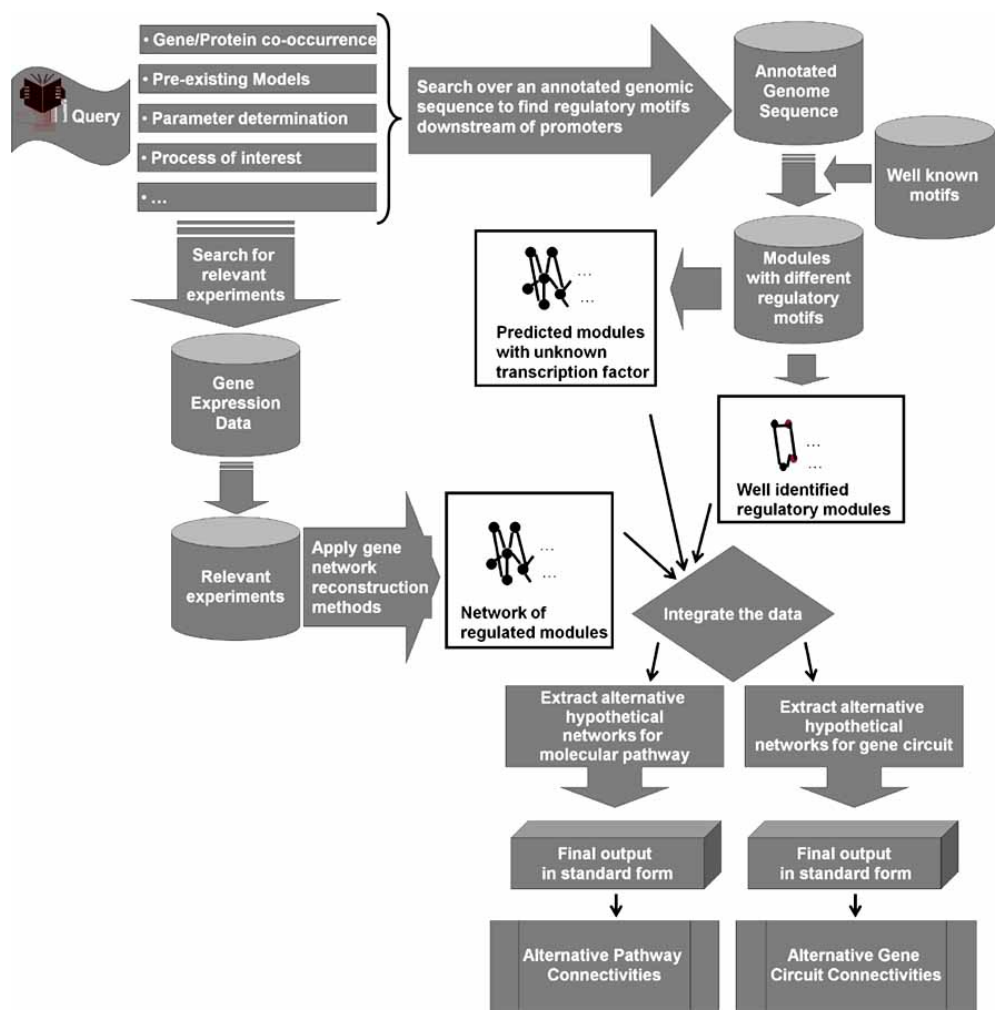


Fig. (2). Contd...

C

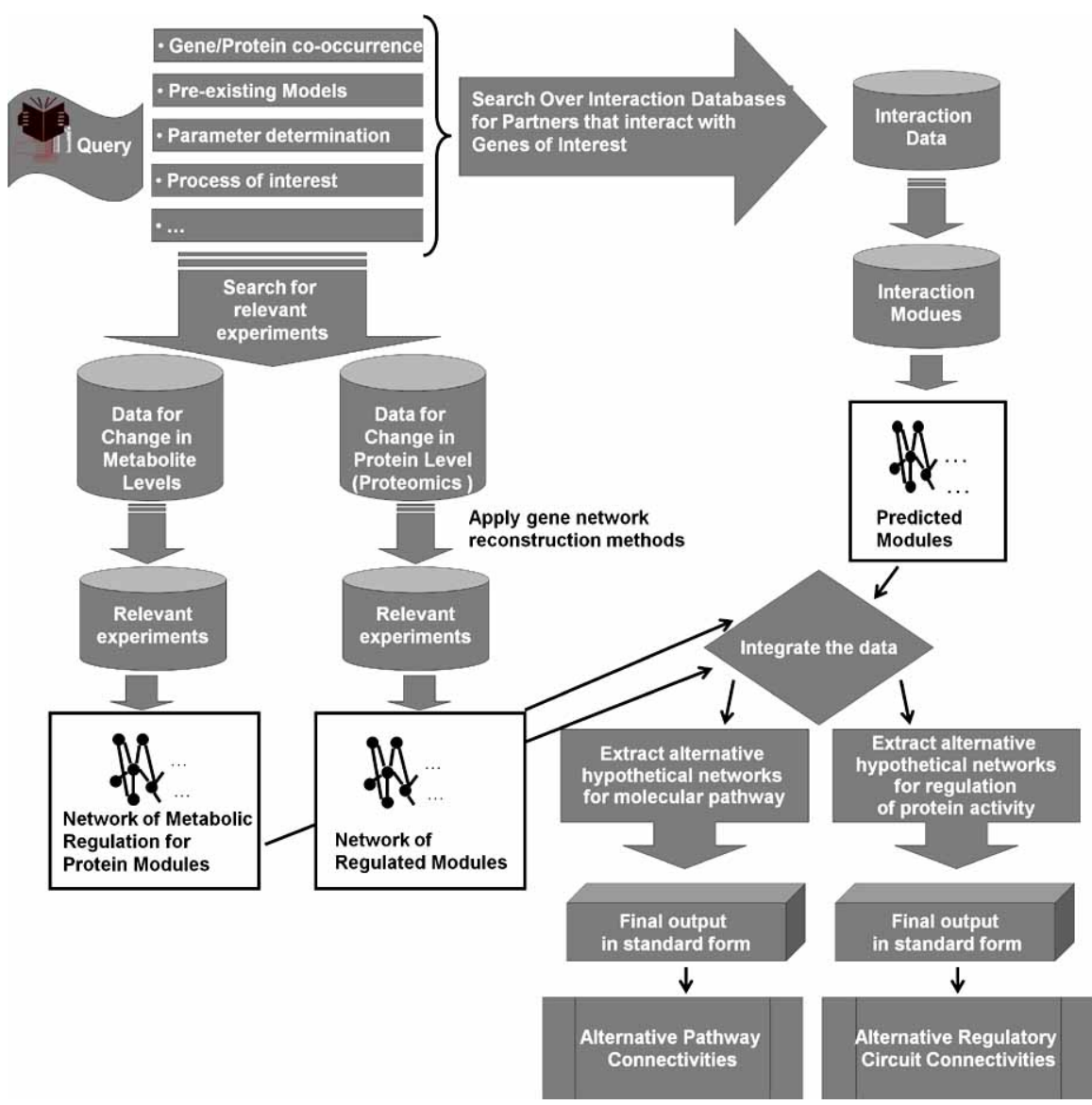

D

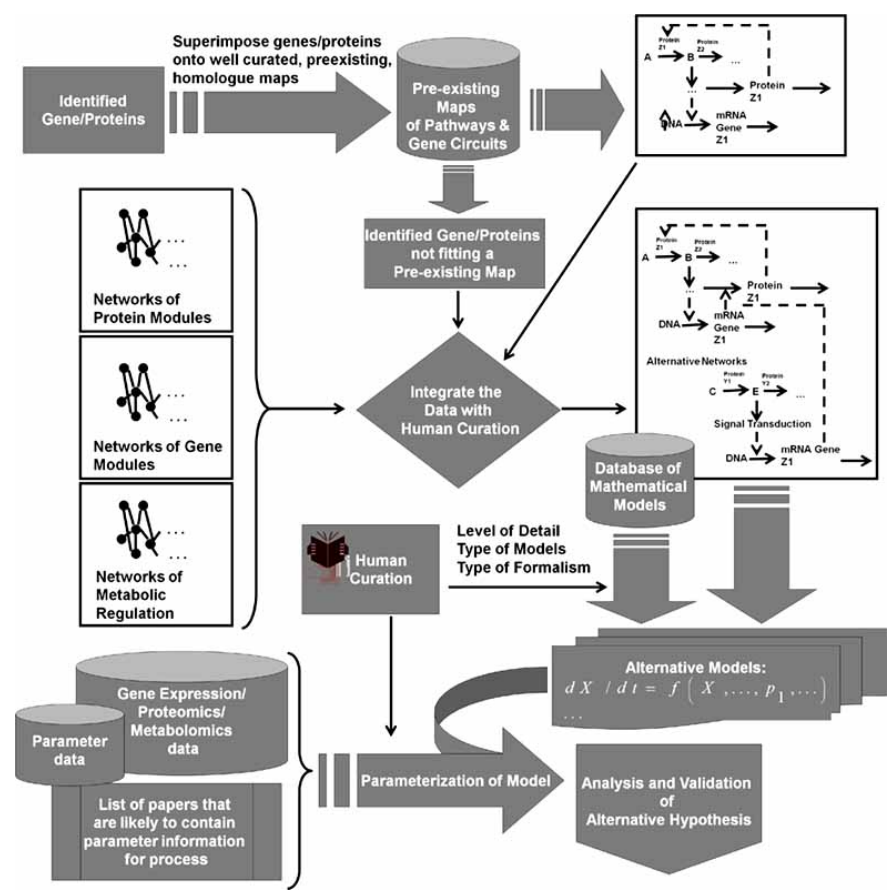

Fig. (2). Detailed schemes for the data mining of the different datasets for pathway and circuit reconstruction. A - Mining the literature. Automated analysis of abstracts and full text of papers can assist in reconstructing functional molecular networks of the cell. B - Mining gene expression data and genome sequence. Combining the analysis of gene expression data with that of sequence data, functional networks of gene regulation can be generated. C - Mining Proteomics and Metabolomics datasets. Proteomics and metabolomics information can be combined to derive protein modules with causal interactions. D - Integrating the data to generate hypotheses and validate models. Integrating the data from $\mathbf{A}, \mathbf{B}$, and $\mathbf{C}$ one can generate mathematical models that can be used to generate and test hypotheses regarding the behavior of molecular systems. See text for a more detailed discussion 
in facilitating and improving the accuracy of in silico reconstruction of molecular pathways in cells [37, 41, 53-55, 61, 206-208]. For example, Alves and Sorribas have combined the use of literature analysis, phylogenetic profiling, analysis of sequences, and protein interaction prediction to reconstruct the regulatory network of mitochondrial ISC biogenesis in yeast [53-55, 58]. Bas Teusink's group has been developing a method, AUTOGRAPH, that combines sequence homology analysis with the existence of well curated metabolic maps to reconstruct the complete metabolic networks of new genomes. They have applied their method to the reconstruction of L. lactis metabolism [41]. Su et al. [209, 210] reconstruct both the pathway of phosphate assimilation and the gene circuits that regulate the expression of that pathway in Synechococcus, by combining genomic information with information about interactions between different genes and proteins. A combination of literature analysis and microarray data analysis has also been used to derive a regulatory network for $E$. coli and to test the consistency of microarray data based predictions [211]. There is an overlap of approximately $80 \%$ between the networks derived by the two methods. A reconstruction analysis of the regulatory network for the galactose biosynthesis pathway in yeast successfully predicts the genes with stronger regulatory influence on the pathway. The analysis has also been made by combining microarray data and protein interaction data [156]. A combination of time series analysis of gene expression and in silico prediction of transcription factor biding sites has been used to define regulatory modules in the inflammatory response of the macrophage, suggesting novel roles for the transcription factors ATF3 and NRF2 [154]. MAPK signaling pathways in the human blood fluke have been reconstructed by integrating phylogenetic conservation analysis and experimental gene expression measurements [212]. An analysis of the human phosphoproteome by combining consensus substrate motifs with context modeling was used for improved prediction of cellular kinase-substrate relationships [174, 213, 214].

Currently, the process of combining different datasets to generate testable biological hypotheses lacks a well defined structure and can only be partially automated. Nevertheless, there is constant progress along the road towards such automation, and for example, both Su et al. [209, 210] and Alves and Sorribas [55] propose and apply structured integrative approach for network reconstruction in molecular biology. An area where integration of bioinformatics and computational biology may be a powerful tool is that of synthetic biology. We will not discuss this subject any further in this paper and refer to the literature for reviews on the subject [215-221].

\section{CHALlENGES TO AUTOMATION IN COMPUTA- TIONAL SYSTEMS BIOLOGY}

Automatically integrating the information from the different datasets for pathway and circuit reconstruction in molecular systems biology is not trivial. The design of a global solution for this integration requires careful consideration of the goals, challenges, and limitations of the available a) data, b) data mining methods, and c) mathematical models.
At a first glance, one might think that the amount of data being generated by HTP methods is the most difficult challenge for the integration process. However, enough computational power is available to deal with this problem and data accumulation may not be a major issue. In our perspective, the major challenges are likely to be a) the definition of the necessary information content for a given type of data, b) the development of universal standards for the reporting and deposition of that data into databases, and c) the integration of information mined from different types of data into a coherent whole. It is crucial that the relevant information that is needed to address a given biological problem is well organized and easily accessible. Developing and applying standards in data reporting plays a central role in facilitating the automation of integrative approaches, because the existent of regularities in data structure is fundamental for the development of efficient computational methods.

\section{Minimal Information Content and Data Reporting Stan- dards}

Achieving consistency in data organization, classification and storage into databases is crucial for achieving automated data integration. An important step in achieving such consistency is deciding what information to store in databases and how to report and organize that information.

It is not easy to define the minimal information required to describe the validity and scope of the deposited data, because the relevant information will change depending on the problem one wants to address when using the deposited such data. In some cases the data will have less than the minimal information required to correctly assess the conditions in which the experiment was done and the caveats that apply to the results. In other cases there will exist an excess of information that may be confusing and difficult to organize for one's purpose. An additional problem in comparing similar data from different origins is the following. When different groups replicate experiments using similar techniques, most of the times there are differences either in the exact conditions of the experiment or in the method for data acquisition and treatment. This may lead to contradictory results for what is apparently the same experiment.

If one wants to potentiate automated data mining and integration, a uniform language and ontology that can be used to report all experiments and data of a given type is needed. This ontology and language should contain sufficient information to decide if two data sets replicate the same experiment or not. Whatever standard ontologies evolve for the different datasets, such classification schemes must a) be self consistent, b) be applicable to any organism, c) have the fullest possible coverage of biological/experimental functions, d) adapt to new knowledge and information, and e) be easily integrated with ontologies for other types of datasets.

Several ontologies have been developed to describe the different datasets described in the previous sections (for example [222-233]). No set of ontologies is yet universally accepted. However, the Open Biomedical Ontologies (OBO), and the Gene Ontology (GO) are becoming de facto standards in the area [227]. Creating an ontology or a report language is not an easy task and the lack of an appropriate initial structure may compromise future utility. For example, 
the GO has an uneven amount of information given for different classes of terms at the same depth of classification [234], which may become a problem in future. An area where information content standards are essential if one wants to facilitate automated model building is that of reporting parameter values for kinetic and thermodynamic experiments (see above section 3 and supplementary appendix). Standard report languages that, to some extent integrate relevant ontology information, have been proposed for HTP experiments [235], mathematical models [24, 236], gene that is expression data [237], mass spectrometry data [http://psidev.sourceforge.net $/ \mathrm{ms} / \mathrm{xml} / \mathrm{mzdata} / \mathrm{mzdata} . \mathrm{html}$, protein interaction data [160], and metabolomics data [225]. It is unclear if any of these languages obeys appropriate criteria for minimum information content and they are still far from being universally applied. However, computer-based algorithms and methods will only be able to automatically crosscorrelate all available information in an efficient and errorfree way when reporting of HTP experiments and data has converged to some standard.

Imagine that such standards exist and that one wants to automatically build the topology of the complete network of molecular interactions for an organism. An appropriate classification of the different data would, in principle: a) organize all enzymes into metabolic pathways; b) organize all signal transduction proteins, into signal transduction pathways; and c) organize all transcription factors (TF) and genes with binding sites for those TF, into gene circuits (Fig. 3). Whenever a new genome is sequenced and annotated, its genes can be inserted into the maps, displaying which pathways and circuits are present in that specific organism. As differences in regulation between organisms are found or new pathways and circuits are discovered and reported, the classifications and maps themselves can be updated.

\section{Informational Models for Integrated Data Analysis}

There are different organizational models that can be used to store and integrate molecular biology data. One model is that of a central warehouse that stores database information (e.g. [238-243]). These databases are then linked to a server that provides different types of analytical tools. These tools allow users to mine and, up to a point, integrate information from the databases. Often, these central warehouses have a few mirrors distributed over the world wide web. Another type of integration service that is often found on the internet is the Metaserver. These servers, which usually analyze one type of data (e.g. [244-266]), submit queries to many different central warehouses and then process and integrate all the outputs.

Another organizational model for information storage and analysis is that of distributed sources of information and analytical services. Such an approach underlies GRID technology. At this moment there are at least three GRID-based approaches to the development of integrative platforms: BioMOBY [267-271], myGRID [272] or caBIO [273]. They rely on different levels of analysis and aim at integrating services and databases provided by different providers on the web. Such distributed architectures take advantage of the decentralized nature of the information and crawl over the internet space, identifying and accessing different types of data. The data are then pipeline into appropriate services, also decentralized and identified over the internet or in a central repository of services, to perform the analysis required by the user. However, there is still a long way to go before full automated integration of all available types of biological data that are available on the web is achieved.

Currently, the semantic web or web 3.0 is under development [274]. This new technology is expected to integrate information using machine learning methods. The effect of such technology in facilitating automated analysis and model building in molecular biology is potentially large [274-281].

\section{Constraints to Automated Reconstruction of Biological Circuits}

It is a truism that no one can be an expert in everything, which makes collaborative work fundamental in an integrative endeavor such as pathway reconstruction in molecular systems biology. However, it is also true that sometimes the demand for collaborative work placed upon researchers by both funding agencies and lack of time to familiarize themselves with different areas, rather than enabling research synergisms, is a hindrance to the progress of the research. Development of a structured integrative approach for network reconstruction and hypotheses evaluation would be an important contribution towards increasing the synergism among groups interested in different parts of the same biological problem.

Independently of the informational model(s) for data reporting, storage and integration, the user interface must be designed taking into account the target audience(s) for the different services. That audience will potentially be as diverse as the entire molecular biology community itself is. Hence, an integrative software service must take into account users with different expertise and different goals. Therefore, a flexible pipeline should exist for data processing and analysis. This pipeline should allow for different types of reconstruction questions to be asked within the integrative architecture. Some users will be satisfied by clicking in buttons and obtaining the final result, while other will want to manipulate the parameters and algorithms behind the interface for their own purposes and for refining standard analysis. There is a need to provide tools that are sufficiently constrained to reduce scientifically unsound use and sufficiently flexible to allow expert users to refine methods and data inputs. It is possible that the development of different tools for the different audiences is the most adequate way to address this problem.

Furthermore, one must be prepared to allow the users to perform different levels of reconstruction and to introduce new qualitative and quantitative information based on their own expertise. While some will be interested in the static reconstruction of pathways and circuits, others will be interested in the dynamic aspects of that reconstruction. Additionally, while some will be interested in a broad picture of what an organism can do, others will want to pursue a more detailed analysis of parts of the cellular response of that organism and only be interested in AI specific pathways. Thus, if one wishes to develop a methodology and implement it in a set of tools that can be useful to a wide audience and used in a scientifically sound way, one has to take several, sometimes contradictory, constraints into account. Human cura- 


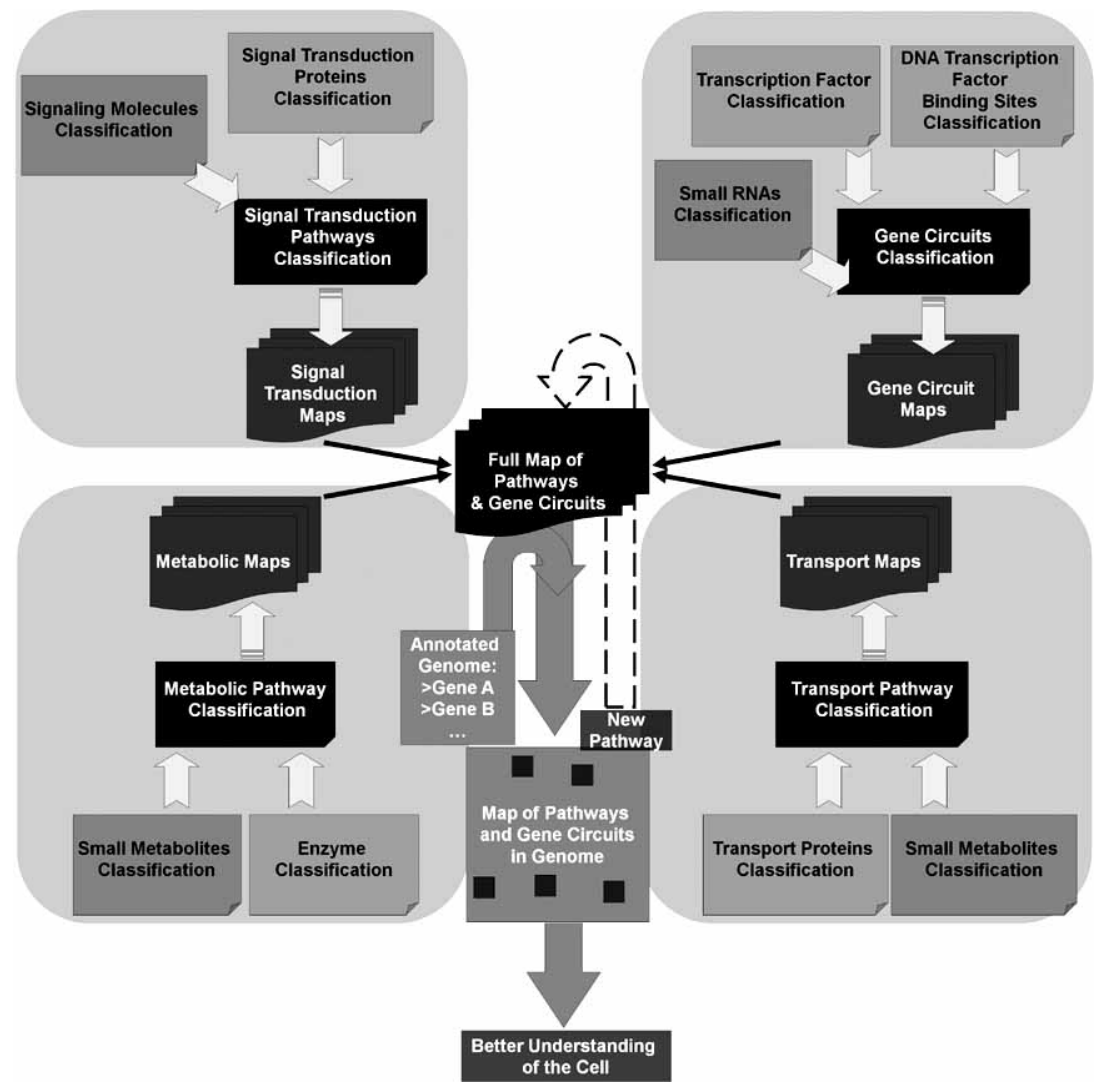

Fig. (3). Creating and integrating maps for pathways and gene circuits and applying them to the reconstruction of pathways in a genome will enable a better understanding of cellular physiology and behavior. Pre-existing gene circuits, metabolic pathways, transport pathways and signal transduction pathways can be used as a template for the assembly of the cellular pathways in newly annotated genomes. New pathways that are found in those genomes can be added to the set of pre-existing pathways. See text for a more detailed discussion

tion is and will continue to be an important part in the process, at even when AI development is able to generate tools that, to some degree, can replace expert intervention.

From a technical point of view, it is unlikely that a single research group will be able to come with an allencompassing software platform that will allow for such an enormous diversity of reconstructions and goals. Thus, one of the requirements for such platforms is that they are open to external contributions. However, this openness must be somewhat more controlled than what is one finds in most of the open source projects that exist nowadays. Contributing programmers would have to adhere to some programming, organizational, and nomenclature standards, in a structure similar to that of wikipedia. The reason for such constraints is that in many cases there exists both duplication of efforts and inconsistent nomenclature even in complementary packages. An example for both these problems are many packages for the analysis of HTP data for developed the R platform.

Finally, an integrative platform should include some form of machine learning algorithms to analyze older datasets. It is unlikely that many resources are dedicated to reformatting data from previous decades, making that data compatible with whatever standards percolate for each type of dataset. Trainable machine learning algorithms are currently the best hope of mining the older data efficiently. This is an important challenge for the AI community.

\section{SUMMARY AND CONCLUSIONS}

In this work we analyze the in silico reconstruction of cellular pathways within the context of molecular systems biology. We start with a discussion of the data sets that are available for this reconstruction in the post genomic era. We describe how systematic integration of the different types of information can be used to create mathematical models that generate testable biological hypotheses about the functioning of the reconstructed system. We then review examples of how such data have been integrated to reconstruct pathways and obtain a systemic understanding of how those pathways work. Finally, we provide a general discussion of how different bioinformatics and computational biology tools can be integrated for automated model generation. We are aware that a full automation of this process may not be possible. However, if we are ever to approach such a goal, at least two issues must be addressed:

a) Better and uniform standards of reporting for the different datasets.

b) Better machine learning methods/artificial intelligence algorithms to facilitate automation of the analysis.

Any improvement in these areas will translate into a more efficient and more accurate network reconstruction and facilitate the systemic understanding of molecular pathways and circuits. 


\section{ACKNOWLEDGEMENTS}

This work has been partially supported by grants BFU2005-0234BMC and BFU2007-62772/BMC of the Spanish Ministerio de Educación y Ciencia. RA was supported by a Ramon y Cajal award from the Spanish Ministerio de Educacin y Ciencia. We also thank two anonymous reviewers for helpful suggestions that significantly improved this paper.

\section{REFERENCES}

[1] Eisenberg D, Marcotte E, McLachlan AD, Pellegrini M. Bioinformatic challenges for the next decade(s). Philos Trans $R$ Soc Lond $B$ Biol Sci 2006; 361: 525-527.

[2] Goel G, Chou IC, Voit EO. Biological systems modeling and analysis: a biomolecular technique of the twenty-first century. $J$ Biomol Tech 2006; 17: 252-269.

[3] Chance B, Garfinkel D, Higgins J, Hess B. Metabolic control mechanisms. 5. A solution for the equations representing interaction between glycolysis and respiration in ascites tumor cells. $J$ Biol Chem 1960; 235: 2426-2439.

[4] Chance B, Greenstein DS, Higgins J, Yang CC. The mechanism of catalase action. II. Electric analog computer studies. Arch Biochem 1952; 37: 322-339.

[5] Garfinkel D, Garfinkel L, Pring M, Green SB, Chance B. Computer applications to biochemical kinetics. Annu Rev Biochem 1970; 39: 473-498.

[6] Garfinkel D, Hess B. Metabolic Control Mechanisms. Vii.a Detailed Computer Model of the Glycolytic Pathway in Ascites Cells. J Biol Chem 1964; 239: 971-983.

[7] Hess B, Boiteux A. Mechanism of glycolytic oscillation in yeast. I. Aerobic and anaerobic growth conditions for obtaining glycolytic oscillation. Hoppe Seylers Z Physiol Chem 1968; 349: 1567-1574.

[8] Heinrich R, Rapoport TA. Linear theory of enzymatic chains; its application for the analysis of the crossover theorem and of the glycolysis of human erythrocytes. Acta Biol Med Ger 1973; 31: 479-494.

[9] Heinrich R, Rapoport TA. A linear steady-state treatment of enzymatic chains. Critique of the crossover theorem and a general procedure to identify interaction sites with an effector. Eur J Biochem 1974; 42: 97-105.

[10] Heinrich R, Rapoport TA. A linear steady-state treatment of enzymatic chains. General properties, control and effector strength. Eur J Biochem 1974; 42: 89-95.

[11] Kacser H. Kinetic models of development and heredity. Symp Soc Exp Biol 1960; 14: 13-27.

[12] Kacser H, Burns JA. The control of flux. Symp Soc Exp Biol 1973; 27: 65-104.

[13] Rapoport TA, Heinrich R, Jacobasch G, Rapoport S. A linear steady-state treatment of enzymatic chains. A mathematical model of glycolysis of human erythrocytes. Eur J Biochem 1974; 42: 107120.

[14] Savageau MA. Biochemical systems analysis. II. The steady-state solutions for an n-pool system using a power-law approximation. $J$ Theor Biol 1969; 25: 370-379.

[15] Savageau MA. Biochemical systems analysis. I. Some mathematical properties of the rate law for the component enzymatic reactions. J Theor Biol 1969; 25: 365-369.

[16] Savageau MA. Biochemical systems analysis. 3. Dynamic solutions using a power-law approximation. J Theor Biol 1970; 26: 215-226.

[17] Fitch WM. An improved method of testing for evolutionary homology. J Mol Biol 1966; 16: 9-16.

[18] Fitch WM. Locating gaps in amino acid sequences to optimize the homology between two proteins. Biochem Genet 1969; 3: 99-108.

[19] Fitch WM. Further improvements in the method of testing for evolutionary homology among proteins. J Mol Biol 1970; 49: 1-14.

[20] Needleman SB, Wunsch CD. A general method applicable to the search for similarities in the amino acid sequence of two proteins. $J$ Mol Biol 1970; 48: 443-453.

[21] Smith TF, Waterman MS, Fitch WM. Comparative biosequence metrics. J Mol Evol 1981; 18: 38-46.

[22] Bertalanffy K. Der Organismus als physikalisches System betrachtet. Die Naturwissenschaften 1940; 28.
[23] Csete ME, Doyle JC. Reverse engineering of biological complexity. Science 2002; 295: 1664-1669.

[24] Hucka M, Finney A, Bornstein BJ, et al. Evolving a lingua franca and associated software infrastructure for computational systems biology: the Systems Biology Markup Language (SBML) project. Syst Biol (Stevenage) 2004; 1: 41-53.

[25] Kitano H. Systems biology: a brief overview. Science 2002; 295: 1662-1664.

[26] Kitano H, Oda K, Kimura T, Matsuoka Y, Csete M, Doyle J, Muramatsu M. Metabolic syndrome and robustness tradeoffs. Diabetes 2004; 53 Suppl 3: S6-S15.

Stelling J, Sauer U, Szallasi Z, Doyle FJ, 3rd, Doyle J. Robustness of cellular functions. Cell 2004; 118: 675-685.

Tanaka R, Csete M, Doyle J. Highly optimised global organisation of metabolic networks. Syst Biol (Stevenage) 2005; 152: 179-184.

[29] Mollick E. Establishing Moore's law. Ieee Ann Hist Comput 2006; 28: 62-75.

[30] Proteomics. Nat Biotechnol,: IT45-46.

[31] Allen TE, Price ND, Joyce AR, Palsson BO. Long-range periodic patterns in microbial genomes indicate significant multi-scale chromosomal organization. PLoS Comput Biol 2006; 2: e2.

[32] Duarte NC, Becker SA, Jamshidi N, et al. Global reconstruction of the human metabolic network based on genomic and bibliomic data. Proc Natl Acad Sci USA 2007; 104: 1777-1782.

[33] Duarte NC, Herrgard MJ, Palsson BO. Reconstruction and validation of Saccharomyces cerevisiae iND750, a fully compartmentalized genome-scale metabolic model. Genome Res 2004; 14: 12981309.

[34] Duarte NC, Palsson BO, Fu P. Integrated analysis of metabolic phenotypes in Saccharomyces cerevisiae. BMC Genomics 2004; 5: 63.

[35] Edwards JS, Ibarra RU, Palsson BO. In silico predictions of Escherichia coli metabolic capabilities are consistent with experimental data. Nat Biotechnol 2001; 19: 125-130.

[36] Feist AM, Scholten JC, Palsson BO, Brockman FJ, Ideker T. Modeling methanogenesis with a genome-scale metabolic reconstruction of Methanosarcina barkeri. Mol Syst Biol 2006; 2: 20060004.

[37] Francke C, Siezen RJ, Teusink B. Reconstructing the metabolic network of a bacterium from its genome. Trends Microbiol 2005; 13: $550-558$

[38] Ibarra RU, Edwards JS, Palsson BO. Escherichia coli K-12 undergoes adaptive evolution to achieve in silico predicted optimal growth. Nature 2002; 420: 186-189.

[39] Ibarra RU, Fu P, Palsson BO, DiTonno JR, Edwards JS. Quantitative analysis of Escherichia coli metabolic phenotypes within the context of phenotypic phase planes. J Mol Microbiol Biotechnol 2003; 6: 101-108.

[40] Mahadevan R, Bond DR, Butler JE, et al. Characterization of metabolism in the $\mathrm{Fe}$ (III)-reducing organism Geobacter sulfurreducens by constraint-based modeling. Appl Environ Microbiol 2006; 72: $1558-1568$.

[41] Notebaart RA, van Enckevort FH, Francke C, Siezen RJ, Teusink B. Accelerating the reconstruction of genome-scale metabolic networks. BMC Bioinformatics 2006; 7: 296.

[42] Oh YK, Palsson BO, Park SM, Schilling CH, Mahadevan R. Genome-scale reconstruction of metabolic network in Bacillus subtilis based on high-throughput phenotyping and gene essentiality data. $J$ Biol Chem 2007; 282: 28791-28799.

[43] Price ND, Thiele I, Palsson BO. Candidate states of Helicobacter pylori's genome-scale metabolic network upon application of "loop law" thermodynamic constraints. Biophys J 2006; 90: 3919-3928.

[44] Reed JL, Vo TD, Schilling CH, Palsson BO. An expanded genomescale model of Escherichia coli K-12 (iJR904 GSM/GPR). Genome Biol 2003; 4: R54.

[45] Rossell S, van der Weijden CC, Lindenbergh A, et al. Unraveling the complexity of flux regulation: a new method demonstrated for nutrient starvation in Saccharomyces cerevisiae. Proc Natl Acad Sci USA 2006; 103: 2166-2171.

[46] Schilling CH, Covert MW, Famili I, et al. Genome-scale metabolic model of Helicobacter pylori 26695. J Bacteriol 2002; 184: 45824593.

[47] Schilling CH, Palsson BO. Assessment of the metabolic capabilities of Haemophilus influenzae Rd through a genome-scale pathway analysis. J Theor Biol 2000; 203: 249-283.

[48] Teusink B, van Enckevort FH, Francke C, et al. In silico reconstruction of the metabolic pathways of Lactobacillus plantarum: 
comparing predictions of nutrient requirements with those from growth experiments. Appl Environ Microbiol 2005; 71: 7253-7262.

[49] Teusink B, Wiersma A, Molenaar D, et al. Analysis of growth of Lactobacillus plantarum WCFS1 on a complex medium using a genome-scale metabolic model. J Biol Chem 2006; 281: 4004140048.

[50] Thiele I, Price ND, Vo TD, Palsson BO. Candidate metabolic network states in human mitochondria. Impact of diabetes, ischemia, and diet. J Biol Chem 2005; 280: 11683-11695.

[51] Thiele I, Vo TD, Price ND, Palsson BO. Expanded metabolic reconstruction of Helicobacter pylori (iIT341 GSM/GPR): an in silico genome-scale characterization of single- and double-deletion mutants. J Bacteriol 2005; 187: 5818-5830.

[52] Yeung M, Thiele I, Palsson BO. Estimation of the number of extreme pathways for metabolic networks. BMC Bioinformatics 2007; 8: 363 .

[53] Alves R, Herrero E, Sorribas A. Predictive reconstruction of the mitochondrial iron-sulfur cluster assembly metabolism. II. Role of glutaredoxin Grx5. Proteins 2004; 57: 481-492.

[54] Alves R, Herrero E, Sorribas A. Predictive reconstruction of the mitochondrial iron-sulfur cluster assembly metabolism: I. The role of the protein pair ferredoxin-ferredoxin reductase (Yah1-Arh1). Proteins 2004; 56: 354-366.

[55] Alves R, Sorribas A. In silico pathway reconstruction: Iron-sulfur cluster biogenesis in Saccharomyces cerevisiae. BMC Syst Biol 2007; 1: 10 .

[56] Haugen AC, Kelley R, Collins JB, et al. Integrating phenotypic and expression profiles to map arsenic-response networks. Genome Biol 2004; 5: R95.

[57] Panina EM, Vitreschak AG, Mironov AA, Gelfand MS. Regulation of aromatic amino acid biosynthesis in gamma-proteobacteria. $J$ Mol Microbiol Biotechnol 2001; 3: 529-543.

[58] Vilella F, Alves R, Rodriguez-Manzaneque MT, et al. Evolution and cellular function of monothiol glutaredoxins: involvement in iron-sulphur cluster assembly. Comparative and Functional Genomics 2004; 5: 328-341.

[59] Workman CT, Mak HC, McCuine S, et al. A systems approach to mapping DNA damage response pathways. Science 2006; 312 : 1054-1059.

[60] Raes J, Korbel JO, Lercher MJ, von Mering C, Bork P. Prediction of effective genome size in metagenomic samples. Genome Biol 2007; 8: R10.

[61] Herrgard MJ, Covert MW, Palsson BO. Reconstruction of microbial transcriptional regulatory networks. Curr Opin Biotechnol 2004; 15 : 70-77.

[62] Herrgard MJ, Lee BS, Portnoy V, Palsson BO. Integrated analysis of regulatory and metabolic networks reveals novel regulatory mechanisms in Saccharomyces cerevisiae. Genome Res 2006; 16: 627-635.

[63] Herrgard MJ, Palsson BO. Untangling the web of functional and physical interactions in yeast. J Biol 2005; 4: 5 .

[64] Richards DE. Medline at thirty-five. Evid Based Dent 2006; 7: 89.

[65] Lowe J, Chapman S. The citation index: what it is and what it isn't. Aust N Z J Public Health 2000; 24: 5.

[66] Heinemann M, Kummel A, Ruinatscha R, Panke S. In silico genome-scale reconstruction and validation of the Staphylococcus aureus metabolic network. Biotechnol Bioeng 2005; 92: 850-864.

[67] Li Z, Chan C. Integrating gene expression and metabolic profiles. $J$ Biol Chem 2004; 279: 27124-27137.

[68] Fernandez JM, Hoffmann R, Valencia A. iHOP web services. $\mathrm{Nu}$ cleic Acids Res 2007; 35: W21-26.

[69] Hoffmann R, Krallinger M, Andres E, Tamames J, Blaschke C, Valencia A. Text mining for metabolic pathways, signaling cascades, and protein networks. Sci STKE 2005, 2005: pe21.

[70] Hoffmann R, Valencia A. Implementing the iHOP concept for navigation of biomedical literature. Bioinformatics 2005; 21 Suppl 2: ii252-ii258.

[71] Stapley BJ, Benoit G. Biobibliometrics: information retrieval and visualization from co-occurrences of gene names in Medline abstracts. Pac Symp Biocomput 2000; 529-540.

[72] Higgins ME, Claremont M, Major JE, Sander C, Lash AE. CancerGenes: a gene selection resource for cancer genome projects. Nucleic Acids Res 2007; 35: D721-726.

[73] Afifi M. PubMed-indexed duplicate publications in the last decade, 1996-2006. Ann Saudi Med 2007; 27: 302-304; author reply 304.
[74] Falagas ME, Pitsouni EI, Malietzis GA, Pappas G. Comparison of PubMed, Scopus, Web of Science, and Google Scholar: strengths and weaknesses. FASEB J 2008; 22: 338-342.

[75] Gass A, Doyle H. PLOS position on NIH public access policy. Science 2005; 308: 356.

[76] Butler D. BioMed Central boosted by editorial board. Nature 2000; 405: 384.

[77] Sabatti C, Rohlin L, Lange K, Liao JC. Vocabulon: a dictionary model approach for reconstruction and localization of transcription factor binding sites. Bioinformatics 2005; 21: 922-931.

[78] Ahren DG, Ouzounis CA. Robustness of metabolic map reconstruction. J Bioinform Comput Biol 2004; 2: 589-593.

[79] Karp PD, Paley S, Romero P. The Pathway Tools software. Bioinformatics 2002; 1: S225-232.

[80] Nikitin F, Rance B, Itoh M, Kanehisa M, Lisacek F. Using protein motif combinations to update KEGG pathway maps and orthologue tables. Genome Inform 2004; 15: 266-275.

[81] Paley SM, Karp PD. The Pathway Tools cellular overview diagram and Omics Viewer. Nucleic Acids Res 2006; 34: 3771-3778.

[82] Ahn GT, Kim JH, Hwang EY, Lee MJ, Han IS. SCOPExplorer: a tool for browsing and analyzing structural classification of proteins (SCOP) data. Mol Cells 2004; 17: 360-364.

[83] Chi PH, Shyu CR, Xu D. A fast SCOP fold classification system using content-based E-Predict algorithm. BMC Bioinformatics 2006; 7: 362 .

[84] Getz G, Starovolsky A, Domany E. F2CS. FSSP to CATH and SCOP prediction server. Bioinformatics 2004; 20: 2150-2152.

[85] Gewehr JE, Hintermair V, Zimmer R. AutoSCOP. automated prediction of SCOP classifications using unique pattern-class mappings. Bioinformatics 2007; 23: 1203-1210.

[86] Lo Conte L, Ailey B, Hubbard TJ, Brenner SE, Murzin AG, Chothia C. SCOP. a structural classification of proteins database. Nucleic Acids Res 2000; 28: 257-259.

[87] Suhrer SJ, Wiederstein M, Sippl MJ. QSCOP--SCOP quantified by structural relationships. Bioinformatics 2007; 23: 513-514.

[88] Tung CH, Yang JM. fastSCOP. a fast web server for recognizing protein structural domains and SCOP superfamilies. Nucleic Acids Res 2007; 35: W438-443.

[89] Andreeva A, Howorth D, Brenner SE, Hubbard TJ, Chothia C, Murzin AG. SCOP database in 2004: refinements integrate structure and sequence family data. Nucleic Acids Res 2004; 32: D226229.

[90] Andreeva A, Howorth D, Chandonia, et al. Data growth and its impact on the SCOP database: new developments. Nucleic Acids Res 2008; 36: D419-425.

[91] Greene LH, Lewis TE, Addou S, et al. The CATH domain structure database: new protocols and classification levels give a more comprehensive resource for exploring evolution. Nucleic Acids Res 2007; 35: D291-297.

[92] Orengo CA, Pearl FM, Thornton JM. The CATH domain structure database. Methods Biochem Anal 2003; 44: 249-271.

[93] Huynen MA, Snel B, Bork P, Gibson TJ. The phylogenetic distribution of frataxin indicates a role in iron-sulfur cluster protein assembly. Hum Mol Genet 2001; 10: 2463-2468.

[94] Genschel U. Coenzyme A biosynthesis: reconstruction of the pathway in archaea and an evolutionary scenario based on comparative genomics. Mol Biol Evol 2004; 21: 1242-1251.

[95] Striepen B, Pruijssers AJ, Huang J, et al. Gene transfer in the evolution of parasite nucleotide biosynthesis. Proc Natl Acad Sci USA 2004; 101: 3154-3159.

[96] Suhre K. Inference of gene function based on gene fusion events: the rosetta-stone method. Methods Mol Biol 2007; 396: 31-42.

[97] Suhre K, Claverie JM. FusionDB. a database for in-depth analysis of prokaryotic gene fusion events. Nucleic Acids Res 2004; 32: D273-276.

[98] Panina EM, Vitreschak AG, Mironov AA, Gelfand MS. Regulation of biosynthesis and transport of aromatic amino acids in low-GC Gram-positive bacteria. FEMS Microbiol Lett 2003; 222: 211-220.

[99] Berger MF, Bulyk ML. Protein binding microarrays (PBMs) for rapid, high-throughput characterization of the sequence specificities of DNA binding proteins. Methods Mol Biol 2006; 338: 245260.

[100] Berger MF, Philippakis AA, Qureshi AM, He FS, Estep PW, 3rd, Bulyk ML. Compact, universal DNA microarrays to comprehensively determine transcription-factor binding site specificities. Nat Biotechnol 2006; 24: 1429-1435. 
[101] Bulyk ML. Computational prediction of transcription-factor binding site locations. Genome Biol 2003; 5: 201.

[102] Bulyk ML. Discovering DNA regulatory elements with bacteria. Nat Biotechnol 2005; 23: 942-944.

[103] Bulyk ML. Analysis of sequence specificities of DNA-binding proteins with protein binding microarrays. Methods Enzymol 2006; 410: 279-299.

[104] Bulyk ML. DNA microarray technologies for measuring proteinDNA interactions. Curr Opin Biotechnol 2006; 17: 422-430.

[105] Bulyk ML. Protein binding microarrays for the characterization of DNA-protein interactions. Adv Biochem Eng Biotechnol 2007; 104: 65-85.

[106] Bulyk ML, McGuire AM, Masuda N, Church GM. A motif cooccurrence approach for genome-wide prediction of transcriptionfactor-binding sites in Escherichia coli. Genome Res 2004; 14: 201 208.

[107] McCord RP, Bulyk ML. Functional trends in structural classes of the DNA binding domains of regulatory transcription factors. Pac Symp Biocomput 2008; 441-452.

[108] Mukherjee S, Berger MF, Jona G, et al. Rapid analysis of the DNA-binding specificities of transcription factors with DNA microarrays. Nat Genet 2004; 36: 1331-1339.

[109] Ostrin EJ, Li Y, Hoffman K, Liu J, Wang K, Zhang L, Mardon G, Chen R. Genome-wide identification of direct targets of the Drosophila retinal determination protein Eyeless. Genome Res 2006; 16: 466-476.

[110] Long F, Liu H, Hahn C, Sumazin P, Zhang MQ, Zilberstein A. Genome-wide prediction and analysis of function-specific transcription factor binding sites. In Silico Biol 2004; 4: 395-410.

[111] Gertz J, Fay JC, Cohen BA. Phylogeny based discovery of regulatory elements. BMC Bioinformatics 2006; 7: 266.

[112] Gertz J, Riles L, Turnbaugh P, Ho SW, Cohen BA. Discovery, validation, and genetic dissection of transcription factor binding sites by comparative and functional genomics. Genome Res $\mathbf{2 0 0 5}$; 15: $1145-1152$.

[113] Tran TT, Dam P, Su Z, et al. Operon prediction in Pyrococcus furiosus. Nucleic Acids Res 2007; 35: 11-20.

[114] Ashraf SI, Kunes S. A trace of silence: memory and microRNA at the synapse. Curr Opin Neurobiol 2006; 16: 535-539.

[115] Chin JW. Programming and engineering biological networks. Curr Opin Struct Biol 2006; 16: 551-556.

[116] Ciesla J. Metabolic enzymes that bind RNA. yet another level of cellular regulatory network? Acta Biochim Pol 2006; 53: 11-32.

[117] Davidson EA, Ellington AD. Synthetic RNA circuits. Nat Chem Biol 2007; 3: 23-28.

[118] Lee CT, Risom T, Strauss WM. Evolutionary conservation of microRNA regulatory circuits: an examination of microRNA gene complexity and conserved microRNA-target interactions through metazoan phylogeny. DNA Cell Biol 2007; 26: 209-218.

[119] Narayanaswamy R, Ellington AD. Engineering RNA-based circuits. Handb Exp Pharmacol 2006; 423-445.

[120] Redei GP, Koncz C, Phillips JD. Changing images of the gene. $A d v$ Genet 2006; 56: 53-100.

[121] Thomas CM. Transcription regulatory circuits in bacterial plasmids. Biochem Soc Trans 2006; 34: 1072-1074.

[122] Mellin JR, Goswami S, Grogan S, Tjaden B, Genco CA. A novel fur- and iron-regulated small RNA, NrrF, is required for indirect fur-mediated regulation of the sdhA and sdhC genes in Neisseria meningitidis. J Bacteriol 2007; 189: 3686-3694.

[123] Tjaden B. Prediction of small, noncoding RNAs in bacteria using heterogeneous data. J Math Biol 2008; 56: 183-200.

[124] Tjaden B, Goodwin SS, Opdyke JA, Guillier M, Fu DX, Gottesman $\mathrm{S}$, Storz G. Target prediction for small, noncoding RNAs in bacteria. Nucleic Acids Res 2006; 34: 2791-2802.

[125] Zhang A, Wassarman KM, Rosenow C, Tjaden BC, Storz G, Gottesman S. Global analysis of small RNA and mRNA targets of Hfq. Mol Microbiol 2003; 50: 1111-1124.

[126] To CC, Vohradsky J. Supervised inference of gene-regulatory networks. BMC Bioinformatics 2008, 9: 2.

[127] Hsu SD, Chu CH, Tsou AP, et al. miRNAMap 2.0: genomic maps of microRNAs in metazoan genomes. Nucleic Acids Res 2008; 36 : D165-169.

[128] Carlson MR, Zhang B, Fang Z, Mischel PS, Horvath S, Nelson SF. Gene connectivity, function, and sequence conservation: predictions from modular yeast co-expression networks. BMC Genomics 2006; 7 : 40 .
[129] D'Haeseleer P, Liang S, Somogyi R. Genetic network inference: from co-expression clustering to reverse engineering. Bioinformatics 2000; 16: 707-726.

[130] Greller LD, Somogyi R. Reverse engineers map the molecular switching yards. Trends Biotechnol 2002; 20: 445-447.

[131] Maki Y, Takahashi Y, Arikawa Y, et al. An integrated comprehensive workbench for inferring genetic networks: voyagene. J Bioinform Comput Biol 2004; 2: 533-550.

[132] Maki Y, Tominaga D, Okamoto M, Watanabe S, Eguchi Y. Development of a system for the inference of large scale genetic networks. Pac Symp Biocomput 2001; 446-458.

[133] Kao KC, Yang YL, Boscolo R, Sabatti C, Roychowdhury V, Liao JC. Transcriptome-based determination of multiple transcription regulator activities in Escherichia coli by using network component analysis. Proc Natl Acad Sci USA 2004; 641-646.

[134] Liao JC, Boscolo R, Yang YL, Tran LM, Sabatti C, Roychowdhury VP. Network component analysis: reconstruction of regulatory signals in biological systems. Proc Natl Acad Sci USA 2003; 100: 15522-15527.

[135] Sabatti C, Rohlin L, Oh MK, Liao JC. Co-expression pattern from DNA microarray experiments as a tool for operon prediction. $\mathrm{Nu}$ cleic Acids Res 2002; 30: 2886-2893.

[136] Zou M, Conzen SD. A new dynamic Bayesian network (DBN) approach for identifying gene regulatory networks from time course microarray data. Bioinformatics 2005; 21: 71-79.

[137] Almaas E. Biological impacts and context of network theory. J Exp Biol 2007; 210: 1548-1558.

[138] Hardy S, Robillard PN. Petri net-based method for the analysis of the dynamics of signal propagation in signaling pathways. Bioinformatics 2008; 24: 209-217.

[139] Jagalur M, Kulp D. An information theoretic method for reconstructing local regulatory network modules from polymorphic samples. Comput Syst Bioinformatics Conf 2007; 6: 133-143.

[140] Margolin AA, Califano A. Theory and limitations of genetic network inference from microarray data. Ann N Y Acad Sci 2007; 1115: 51-72.

[141] Faith JJ, Hayete B, Thaden JT, et al. Large-scale mapping and validation of Escherichia coli transcriptional regulation from a compendium of expression profiles. PLoS Biol 2007; 5: e8.

[142] Hayete B, Gardner TS, Collins JJ. Size matters: network inference tackles the genome scale. Mol Syst Biol 2007; 3: 77.

[143] Margolin AA, Wang K, Lim WK, Kustagi M, Nemenman I, Califano A. Reverse engineering cellular networks. Nat Protoc 2006; 1 : 662-671.

[144] Babu MM, Luscombe NM, Aravind L, Gerstein M, Teichmann SA. Structure and evolution of transcriptional regulatory networks. Curr Opin Struct Biol 2004; 14: 283-291.

[145] Balaji S, Babu MM, Iyer LM, Luscombe NM, Aravind L. Comprehensive analysis of combinatorial regulation using the transcriptional regulatory network of yeast. J Mol Biol 2006; 360: 213-227.

[146] Luscombe NM, Babu MM. GenCompass: a universal system for analysing gene expression for any genome. Trends Biotechnol 2004; 22: 552-555.

[147] Luscombe NM, Babu MM, Yu H, Snyder M, Teichmann SA, Gerstein M. Genomic analysis of regulatory network dynamics reveals large topological changes. Nature 2004, 431: 308-312.

[148] Baranzini SE, Mousavi P, Rio J, et al. Transcription-based prediction of response to IFNbeta using supervised computational methods. PLoS Biol 2005; 3: e2.

[149] Fernald GH, Knott S, Pachner A, et al. Genome-wide network analysis reveals the global properties of IFN-beta immediate transcriptional effects in humans. J Immunol 2007; 178: 5076-5085.

[150] Wen X, Fuhrman S, Michaels GS, Carr DB, Smith S, Barker JL, Somogyi R. Large-scale temporal gene expression mapping of central nervous system development. Proc Natl Acad Sci USA 1998; 95: 334-339.

[151] Wang J, Kraemer E. GFPE. gene-finding program evaluation. Bioinformatics 2003; 19: 1712-1713.

[152] Yugi K, Nakayama Y, Kojima S, Kitayama T, Tomita M. A microarray data-based semi-kinetic method for predicting quantitative dynamics of genetic networks. BMC Bioinformatics 2005; 6: 299.

[153] Stark J, Brewer D, Barenco M, Tomescu D, Callard R, Hubank M. Reconstructing gene networks: what are the limits? Biochem Soc Trans 2003; 31: 1519-1525.

[154] Nilsson R, Bajic VB, Suzuki H, et al. Transcriptional network dynamics in macrophage activation. Genomics 2006; 88: 133-142. 
[155] Barenco M, Tomescu D, Brewer D, Callard R, Stark J, Hubank M. Ranked prediction of p53 targets using hidden variable dynamic modeling. Genome Biol 2006, 7: R25.

[156] Darvish A, Najarian K. Prediction of regulatory pathways using mRNA expression and protein interaction data: application to identification of galactose regulatory pathway. Biosystems 2006; 83: 125-135.

[157] Ceol A, Chatr-aryamontri A, Santonico E, Sacco R, Castagnoli L, Cesareni G. DOMINO. a database of domain-peptide interactions. Nucleic Acids Res 2007; 35: D557-560.

[158] Cesareni G, Ceol A, Gavrila C, Palazzi LM, Persico M, Schneider MV. Comparative interactomics. FEBS Lett 2005; 579: 1828-1833.

[159] Chatr-aryamontri A, Ceol A, Palazzi LM, Nardelli G, Schneider MV, Castagnoli L, Cesareni G. MINT. the Molecular INTeraction database. Nucleic Acids Res 2007; 35: D572-574.

[160] Hermjakob H, Montecchi-Palazzi L, Bader G, et al. The HUPO PSI's molecular interaction format--a community standard for the representation of protein interaction data. Nat Biotechnol 2004; 22 : 177-183.

[161] Kerrien S, Orchard S, Montecchi-Palazzi L, et al. Broadening the horizon--level 2.5 of the HUPO-PSI format for molecular interactions. BMC Biol 2007; 5: 44.

[162] Orchard S, Salwinski L, Kerrien S, et al. The minimum information required for reporting a molecular interaction experiment (MIMIx). Nat Biotechnol 2007; 25: 894-898.

[163] Persico M, Ceol A, Gavrila C, Hoffmann R, Florio A, Cesareni G. HomoMINT. an inferred human network based on orthology mapping of protein interactions discovered in model organisms. BMC Bioinformatics 2005; 6 Suppl 4: S21.

[164] Gong S, Yoon G, Jang I, Bolser D, et al. PSIbase: a database of Protein Structural Interactome map (PSIMAP). Bioinformatics 2005; 21: 2541-2543.

[165] Kim WK, Bolser DM, Park JH. Large-scale co-evolution analysis of protein structural interlogues using the global protein structural interactome map (PSIMAP). Bioinformatics 2004; 20: 1138-1150.

[166] Park D, Lee S, Bolser D, Schroeder M, Lappe M, Oh D, Bhak J. Comparative interactomics analysis of protein family interaction networks using PSIMAP (protein structural interactome map). Bioinformatics 2005; 21: 3234-3240.

[167] Ji ZL, Chen X, Zhen CJ, et al. KDBI. Kinetic Data of Biomolecular Interactions database. Nucleic Acids Res 2003; 31: 255257.

[168] Koike A, Takagi T. PRIME. automatically extracted PRotein Interactions and Molecular Information databasE. In Silico Biol 2005; 5 : 9-20.

[169] Mak HC, Daly M, Gruebel B, Ideker T. CellCircuits: a database of protein network models. Nucleic Acids Res 2007; 35: D538-545.

[170] Mewes HW, Dietmann S, Frishman D, et al. MIPS. analysis and annotation of genome information in 2007. Nucleic Acids Res 2008; 36: D196-201.

[171] Warner GJ, Adeleye YA, Ideker T. Interactome networks: the state of the science. Genome Biol 2006; 7: 301.

[172] Xenarios I, Salwinski L, Duan XJ, Higney P, Kim SM, Eisenberg D. DIP, the Database of Interacting Proteins: a research tool for studying cellular networks of protein interactions. Nucleic Acids Res 2002; 30: 303-305.

[173] Bettencourt-Dias M, Giet R, Sinka R, et al. Genome-wide survey of protein kinases required for cell cycle progression. Nature 2004, 432: 980-987.

[174] Linding R, Jensen LJ, Pasculescu A, Olhovsky M, Colwill K, Bork P, Yaffe MB, Pawson T. NetworKIN. a resource for exploring cellular phosphorylation networks. Nucleic Acids Res 2008; 36: D695699.

[175] Lim YP, Diong LS, Qi R, Druker BJ, Epstein RJ. Phosphoproteomic fingerprinting of epidermal growth factor signaling and anticancer drug action in human tumor cells. Mol Cancer Ther 2003, 2: 1369-1377.

[176] Gruhler A, Olsen JV, Mohammed S, Mortensen P, Faergeman NJ, Mann M, Jensen ON. Quantitative phosphoproteomics applied to the yeast pheromone signaling pathway. Mol Cell Proteomics 2005; 4: 310-327.

[177] Nuhse TS, Stensballe A, Jensen ON, Peck SC. Phosphoproteomics of the Arabidopsis plasma membrane and a new phosphorylation site database. Plant Cell 2004; 16: 2394-2405.

[178] Peck SC. Phosphoproteomics in Arabidopsis: moving from empirical to predictive science. J Exp Bot 2006; 57; 1523-1527.
[179] Wu J, Smith LT, Plass C, Huang TH. ChIP-chip comes of age for genome-wide functional analysis. Cancer Res 2006; 66: 68996902.

[180] Jung GY, Stephanopoulos G. A functional protein chip for pathway optimization and in vitro metabolic engineering. Science 2004; 304: 428-431.

[181] Kim M, Lee SY, Choi H, Shin YB, Jung SO, Kim MG, Chung BH. On-chip Escherichia coli culture, purification, and detection of expressed proteins. Eur Biophys J 2006; 35: 655-662.

[182] Marino S, Voit EO. An automated procedure for the extraction of metabolic network information from time series data. J Bioinform Comput Biol 2006, 4: 665-691.

[183] Veflingstad SR, Almeida J, Voit EO. Priming nonlinear searches for pathway identification. Theor Biol Med Model 2004; 1 : 8 .

[184] Voit EO, Almeida J, Marino S, Lall R, Goel G, Neves AR, Santos H. Regulation of glycolysis in Lactococcus lactis: an unfinished systems biological case study. Syst Biol (Stevenage) 2006; 153: 286-298.

[185] Alvarez-Vasquez F, Sims KJ, Cowart LA, Okamoto Y, Voit EO, Hannun YA. Simulation and validation of modelled sphingolipid metabolism in Saccharomyces cerevisiae. Nature 2005; 433: 425430 .

[186] Vance W, Arkin A, Ross J. Determination of causal connectivities of species in reaction networks. Proc Natl Acad Sci USA 2002; 99: 5816-5821.

[187] Famili I, Forster J, Nielsen J, Palsson BO. Saccharomyces cerevisiae phenotypes can be predicted by using constraint-based analysis of a genome-scale reconstructed metabolic network. Proc Natl Acad Sci USA 2003; 100: 13134-13139.

[188] Becker SA, Palsson BO. Three factors underlying incorrect in silico predictions of essential metabolic genes. BMC Syst Biol 2008, 2: 14.

[189] Chen KC, Calzone L, Csikasz-Nagy A, Cross FR, Novak B, Tyson $\mathrm{JJ}$. Integrative analysis of cell cycle control in budding yeast. $\mathrm{Mol}$ Biol Cell 2004; 15: 3841-3862.

[190] Cross FR, Archambault V, Miller M, Klovstad M. Testing a mathematical model of the yeast cell cycle. Mol Biol Cell 2002; 13: 52-70.

[191] Cross FR, Siggia ED. Mode locking the cell cycle. Phys Rev E Stat Nonlin Soft Matter Phys 2005; 72: 021910.

[192] Boros LG, Brandes JL, Lee WN, et al. Thiamine supplementation to cancer patients: a double edged sword. Anticancer Res 1998; 18 : 595-602.

[193] Boros LG, Brandes JL, Yusuf FI, Cascante M, Williams RD, Schirmer WJ. Inhibition of the oxidative and nonoxidative pentose phosphate pathways by somatostatin: a possible mechanism of antitumor action. Med Hypotheses 1998; 50: 501-506.

[194] Boros LG, Lee PW, Brandes JL, et al. Nonoxidative pentose phosphate pathways and their direct role in ribose synthesis in tumors: is cancer a disease of cellular glucose metabolism? Med Hypotheses 1998; 50: 55-59.

[195] Cascante M, Boros LG, Comin-Anduix B, de Atauri P, Centelles JJ, Lee PW. Metabolic control analysis in drug discovery and disease. Nat Biotechnol 2002; 20: 243-249.

[196] Girgis S, Pai SM, Girgis IG, Batra VK. Pharmacodynamic parameter estimation: population size versus number of samples. AAPS $J$ 2005; 7: 46.

[197] Beltz WF. Estimation and use of kinetic parameter distributions in metabolism and nutrition. Adv Food Nutr Res 1996; 40: 265-279.

[198] Tyukin I, van Leeuwen C, Prokhorov D. Parameter estimation of sigmoid superpositions: dynamical system approach. Neural Comput 2003; 15: 2419-2455.

[199] Hautaniemi S, Kharait S, Iwabu A, Wells A, Lauffenburger DA. Modeling of signal-response cascades using decision tree analysis. Bioinformatics 2005; 21: 2027-2035.

[200] Kharait S, Hautaniemi S, Wu S, Iwabu A, Lauffenburger DA, Wells A. Decision tree modeling predicts effects of inhibiting contractility signaling on cell motility. BMC Syst Biol 2007; 1: 9.

[201] Chance B, Greenstein DS, Roughton FJ. The mechanism of catalase action. I. Steady-state analysis. Arch Biochem 1952; 37: 301321.

[202] Sorribas A, Hernandez-Bermejo B, Vilaprinyo E, Alves R. Cooperativity and saturation in biochemical networks: A saturable formalism using Taylor series approximations. Biotechnol Bioeng 2006. 
[203] Michaelis L, Menten M. Die Kinetik der Invertinwirkung. Biochem Z 1913; 49: 333-369.

[204] Alves R, Vilaprinyo E, Hernandez-Bermejo B, Sorribas A. Mathematical formalisms based on approximated kinetic representations for modeling genetic and metabolic pathways. Biotechnology and Genetic Engineering Reviews 2008; 25: submitted.

[205] Sorribas A, Hernandez-Bermejo B, Vilaprinyo E, Alves R. Cooperativity and saturation in biochemical networks: a saturable formalism using Taylor series approximations. Biotechnol Bioeng 2007; 97: 1259-1277.

[206] Ideker T. A systems approach to discovering signaling and regulatory pathways--or, how to digest large interaction networks into relevant pieces. Adv Exp Med Biol 2004; 547: 21-30.

[207] Ideker T, Lauffenburger D. Building with a scaffold: emerging strategies for high- to low-level cellular modeling. Trends Biotechnol 2003; 21: 255-262.

[208] Ideker T, Valencia A. Bioinformatics in the human interactome project. Bioinformatics 2006; 22: 2973-2974.

[209] Su Z, Dam P, Chen X, Olman V, Jiang T, Palenik B, Xu Y. Computational inference of regulatory pathways in microbes: an application to phosphorus assimilation pathways in Synechococcus sp. WH8102. Genome Inform 2003, 14: 3-13.

[210] Su Z, Mao F, Dam P, Wu H, Olman V, Paulsen IT, Palenik B, Xu Y. Computational inference and experimental validation of the nitrogen assimilation regulatory network in cyanobacterium Synechococcus sp. WH. Nucleic Acids Res 2006; 34: 1050-1065.

[211] Gutierrez-Rios RM, Rosenblueth DA, Loza JA, et al. Regulatory network of Escherichia coli: consistency between literature knowledge and microarray profiles. Genome Res 2003; 13: 2435-2443.

[212] Wang L, Yang Z, Li Y, et al. Reconstruction and in silico analysis of the MAPK signaling pathways in the human blood fluke, Schistosoma japonicum. FEBS Lett 2006; 580: 3677-3686.

[213] Ingham RJ, Colwill K, Howard C, et al. WW domains provide a platform for the assembly of multiprotein networks. Mol Cell Biol 2005; 25: 7092-7106.

[214] Linding R, Jensen LJ, Ostheimer GJ, et al. Systematic discovery of in vivo phosphorylation networks. Cell 2007; 129: 1415-1426.

[215] Forster AC, Church GM. Synthetic biology projects in vitro. Genome Res 2007, 17: 1-6.

[216] Greber D, Fussenegger M. Mammalian synthetic biology: engineering of sophisticated gene networks. J Biotechnol 2007; 130: 329-345.

[217] Kaznessis YN. Models for synthetic biology. BMC Syst Biol 2007; $1: 47$.

[218] Keasling JD. Synthetic biology for synthetic chemistry. ACS Chem Biol, 2008; 3: 64-76.

[219] Pleiss J. The promise of synthetic biology. Appl Microbiol Biotechnol 2006; 73: 735-739.

[220] Saito H, Inoue T. RNA and RNP as new molecular parts in synthetic biology. J Biotechnol 2007; 132: 1-7.

[221] Sole RV, Munteanu A, Rodriguez-Caso C, Macia J. Synthetic protocell biology: from reproduction to computation. Philos Trans R Soc Lond B Biol Sci 2007; 362: 1727-1739.

[222] Aslett M, Wood V. Gene Ontology annotation status of the fission yeast genome: preliminary coverage approaches $100 \%$. Yeast 2006; 23: 913-919.

[223] Azuaje F, Al-Shahrour F, Dopazo J. Ontology-driven approaches to analyzing data in functional genomics. Methods Mol Biol 2006; 316: 67-86.

[224] Dybkaer R. An ontology on property for physical, chemical, and biological systems. APMIS Suppl 2004: 1-210.

[225] Jenkins H, Hardy N, Beckmann M, et al. A proposed framework for the description of plant metabolomics experiments and their results. Nat Biotechnol 2004, 22: 1601-1606.

[226] Lefranc MP. IMGT-ONTOLOGY and IMGT databases, tools and Web resources for immunogenetics and immunoinformatics. $\mathrm{Mol}$ Immunol 2004; 40: 647-660.

[227] Lomax J. Get ready to GO! A biologist's guide to the Gene Ontology. Brief Bioinform 2005, 6: 298-304.

[228] Shapiro JS, Bakken S, Hyun S, Melton GB, Schlegel C, Johnson SB. Document ontology: supporting narrative documents in electronic health records. AMIA Annu Symp Proc 2005; 684-688.

[229] Snowden DJ. Multi-ontology sense making: a new simplicity in decision making. Inform Prim Care 2005; 13: 45-54.
[230] Whetzel PL, Brinkman RR, Causton HC, et al. Development of FuGO. an ontology for functional genomics investigations. Omics 2006; 10: 199-204.

[231] Whetzel PL, Parkinson H, Stoeckert CJ, Jr.: Using ontologies to annotate microarray experiments. Methods Enzymol 2006; 411: 325-339.

[232] Yu AC. Methods in biomedical ontology. J Biomed Inform 2006; 39: 252-266.

[233] Yue L, Reisdorf WC. Pathway and ontology analysis: emerging approaches connecting transcriptome data and clinical endpoints. Curr Mol Med 2005; 5: 11-21.

[234] Myers CL, Barrett DR, Hibbs MA, Huttenhower C, Troyanskaya OG. Finding function: evaluation methods for functional genomic data. BMC Genomics 2006; 7: 187.

[235] Jones AR, Pizarro A, Spellman P, Miller M. FuGE. Functional Genomics Experiment Object Model. Omics 2006; 10: 179-184.

[236] Le Novere N, Finney A, Hucka M, et al. Minimum information requested in the annotation of biochemical models (MIRIAM). Nat Biotechnol 2005; 23: 1509-1515.

[237] Spellman PT, Miller M, Stewart J, et al. Design and implementation of microarray gene expression markup language (MAGE-ML). Genome Biol 2002; 3: RESEARCH0046.

[238] Chervitz SA, Hester ET, Ball CA, et al. Using the Saccharomyces Genome Database (SGD) for analysis of protein similarities and structure. Nucleic Acids Res 1999; 27: 74-78.

[239] Christie KR, Weng S, Balakrishnan R, et al. Saccharomyces Genome Database (SGD) provides tools to identify and analyze sequences from Saccharomyces cerevisiae and related sequences from other organisms. Nucleic Acids Res 2004, 32: D311-314.

[240] Dwight SS, Harris MA, Dolinski K, et al. Saccharomyces Genome Database (SGD) provides secondary gene annotation using the Gene Ontology (GO). Nucleic Acids Res 2002; 30: 69-72.

[241] Ostell JM, Wheelan SJ, Kans JA. The NCBI data model. Methods Biochem Anal 2001; 43: 19-43.

[242] Shah SP, Huang Y, Xu T, Yuen MM, Ling J, Ouellette BF. Atlas a data warehouse for integrative bioinformatics. BMC Bioinformatics 2005; 6: 34 .

[243] Weng S, Dong Q, Balakrishnan R, et al. Saccharomyces Genome Database (SGD) provides biochemical and structural information for budding yeast proteins. Nucleic Acids Res 2003; 31: 216-218.

[244] Kolinski A, Bujnicki JM. Generalized protein structure prediction based on combination of fold-recognition with de novo folding and evaluation of models. Proteins 2005; 61 Suppl 7: 84-90.

[245] Lundstrom J, Rychlewski L, Bujnicki J, Elofsson A. Pcons: a neural-network-based consensus predictor that improves fold recognition. Protein Sci 2001; 10: 2354-2362.

[246] Sen TZ, Kloster M, Jernigan RL, Kolinski A, Bujnicki JM, Kloczkowski A. Predicting the complex structure and functional motions of the outer membrane transporter and signal transducer FecA. Biophys J 2008.

[247] Bujnicki JM, Elofsson A, Fischer D, Rychlewski L. Structure prediction meta server. Bioinformatics 2001; 17: 750-751.

[248] Eyrich VA, Rost B. META-PP. single interface to crucial prediction servers. Nucleic Acids Res 2003; 31: 3308-3310.

[249] Grana O, Eyrich VA, Pazos F, Rost B, Valencia A. EVAcon: a protein contact prediction evaluation service. Nucleic Acids Res 2005; 33: W347-351.

[250] Koh IY, Eyrich VA, Marti-Renom MA, A et al. EVA. Evaluation of protein structure prediction servers. Nucleic Acids Res 2003; 31: 3311-3315.

[251] Fischer D. Servers for protein structure prediction. Curr Opin Struct Biol 2006; 16: 178-182.

[252] Friedberg I, Harder T, Godzik A. JAFA. a protein function annotation metaserver. NucleicAcids Res 2006, 34: W379-381

[253] Geueke M, Stausberg J. A meta-data-based learning resource server for medicine. Comput Methods Programs Biomed 2003; 72: 197208.

[254] Ginalski K, Pas J, Wyrwicz LS, von Grotthuss M, Bujnicki JM, Rychlewski L. ORFeus: Detection of distant homology using sequence profiles and predicted secondary structure. Nucleic Acids Res 2003; 31: 3804-3807.

[255] von Grotthuss M, Pas J, Wyrwicz L, Ginalski K, Rychlewski L. Application of 3D-Jury, GRDB, and Verify3D in fold recognition. Proteins 2003; 53 Suppl 6: 418-423.

[256] Kosinski J, Cymerman IA, Feder M, Kurowski MA, Sasin JM, Bujnicki JM. A "FRankenstein's monster" approach to comparative 
modeling: merging the finest fragments of Fold-Recognition models and iterative model refinement aided by $3 \mathrm{D}$ structure evaluation. Proteins 2003; 53 Suppl 6: 369-379.

[257] Kosinski J, Gajda MJ, Cymerman IA, et al. FRankenstein becomes a cyborg: the automatic recombination and realignment of fold recognition models in CASP6. Proteins 2005; 61 Suppl 7: 106-113.

[258] Kurowski MA, Bujnicki JM. GeneSilico protein structure prediction meta-server. Nucleic Acids Res 2003; 31: 3305-3307.

[259] Sasin JM, Kurowski MA, Bujnicki JM. STRUCLA. a WWW metaserver for protein structure comparison and evolutionary classification. Bioinformatics 2003, 19 Suppl 1: i252-254.

[260] Lemkin PF. The 2DWG meta-database of two-dimensional electrophoretic gel images on the Internet. Electrophoresis 1997; 18: 2759-2773.

[261] Saini HK, Fischer D. Meta-DP. domain prediction meta-server. Bioinformatics 2005; 21: 2917-2920.

[262] Saini HK, Fischer D. FRalanyzer: a tool for functional analysis of fold-recognition sequence-structure alignments. Nucleic Acids Res 2007; 35: W499-502.

[263] von Grotthuss M, Koczyk G, Pas J, Wyrwicz LS, Rychlewski L. Ligand.Info small-molecule Meta-Database. Comb Chem High Throughput Screen 2004, 7: 757-761.

[264] Wallner B, Elofsson A. Pcons5: combining consensus, structural evaluation and fold recognition scores. Bioinformatics 2005; 21: 4248-4254.

[265] Wallner B, Elofsson A. Prediction of global and local model quality in CASP7 using Pcons and ProQ. Proteins 2007; 69 Suppl 8: 184-193.

[266] Wallner B, Larsson P, Elofsson A. Pcons.net: protein structure prediction meta server. Nucleic Acids Res 2007; 35: W369-374.

[267] Carrere S, Gouzy J. REMORA. a pilot in the ocean of BioMoby web-services. Bioinformatics 2006, 22: 900-901.

[268] Kawas E, Senger M, Wilkinson MD. BioMoby extensions to the Taverna workflow management and enactment software. BMC Bioinformatics 2006; 7: 523.

[269] Wilkinson M. Gbrowse Moby: a Web-based browser for BioMoby Services. Source Code Biol Med 2006; 1: 4.
[270] Wilkinson M, Schoof H, Ernst R, Haase D. BioMOBY successfully integrates distributed heterogeneous bioinformatics Web Services. The PlaNet exemplar case. Plant Physiol 2005; 138: 5-17.

[271] Wilkinson MD, Links M. BioMOBY. an open source biological web services proposal. Brief Bioinform 2002, 3: 331-341.

[272] Stevens RD, Robinson AJ, Goble CA. myGrid: personalised bioinformatics on the information grid. Bioinformatics 2003; 19: i302304.

[273] Covitz PA, Hartel F, Schaefer C, et al. caCORE. a common infrastructure for cancer informatics. Bioinformatics 2003; 19: 24042412.

[274] Feigenbaum L, Herman I, Hongsermeier T, Neumann E, Stephens S. The Semantic Web in action. Sci Am 2007; 297: 64-71.

[275] Dhanapalan L, Chen JY. A case study of integrating protein interaction data using semantic web technology. Int J Bioinform Res Appl 2007; 3: 286-302.

[276] Neumann E, Prusak L. Knowledge networks in the age of the Semantic Web. Brief Bioinform 2007; 8: 141-149.

[277] Post LJ, Roos M, Marshall MS, van Driel R, Breit TM. A semantic web approach applied to integrative bioinformatics experimentation: a biological use case with genomics data. Bioinformatics 2007; 23: 3080-3087.

[278] Quan D. Improving life sciences information retrieval using semantic web technology. Brief Bioinform 2007, 8: 172-182.

[279] Ruttenberg A, Clark T, Bug W, et al. Advancing translational research with the Semantic Web. BMC Bioinformatics 2007, 8: S2.

[280] Smith A, Cheung K, Krauthammer M, Schultz M, Gerstein M. Leveraging the structure of the Semantic Web to enhance information retrieval for proteomics. Bioinformatics 2007; 23: 3073-3079.

[281] Smith AK, Cheung KH, Yip KY, Schultz M, Gerstein MK. LinkHub: a Semantic Web system that facilitates cross-database queries and information retrieval in proteomics. BMC Bioinformatics 2007; 3: S5. 


\section{SUPPLEMENTARY APPENDIX: AVAILABLE DATA- SETS, ANALYTICAL METHODS AND TOOLS}

Here we provide a more in depth analysis of the different datasets that are available for metabolic reconstruction and of the tools that can be used to mine those data sets for information.

\section{S.1 Literature Data}

\section{Available Datasets}

Because thousands of scientific papers are published monthly within many areas of molecular biology, it is not feasible for anyone to read them all. A digest of the information contained in the literature is available on-line, in literature databases that contain the abstract, title and keyword information such as MEDLINE [1], PUBMED [2], Web of Science [3, 4] or others [5]. The full text of many papers and some books is also available in databases available in journal home pages. The information in these databases is organized according to strict criteria that facilitate finding papers reporting on many different subjects. The various databases are associated to diverse search engines that have different sensitivities and goals [6-11]. Automated analysis of a natural text within a given literature database to find specific pieces of information (gene names, gene function, parameter values, interaction information between individual molecular components, etc.) is a rapidly evolving field [12]. Truly flexible, multipurpose, and automated network mining from the full text of live documents brings enormous added value from the literature datasets to molecular systems biology research [13-16]. Values for kinetic and thermodynamic parameters for many different reactions and processes are also buried in the literature. Mining for this data has been mostly manual, and parameter information stored in databases is not in general sufficient to evaluate the usability of such data (e.g. BRENDA and enzyme parameters [17-19]).

\section{Analytical Methods and Tools for Text Mining}

Natural language processing and mining is developing rapidly [3, 6, 20-39]. Currently, several alternative models are being used to develop tools that mine the literature. One of the models is ontology-based and relies on creating classifications that reduce ambiguity in the text to be mined (e.g. $[3,22,25])$. Another model is based upon the existence of thesaurus and dictionaries of synonyms [26, 40]. A third model, based on machine learning and using a combination of ontologies and thesaurus, allows the search algorithm to be trained while mining text information (e. g. [20, 21]). This should improve the performance of the methods in a near future. As a general goal, it is increasingly important to make the methods for automated text mining available to the biological researchers in applications that facilitate the derivation of biologically relevant information. Some text mining tools that fulfill those requirements are already available (e. g. [20, 36, 40-48]). For example, they can be used to extract network information [41, 42, 44, 47] or protein localization [48] from raw text and literature analysis. It would also be invaluable to develop specific software applications that allow researchers to accurately identify parameter value reports. Ideally, an automated mining of parameter information would allow for the identification of organism, reaction, units and conditions of parameter determination.

It is likely that the major hindrance to a precise and complete mining of the literature information by automated text mining tools will be the decades of accumulated literature using non-standardized nomenclature and classifications (see main text). Possible remediation for these problems are a) creating better dictionaries of synonyms, and b) using artificial intelligence and machine learning methods to increase the size of the dictionaries and allow the algorithms to make educated guesses regarding correspondence of terms. Part of this upgrading of the dictionaries could be done according to a combination of machine learning and a "wiki-like" model. That is, as users executed their jobs they could provide information and feedback to the methods regarding new synonyms and correct/incorrect guesses made by the software.

\section{S.2 Sequence Data}

\section{Available Datasets}

With the increasing number of genome sequencing projects that are completed or underway, increasing amounts of sequence data are available. Sequence datasets are too numerous to mention. However, a few central repositories contain most of the sequence information, often duplicated among the repositories. The $\boldsymbol{N C B I}$ web pages [36-42] and the $\boldsymbol{K} \boldsymbol{E} \boldsymbol{G} \boldsymbol{G}$ web pages [43-47] contain annotation information for most organisms with fully sequenced genomes. $\boldsymbol{E x}$ pasy $[48,49]$ also has this information with a focus on the proteins. The $\boldsymbol{T I G R}$ institute $[50,51]$ web pages and the DOE Joint Genome Institute [52] web pages also contain much of this information. Then, individual genome project web pages contain a wealth of functional details regarding their genome of interest and its genes. This is the case for example of the $\boldsymbol{S G D}$ resource $[53,54]$ for the yeast $\boldsymbol{S a c}$ charomyces cerevisiae, of WormBase for C. elegans [49] or FlyBase for Drosophila [50, 51]. There are also databases available for RNA genes and gene targets (e. g. [52-55]) as well as for regulatory sequences in the genome of different species (e. g. [56]).

\section{Analytical Methods and Tools for Functional Annotation of Sequences}

We will not discuss the computational tools and methods used for genome sequencing and annotation. Those interested can find detailed explanations of the historical evolution of genome sequencing methods in the paper by Ankeny [57] and the references therein. For more recent reviews on the subject see [58-61].

Once the genome sequence is completed and assembled, one faces the task of finding the open reading frames (ORFs). Searching for homology to known genes is one of the methods for genome annotation. The de facto standard tool for aligning homologous sequences is the BLAST alignment program [62]. When no sufficient homology can be found, other methods and tools exist to predict ORFs. An overview of such methods can be found in [63]. By and large, the gene finding methods split into signal finding methods or content finding methods. Signal finding methods look for elements that signal the beginning and the end of genes, such as the ATG codon, or sequences that are recog- 
nized as promoter sequences. However, many other signals that can be used for this purpose exist in genomes. These signals include for example transcription factor binding sites or ribosome binding sites in prokaryotes. Content finding methods are based upon finding differences in general statistical properties between coding and non-coding sequences of the genome. For example, in a genome the frequency of dinucleotides is different in coding and non-coding sequences, as is the GC content of the sequence. These differences can be used to separate the two types of sequences. Different gene finding tools use alternative combinations of methods to find signals and content, thus improving their probability of finding true ORFs [64-70]. The available tools for gene finding include GENEMARK [64], SNAP [68], Ensembl [71], SPG2 or TWINSCAN (e.g. [67]), among many others.

Metagenomic sequencing efforts, where the DNA sequence of an environment is sequenced and must be assembled, are now emerging [72-76]. Finding genes in these sequences is not easy because often one does not know to which genome a sequence belongs to. Ideally, the sequences should be assembled, whenever possible, into its individual genomes which can be analyzed to find genes. However, if such assembly is not possible, specialized programs must be used to predict genes in large fractions of orphan DNA [77, 78]. Metagene [69] is an example of a tool developed specifically for prokaryotic gene finding in metagenomic samples.

Several centralized servers such as Expasy [79], KEGG [80-83] or $N \boldsymbol{C B I}$ [84] provide tools that allow researchers to infer functional information from sequence data. The information made available for any given sequence ranges from the actual molecular function of an individual gene/protein to the prediction of post translational modifications in a protein [77] or the prediction of its location within the cell [85-88]. Also, several on-line services provide maps of metabolic pathways, gene circuits, and signal transduction pathways [89-100]. By superimposing the different genes identified within a genome onto those maps, one gains knowledge about qualitative aspects of cellular behavior. For example, if there are no genes coding for a given amino acid pathway within a genome one can expect that the organism will require that amino acid as a part of its diet. Some tools and servers that allow for analysis of phylogenetic conservation and congruence studies between genes in sets of fully sequenced genomes are also available [101-108]. There are also tools available for the analysis of RNA genes and for the analysis of regulation by RNA [109-115].

\section{S.3 Structural Data: Mining for Function}

\section{Available Datasets}

As is the case for sequence data, the amount of structural data for the molecular components of cells is also increasing steadily. The whole proteome structural genomics projects $[116,117]$ that are currently under way contribute to this increase [118]. There is a central repository of protein and nucleic acid structures at the protein databank (PDB) [119]. The structures deposited at the $\boldsymbol{P D B}$ include complexes formed between proteins and even provide information regarding the stoichiometry of those complexes. Many of the structures contained in the $\boldsymbol{P D B}$ can also be found elsewhere, for example at the NCBI [84].

\section{Analytical Methods and Tools}

Computational methods and tools are necessary from the ground up in the analysis of structural data. The most common ways to obtain protein structure are:

a) Submitting purified protein crystals to high energy radiation bombardment (e. g. X-Ray or neutrons) and capturing snapshots of the radiation diffracted by the protein crystals. These snapshots are then reconstituted into a 3D structure using appropriate software [120-125].

b) Using NMR technology to take spectral snapshots of the protein in solution [126-130], that are then reconstituted into a 3D structure using appropriate software.

Technical details regarding structure determination are well beyond the scope of this review. For practical reasons, our main focus will be on structure visualization, analysis and prediction. Once the proteins structures are available they are reported and stored using a specific data format [131-133] that includes, among other things, the 3D coordinates of the different atoms in the protein, the native organism, and the oligomerization state of the biologically relevant form of the protein. An analysis of these structures requires tools for their visualisation. One of the simplest tools available is RasMol [134]. This free tool allows the researcher to visualize and do minimal manipulation of the structure files. Another free tool is DEEPVIEW [135]. This tool is more sophisticated and, for example, it allows for point mutations to be introduced into the structure and energy minimization to be performed. It also allows researcher to do their own structural modelling of their protein of interest if the structure has not been determined yet. There are alternative methods for structural modelling. The most successful can be roughly grouped as follows:

a) Fold prediction. In some cases, when not enough information is available to obtain a 3D structure prediction, there are methods that allow the prediction of the secondary structure of a protein $[136,137]$. Currently, many of the methods used for fold prediction are used as intermediate steps for obtaining a 3D structure prediction of proteins for which there are no known homologues in the PDB.

b) Homology modelling. The researcher has a sequence of interest and finds homologues of that sequence that have had their structure determined. By doing a sequence alignment, the researcher can then superimpose the sequence onto the known structure, followed by energy optimization. Many servers do homology modelling. SWISSMODEL [135] and 3DJIGSA W [138] are a few of these. To find a list of other such servers one can consult the special issues of the journal Proteins that report the CASP (critical assessment of structural prediction) results [139-145]. 
c) Threading. In the absence of homologues with known structure, one can thread the sequence over a known structure of a protein that one thinks is likely to have structural similarity, followed by energy minimization.

d) $\quad \boldsymbol{A} \boldsymbol{b}$ initio modelling. By using short stretches of homology over different protein structures one can also create models for the structure of a protein that has no homologues with a known structure. Robetta is an example of a server that allows researchers to do $a b$ initio modelling from sequence [146]. To find a list of other such servers see the special issues of the journal Proteins that report the $\boldsymbol{C A S P}$ results [139-145]. An alternative $a b$ initio method is starting with the linear alpha helical structure of a sequence and by doing molecular dynamics simulations study how the protein folds. However, there is not enough computational power available to use this approach as a standard procedure.

The use of in silico protein docking can also reveal details about how different biological molecules physically interact. Interested readers can use different programs and servers to perform such docking studies [147-164].

\section{S.4 Gene Expression Data}

\section{Available Data}

Large datasets measuring changes in gene expression for entire genomes, under different conditions are accessible for many different organisms. These data can be used to infer which genes and proteins are important for a specific cellular response, thus giving researchers information about the role of genes with unknown function. Additionally one can infer information regarding the dynamics of the function, which is something harder, or even impossible, to do from sequence or structural data. Gene expression data is deposited in different databases. The Gene Expression Omnibus (GEO), at the $N C B I$ offers the raw data for many of the micro array experiments published in the literature [165]. Other general databases exist, both for microarray data and for other types of gene expression experiments (e. g. [166-171]). There are also databases for gene expression for specific human diseases (e.g. $[172,173])$ in specific organisms, such as mouse [174], Arabidopsis [175] and others.

\section{Analytical Methods and Tools}

With the advent of fully sequenced genomes, there came the invention of DNA chips and microarrays [176, 177]. In microarray experiments, probes that hybridize mRNA for a large fraction of the individual genes in a genome are imprinted onto a slab of material. Cells are grown and subject to some stressful condition, which may include mutation. Then cells are collected and their mRNAs are purified, amplified and hybridized with the probes in the microarray. By comparison with a control condition, these experiments reveal how much the expression of individual genes changed in response to the stress. For a more detailed description of microarray experiments see for example [178].

Other methods also allow measuring changes in gene expression at the whole genome level. Such methods include for example SAGE [179, 180] or CAGE [181] experiments, where mRNAs are directly amplified and identified in solution without the need of an imprinted microarray. A variation of the classical DNA microarray is the tiling microarray. The probes in these arrays are designed to cover entire regions of the genome, rather than individual genes [182]. These microarrays have shown that there are large islands of expression, for example in the human genome, that are either outside the genes or constitute only fragments of those genes [182, 183].

As is the case with the determination of protein structure, computational methods are needed to process the data in microarray experiments that measure changes in gene expression. The determination of change fold for gene expression in microarray experiments is usually done using differential measurements of fluorescence or radioactivity. Image capture, processing and noise filtering are areas where appropriate algorithms must be used in order to ensure acceptable data acquisition and normalization [178, 184, 185].

Once the data are collected and organized in its final form, then a different set of computational methods is required in order to determine whether a change in gene expression is actually significant or whether it can be attributed to noise [186-189]. There are no general methods that are universally considered as more appropriate to analyze the significance of a given change fold. This is an area of intensive research. Microarray data have problems of reproducibility and robustness, which underlines the importance of experimental design, replicate experiments and appropriate statistical methods as a means to identify significant changes in gene expression.

There are several tools to analyze microarray gene expression data and cluster genes according to their changes in expression. For example, the tools provided in $\boldsymbol{G E O}[165$, 190] can be used to comparing different gene expression profiles. TM4 [191] and $\boldsymbol{B A S E}$ [192] are examples of software platforms that allow for the analysis and comparison of gene expression profiles. Bioconductor [193] is a popular open source software platform that uses a set of functions and procedures written in $\mathrm{R}$ to analyze microarray data.

\section{S.5 Proteomics Data}

\section{Available Data}

What information from proteomics experiments should be stored in databases and how it should be organized is still not consensual [194-200]. In consequence there is still no central repository of proteomics data. PRIDE $[199,201]$ and the Peptide Atlas [202] projects are probably the resources that contain more data from proteomics experiments. The global proteomics machine [203] provides software and internet services that mine data from these and other proteomics data sources. On a smaller scale, the NetworKIN database stores proteomics information about the phosphorylation state of human phosphoproteins [204].

There is, to our knowledge, no good and general HTP method to characterize protein activity on a large scale (however, see the main text for a promising new method.) The development of such methods would allow for the large scale determination of enzyme parameters, binding, and 
thermodynamics constants and would likely create a revolution in mathematical modeling. Nevertheless, and independently of the limitations, the application of proteomics methods to the study of the dynamics of protein post translational modification can be a step forward in obtaining this type of information.

\section{Analytical Methods and Tools}

The progresses in 2D gel electrophoresis and in Mass Spectrometry (MS) and NMR technology have permitted the analysis of whole cell samples in order to identify the protein complement of the cell [205-225]. In general, proteins are separated via electrophoresis. The different proteins are then identified using MS techniques or NMR techniques. Unfortunately, datasets from these studies are not as abundant nor publicly available as those from microarray experiments. Furthermore, a central repository for all the proteomics experimental data is still lacking. Nevertheless, the available proteomics data already provide information regarding community proteomics [226], subcellular localization of proteins [227-229], dynamics of protein turnover [207, 208, 230, 231], post-translational modifications of proteins [217, 232-240], markers of specific responses, and many other aspects of protein function.

Most of the software effort in proteomics is still dedicated to creating tools for identifying proteins from the MS or NMR spectra. These tools work, for example, by using Fourier analysis for spectral identification. The spectra are compared to know protein spectra, thus allowing for the identification of proteins in sample. The data sources mentioned in the previous section provide tools that allow researchers to identify the proteins that are present or absent in each sample.

\section{S.6 Metabolomics Data}

\section{Available Data}

There is, to the knowledge of the authors, no general central public repository of metabolomics data. A few databases already exist, but their content is fragmentary, with respect to the amount of reported metabolomics data [241-244]. Furthermore, the problem of developing a standard in data reporting is a difficult one that has only now began to be addressed [245-249]. Links to some of the current repositories of metabolomics data available on the web can be found at http://www.bmrb.wisc.edu/metabolomics/external_metab_li nks.html. As time progresses and standardization settles into the field, it is likely that central repositories of metabolomics data will be developed. Such data will be invaluable for example to derive parameter values and perform mathematical model validation [250].

\section{Analytical Methods and Tools}

Cells use proteins to take up nutrients and make other small molecular species. There may be more than 200000 metabolites in the plant kingdom alone [200]. Unlike proteomics or genomics, in metabolomics experiments hundreds of types of molecules with different chemical properties must be detected. Thus, detection techniques must be sensitive, robust and versatile. Technological advances in NMR spectroscopy [251, 252] and MS have facilitated the use of these two types of techniques to measure the changes in the concentration of small metabolites over time [245, 250, 253-269]. NMR metabolomics methods are inherently quantitative but have a low sensitive and require larger amounts of a metabolite for identification than MS methods. MS is more sensitive but cannot provide absolute quantification. A more detailed analysis of these and other experimental techniques used in metabolomics experiments can be found in the literature [268, 270, 271].

Computational methods are required at every step to process and analyze metabolomics data [263]. A single spectrum in a metabolomics experiment may contain many different signals. This requires powerful computational and statistical methods as well as accurate spectral maps for the many different types of metabolites. Statistical and computational methods are needed to deconvolute the metabolomics spectra. Pattern recognition methods are required when comparing different metabolomics experiments of the same system under different conditions. Methods for pattern recognition are reviewed for example in [248, 249, 272]. The comparisons between different metabolomics profiles help identifying metabolites whose levels are significantly modified, thus pointing at direct changes in regulation of metabolism between the two conditions. Algorithms such as those developed by Vance et al. [273] can be applied in determining the causal sequence of events in metabolomics experiments. Parameter fitting methods and algorithms can use the data to obtain parameter values for mathematical models [274-278].

\section{S.7 Interaction Data}

\section{Available Data}

Interaction data can be divided into three categories:

Genetic and functional interactions. By genetic interactions data we mean data that provide information regarding essentiality of genes (e.g. [279]) or complementation between different genes [280]. For example, in S. cerevisiae, a multi-copy vector containing the ISA2 gene rescues the $\Delta$ grx 5 mutant phenotype [281]. By functional interaction data we mean data that provide information about which processes and functions are genes and proteins involved in. Genetic and functional interaction data provides very useful information regarding the function of the different genes. It may be invaluable in providing information regarding the pathways and responses in which genes of unknown function are involved. Prophecy is a database that collects this data for $S$. cerevisiae [282]. However, there is, to our knowledge no other resource that systematically collects this information for other organisms. Another type of functional interaction data is that of genes and proteins that are known to belong to specific metabolic pathways, signal transduction pathways and gene circuits. By homology analysis many proteins of any genome can be placed into the different pathways and circuits, thus providing functional information.

Physical interactions. By physical interactions data we mean data that provides information regarding actual physical interactions between different proteins or between proteins and nucleic acid. There are many different types of experiments that provide data regarding these interactions. Automated and large scale Two Hybrid Screens (THS) systematically take the proteins of a genome and scan for physical interactions between each pair of proteins [283-285]. If 
an interaction exists, a chemical product that can be detected is produced or photons are emitted [285, 286]. A systematic application of the THS technology has been reported for yeast, worm, fly, human, H. pylori and other organisms (see [286-296]). Different reporter methods will provide different sensitivity and robustness in THS [291]. The THS assays also have problems with false positive and false negative interactions. This is so because the interaction between proteins is often measured in conditions that may not be the native conditions under which the two proteins meet in the cell. An alternative method for HTP assays of protein interactions is by using classical biochemical co-purification methods followed by MS identification of the purified proteins [287, 297]. So far there is a $10-20 \%$ overlap between dataset of protein interactions that are determined independently [298]. It is conceivable that in the near future protein chips, where the individual proteins of the genome are secured to some support material, will be devised and used to fish out interacting partners from whole cell protein extracts. There are already affinity chips that are used for purification of proteins [211]. Additional sources for protein-protein interaction information are in silico predictions. By using sequence information and evolutionary analysis there are methods that predict, for example, co-evolution of residues in different proteins or gene fusion events in different genomes. Predictions of co-evolution or detection of gene fusion events are interpreted as indicating that there is a physical interaction between two proteins (see [299-302] for a review). On-line resources where information from HTP interaction experiments is deposited include the BIND database [303] the PRIME database [304], the MIPS database [305], the DIP database [306] and the $\boldsymbol{M I N T}$ database [307]. All these databases also contain information regarding small scale interaction experiments, mined from the literature. Some databases focus on specific organisms, as is the case for example of the E. coli database EchoBase [308].

Another type of physical interaction between cellular components that has implications in cell function is the one occurring between proteins and nucleic acids. Information regarding which regulatory motifs are bound by the different transcription factors (TF) in a genome is important because it allows the identification of which genes are regulated by each transcription factor. The development of ChIP-chip technology [309, 310] enables HTP research about which genes are regulated by which TFs in a genome. In ChIP-chip experiments, cells are grown under the conditions of interest and then they are lysed. Then one of a series of methods is used to crosslink DNA and protein, followed by fragmentation of the genomic DNA. The DNA fragments are then copurified with the transcription factors of interest, amplified, and hybridized with a genomic DNA microarray. This hybridization reveals where in the genome the TF binds, allowing the inference of gene circuits controlled by each TF. As is the case for protein-protein interactions, there is no large scale central repository for this type of information. There are however smaller databases that contain information regarding the different aspects of protein-DNA interaction. The NDB, PSIBASE and AANT databases contain information obtained from DNA protein complexes deposited at the PDB [311-313]. NPInter also has information about interactions between protein and non coding RNA in E. coli, S. cer- evisiae, C. elegans, D. melanogaster, M. musculus, and $H$. sapiens [314]. The BDTNP database at Berkeley (https://bdtnp.lbl.gov/Chipper-/index.jsp) is a secured access resource for the analysis of fly related DNA-protein interactions.

\section{Analytical Methods and Tools}

The computational methods used for mining interaction data range from those used to find co-occurrence of genes in the literature, to those used to create protein alignments and to calculate co-evolution of specific residues, and to those used for in silico protein docking. Many algorithms use graph theory to derive networks of functional interactions from the different types of data. From a mathematical modeler's perspective, the representation of networks obtained from mining interaction data is in general far from perfect. Most representations of these networks show a set of nodes (the genes/proteins) connected by edges whenever there is some form of interaction between them (e.g. [315]). This kind of representation is ambiguous and prevents direct utilization of the networks for the generation of mathematical models. Some tools (e.g. pathway tools $[96,100])$ represent networks with diagrams that can be easily and unambiguously parsed as models. However, this is mostly for enzyme network data. Building something similar for systematic reconstruction of gene circuits and signal transduction pathways is difficult until a standardized classification is accepted for signal transduction proteins and transcription factors.

\section{S.8 Kinetic Data}

Kinetic data are fundamental for the development of mathematical models in molecular biology. Having such data in abundance and devising good classification systems for the different functions of cellular species facilitates automated model creation. This job has so far been easier for enzymes than for other types of molecules. Many years ago, the enzyme commission (EC) developed a functional classification scheme for the activity of enzymes that, although not perfect, is very useful when annotating proteins with enzyme functions [316]. Databases such as $\boldsymbol{B R} \boldsymbol{E N D A}$ [19, 317-319] include information about the function of different types of enzymes, and in some cases also about kinetic parameters and thermodynamic energy measurements. Kinetic information can also be found for example in $\boldsymbol{K D B I}$ [320]. $\boldsymbol{E z} \boldsymbol{C a t D B}$ [321, 322] and MaCie [323, 324] include information regarding catalytic mechanisms. ProTherm provides thermodynamics data for mutant proteins [325]. However, the kinetic information is not classified and organized in such a way that researchers can directly take the parameter values and use them to build models. Anyone who is interested in doing so must consult the original sources where the parameter values are reported and make sure that units are consistent and that the experimental conditions during the determination are appropriate for the purposes of the model.

It would be important to have similar functional classifications for other types of proteins, such as receptors, structural proteins, transcription factors and so on. This would facilitate automated building of schema that could then be used to build mathematical models. However, proposed standard for such classifications are still far from perfect or universal. Some classifications based upon the DNA binding 
motifs or the structural binding domain of transcription factors have been proposed (see e.g. [326, 327]). Classifications similar to that proposed by the EC for enzymes have been proposed for signal transduction molecules [328] and transport proteins [329]. However, their use is far from widespread and it is unclear if they will be adopted as a standard.

It would also be extremely useful to have standard functional classifications for:

a) Lipid components. The chemical structure of these lipids may constitute a good basis for such a classification.

b) Nucleic acid molecules, including the different types of small RNAs that are currently being shown to play important roles in regulating and catalyzing functional aspects of the cell metabolism. Although a general classification has been proposed for RNA [330], it focuses on structure, rather than function.

c) Small metabolites. Again, the chemical structure of these small metabolites may constitute a good basis for a functional classification. The Ligand database [331] is a good repository of small metabolic molecules. Other methods, based on chemical and structural information allow for the development of different types of metabolite classifications (e. g. [332]).

Having a classification for the different proteins, genes and other components of the cell has allowed the creation of many resources with more systemic functional information such as lists of pathways, gene circuits and signal transduction pathways (e.g. Metacyc [95], KEGG [80, 82] or $\boldsymbol{E M P}$ [333]). Such resources provide annotated information regarding the function of the different cellular components.

\section{S.9 Mathematical Models}

\section{Available Data}

Mathematical models of specific molecular processes in different organisms are an increasingly important source of information for the understanding of the systemic behavior in molecular biology. Such models have been published since the 1950s and they are mostly scattered in the literature. Datasets that collect and organize these models have been recently started, but relatively few models are included [334-341]. Model annotation is much more challenging than annotation of genes and proteins for several reasons. For any given system, one can create models using different formalisms and at different levels of detail. This depends, among other things, upon the questions one wants to ask of the model. Models of similar processes on different organisms may involve different enzymes, different number of steps and branch points, etc. Finally, the existence of specific regulatory signals that may vary from one condition to another, from one protein isoform to another, or from one organism to the next, introduces further complexity into the modeling process.

Despite all these difficulties, it is clear that a standard model reporting language is useful to reutilize models or part of models that have been previously defined and curated.
Building models is a challenging task and any tools that facilitate the model building process are useful. Currently there is an effort to make newly published models comply with minimal information criteria for publication [338]. There is also a drive to facilitate the interchange of model files between different programs and researchers by asking that models be deposited in central databases, using a standardized modeling language such as SBML or CellML [342345]. A large investment is also being made in the development of tools for model set up and analysis [346-352]. The model database efforts are currently in their infancy and the databases are still small. However, if one is willing to search the literature, one will find many models that are useful in understanding the systemic behavior of molecular biology processes.

\section{Analytical Methods and Tools}

There are different formalisms for writing models and different classes of models. The choice of a given mathematical representation depends on the goals of the modeling exercise, the complexity of the target system, and the available data (either in terms of parameters or in terms of time course data, metabolite levels, enzyme activities, etc.). Furthermore, the same problem can be studied at different levels of complexity. For example, one can find models that range from the modeling of a single enzyme reaction to those that attempt to model the whole cell, going through intermediate scale models that consider small sets of cellular pathways and circuits.

Among the smaller scale models that consider only a very limited number of molecules and reactions we find many different types of modeling. Mainly, quantum modeling is used for investigating the active state of an enzyme reaction [353], molecular dynamics is used to study protein folding [354], stochastic modeling can be used for modeling networks of reactions with a small number of molecules [346]. For large scale models of many pathways, the quantum modeling, molecular dynamics modeling, Monte Carlo modeling and stochastic modeling become unfeasible due to lack of computer power. Sets of ordinary and partial differential equations are common in exploring the dynamic behavior of complex pathways [275, 355, 356]. Qualitative types of modeling such as discrete binary mode modeling [357-359] or flux balance analysis [360-363] are also used to study large networks.

Integration of models from different origins and using different mathematical forms is a very challenging problem. Before discussing possible solutions to this problem, it is worth it briefly detail some of the specific requirements of the most common formalisms. A simple description of a process is appealing because one require less information to build a model from such a description. However, the utility of the resulting models may be limited if our goal is to understand dynamic behavior and design principles. More complex descriptions of a process have better changes of producing models that reproduce a wide range of behavior for the system one is studying. However, the complexity of such models combined with lack of information regarding the process may prevent the creation of more detailed models. 
A similar argument can be made for mathematical representations. Simple linear representations will facilitate the analysis of models but will prevent the model from capturing non linear behavior that is typical of biological systems. Approximation theory provides many alternative formalisms that combine simplicity with non linearity [364]. We now briefly discuss different types of models used in molecular biology.

\section{Finite State Models}

Finite state models analyze the dynamic behavior of networks in which the nodes are allowed only a finite number of states (e.g. on-off). Such a mathematical description is very simple, thus allowing the analysis of complex and large networks. The basic information required to built such models include: (i) the stoichiometric matrix of the reactions taking place in the model, which can be derived from the conceptual scheme of the target system, (ii) the relevant regulatory signals, so that we can appropriately describe the on-off states of the system's elements, and (iii) a set of functions, usually sigmoid, that are used to decide the on-off state of the different elements (e.g. [365]). Finite state models are appealing because they need a minimum of information as input and provide clues about the dynamic properties of a system [358]. However, in general, these models will not be useful if detailed quantitative predictions are needed.

\section{Models Based on Stoichiometry}

Flux-balance analysis (FBA) and graph theoretical approaches study network topology and relate changes in that topology to qualitative changes in the dynamics of the system. These models often study the entire metabolic network of an organism [360, 366-381]. As in the case of the finite state models FBA requires a minimum of information, besides the stoichiometric matrix of the model. From this matrix and using graph theoretical methods and optimization techniques, FBA can, for example evaluate the effect of deleting a gene on the flux distribution, thus identifying the expected phenotypes for mutants in the different enzymes. A disadvantage of these approaches is that they fail to account for dynamic regulation. FBA models are a good choice for genome-wide descriptions and can be used as a base for more detailed modeling of specific pathways.

\section{Stochastic Modeling}

Stochastic models consider the details of the system and either a) use a Master equation to study the time distribution of the metabolite concentration [382-385], or b) consider every molecule in the system and follow their time evolution using chemical kinetics and algorithms that are able to statistically predict each elementary reaction event in the system. Gillespie like algorithms require that all reactions are mass action in order for the methods to work [346-349]. There are now newer stochastic methods that are being developed and loosen this constraint [386]. These models are computationally very heavy. Whenever dealing with processes that involve large pools of molecules, deterministic approaches are good approximations to the more detailed stochastic approach.

\section{Continuous Modeling}

The use of differential equations, either ordinary (for well stirred systems) or partial (for systems with spatial differentiation) to define mathematical models that can be used to quantitatively simulate the dynamics of a molecular system was the first $[387,388]$ and is still the more prevalent choice as a computational modeling tool. There are mathematical rational expressions that simplify complex mechanisms and are considered to represent more or less accurately the dynamics of many different types of individual molecular biology processes. For example, for a simple one substrate enzyme, the Michaelis-Menten rate expression can represent the dynamics of the reaction in well stirred systems [389]. Many other rational expressions have been derived for more complex enzyme atic mechanisms. However, we lack the knowledge of how many processes happen, which prevents the use of these pre-defined kinetic expressions in modeling. Even if the mechanism is known, in most cases the parameter values have not been measured and thus the mathematical representation using rational expression cannot be parameterized. Furthermore, when parameter values are available, the experimental conditions under which they have been measured may invalidate their use. Additional complications occur when one is interested in modeling spatially non-homogenous systems. In such a case PDEs must be used and many of the simplifying assumptions for obtaining rational rate expressions such as the Michaelis Menten kinetics often break down. Thus, depending on the level of mechanistic, spatial and mathematical detail one wants to consider, a given conceptual scheme can generate many different models.

One way to side-step the lack of knowledge regarding mechanism and, in some cases, parameter values is by using approximation theory. Mathematical theory allows us to approximate functions of known and unknown form with structured, canonical, representations that are precise at the operating point of the approximation and accurate over a varying range of values about that operating point. The most widespread and successful approaches use Taylor series to approximate the kinetic functions. This strategy was used by Savageau in the late sixties to generate a non linear representation of molecular biology systems, known as the Powerlaw formalism [390-392]. The Power-law representation can be derived from the conceptual model and some systemic properties can be analyzed without the need of a detailed kinetic characterization [393-406]. Furthermore, we can easily modify a given model by adding terms to any of the equations, which can be an advantage for sharing models. Alternative representations to the Power-law formalism that share some of its advantages are the Lin-log [265, 407, 408] and (log)linear [409] formalisms. Both formalisms require the same information as required for the Power-law formalism, although the final representation differs $[364,410]$. Recently, a Saturable and Cooperative (SC) formalism has been derived by using Taylor series approximation after a powerinverse transformation [364, 410]. In a different strategy, the use of a special rate-law called Convenience kinetics has been proposed as a way of obtaining a general representation [411]. Because power-law models can be easily and automatically obtained from other representations, the use of this 
(and other) formalism(s where such usage is possible) may facilitate HTP modelling building and analysis.

\section{REFERENCES}

[1] Richards DE. Medline at thirty-five. Evid Based Dent 2006; 7: 89.

[2] Reid T, Dunikowski LG. PubMed Central--at last. Can Fam Physician 2006; 52: 159-160, 165.

[3] Abulaish M, Dey L. Knowledge enhancement through ontologyguided text mining. Pattern Recognition and Machine Intelligence, Proceedings 2005; 3776: 601-604.

[4] Sevinc A. Web of science: a unique method of cited reference searching. J Natl Med Assoc 2004; 96: 980-983.

[5] Giglia E. Beyond PubMed. Other free-access biomedical databases. Eura Medicophys 2007; 43: 563-569.

[6] De Groote SL. PubMed, Internet Grateful Med, and Ovid: a comparison of three MEDLINE Internet interfaces. Med Ref Serv $Q$ 2000; 19: 1-13.

[7] Falagas ME, Pitsouni EI, Malietzis GA, Pappas G. Comparison of PubMed, Scopus, Web of Science, and Google Scholar: strengths and weaknesses. FASEB J 2008; 22: 338-342.

[8] Gall C, Brahmi FA. Retrieval comparison of EndNote to search MEDLINE (Ovid and PubMed) versus searching them directly. Med Ref Serv Q 2004; 23: 25-32.

[9] Janke RG. Current Contents Connect and PubMed--a comparison of content and currency. Health Info Libr J 2002; 19: 230-232.

[10] Sutton VR, Hauser SE. Preliminary comparison of the Essie and PubMed search engines for answering clinical questions using MD on Tap, a PDA-based program for accessing biomedical literature. AMIA Aпnи Symp Proc 2005: 1128.

[11] Vanhecke TE, Barnes MA, Zimmerman J, Shoichet S. PubMed vs. HighWire Press: a head-to-head comparison of two medical literature search engines. Comput Biol Med 2007; 37: 1252-1258.

[12] Peng $Y$, Zhang $X$. Integrative data mining in systems biology: from text to network mining. Artif Intell Med 2007; 41: 83-86.

[13] Ananiadou S, Kell DB, Tsujii J. Text mining and its potential applications in systems biology. Trends Biotechnol 2006; 24: 571579.

[14] Liu Y, Navathe SB, Civera J, Dasigi V, Ram A, Ciliax BJ, Dingledine R. Text mining biomedical literature for discovering gene-togene relationships: a comparative study of algorithms. IEEE/ACM Trans Comput Biol Bioinform 2005; 2: 62-76.

[15] Liu Y, Brandon M, Navathe S, Dingledine R, Ciliax BJ. Text mining functional keywords associated with genes. Medinfo 2004; 11: 292-296.

[16] Natarajan J, Berrar D, Dubitzky W, et al. Text mining of full-text journal articles combined with gene expression analysis reveals a relationship between sphingosine-1-phosphate and invasiveness of a glioblastoma cell line. BMC Bioinformatics 2006; 7: 373.

[17] Barthelmes J, Ebeling C, Chang A, Schomburg I, Schomburg D. BRENDA, AMENDA and FRENDA. the enzyme information system in 2007. Nucleic Acids Res 2007; 35: D511-514.

[18] Pharkya P, Nikolaev EV, Maranas CD. Review of the BRENDA Database. Metab Eng 2003; 5: 71-73.

[19] Schomburg I, Chang A, Ebeling C, Gremse M, Heldt C, Huhn G, Schomburg D. BRENDA, the enzyme database: updates and major new developments. Nucleic Acids Res 2004; 32: D431-433.

[20] Adeva JJG, Calvo R. Mining text with Pimiento. IEEE Internet Computing 2006; 10: 27-35.

[21] Antonakaki D, Kanterakis A, Potamias G. Biomedical literature mining for text classification and construction of gene networks. Advances in Artificial Intelligence, Proceedings 2006; 3955: 469473.

[22] Choi YJ, Park SS. Efficient classification method for complex biological literature using text and data mining combination. Intelligent Data Engineering and Automated Learning - Ideal 2006; Proceedings 2006; 4224: 688-696.

[23] Davis N, Demetriou G, Gaizauskas R, Guo YK, Roberts I. Web service architectures for text mining: An exploration of the issues via an e-science demonstrator. Int J Web Ser Res 2006; 3: 95-112.

[24] Denicia-Carral C, Montes-y-Gomez M, Villasenor-Pineda L, Hernandez RG. A text mining approach for definition question answering. Adv Natl Lang Proc Proc 2006; 4139: 76-86.

[25] Doms A, Jakoniene V, Lambrix P, Schroeder M, Wachter T. Ontologies and text mining as a basis for a semantic web for the life sciences. Reasoning Web 2006; 4126: 164-183.
[26] Erhardt RAA, Schneider R, Blaschke C. Status of text-mining techniques applied to biomedical text. Drug Discov Today 2006; 11: $315-325$

[27] Fan WG, Wallace L, Rich S, Zhang ZJ. Tapping the power of text mining. Commun Acm 2006; 49: 77-82.

[28] Hong K, Park J, Yang J, Park S. Biological text mining for extraction of proteins and their interactions. Pattern Recognition and Machine Intelligence, Proceedings 2005; 3776: 645-648.

[29] Hu XH, Zhang XD, Wu D, Zhou XH, Rumm P. Integration of instance-based learning and text mining for identification of potential virus/bacterium as bio-terrorism weapons. Intelligence and Security Informatics, Proceedings 2006; 3975: 548-553.

[30] Jang H, Song SK, Myaeng SH. Text mining for medical documents using a Hidden Markov Model. Info Retri Technol Proc 2006; 4182: 553-559.

[31] Kim HJ. On text mining algorithms for automated maintenance of hierarchical knowledge directory. Knowledge Science, Engineering and Management 2006; 4092: 202-214.

[32] Kuhn T, Royer L, Fuchs NE, Schroder M. Improving text mining with controlled natural language: A case study for protein interactions. Data Integration in the Life Sciences, Proceedings 2006; 4075: 66-81.

[33] Lai KK, Yu L, Wang SY. Multi-agent web text mining on the grid for enterprise decision support. Advanced Web and Network Technologies, and Applications, Proceedings 2006; 3842: 540-544.

[34] Liu Y, Navathe SB, Civera J, Dasigi V, Ram A, Ciliax BJ, Dingledine R. Text mining biomedical literature for discovering gene-togene relationships: A comparative study of algorithms. Ieee-Acm Trans Comput Biol Bioinfo 2005; 2: 62-76.

[35] Malik R, Franke L, Siebes A. Combination of text-mining algorithms increases the performance. Bioinformatics 2006; 22: 21512157.

[36] Rice SB, Nenadic G, Stapley BJ. Mining protein function from text using term-based support vector machines. BMC Bioinformatics 2005; 6 Suppl 1: S22.

[37] SanJuan E, Ibekwe-SanJuan F. Text mining without document context. Info Proc Manag 2006; 42: 1532-1552.

[38] Shaban K, Basir O, Kamel M. Document mining based on semantic understanding of text. Progress in Pattern Recognition, Image Analysis and Applications, Proceedings 2006; 4225: 834-843.

[39] Karamanis N, Lewin I, Seal R, Drysdale R, Briscoe E. Integrating natural language processing with FlyBase curation. Pac Symp Biocomput 2007; $245-256$.

[40] Hoffmann R, Valencia A. Implementing the iHOP concept for navigation of biomedical literature. Bioinformatics 2005; 2: ii252ii258.

[41] Fernandez JM, Hoffmann R, Valencia A. iHOP web services. $\mathrm{Nu}$ cleic Acids Res 2007; 35: W21-26.

[42] Hoffmann R, Krallinger M, Andres E, Tamames J, Blaschke C, Valencia A. Text mining for metabolic pathways, signaling cascades, and protein networks. Sci STKE 2005; 2005: pe21.

[43] Hoffmann R, Valencia A. Life cycles of successful genes. Trends Genet 2003; 19: 79-81.

[44] Hoffmann R, Valencia A. A gene network for navigating the literature. Nat Genet 2004; 36: 664 .

[45] Scherf M, Epple A, Werner T. The next generation of literature analysis: integration of genomic analysis into text mining. Brief Bioinform 2005; 6: 287-297.

[46] Skusa A, Ruegg A, Kohler J. Extraction of biological interaction networks from scientific literature. Brief Bioinform 2005; 6: 263276.

[47] Stapley BJ, Benoit G. Biobibliometrics: information retrieval and visualization from co-occurrences of gene names in Medline abstracts. Pac Symp Biocomput 2000; 529-540.

[48] Stapley BJ, Kelley LA, Sternberg MJ. Predicting the sub-cellular location of proteins from text using support vector machines. Pac Symp Biocomput 2002; 374-385.

[49] Rogers A, Antoshechkin I, Bieri T, Blasiar D, et al. WormBase 2007. Nucleic Acids Res 2008; 36: D612-617.

[50] Crosby MA, Goodman JL, Strelets VB, Zhang P, Gelbart WM FlyBase: genomes by the dozen. Nucleic Acids Res 2007; 35: D486-491.

[51] Wilson RJ, Goodman JL, Strelets VB. FlyBase: integration and improvements to query tools. Nucleic Acids Res 2008, 36: D588593. 
[52] Chiromatzo AO, Oliveira TY, Pereira G, et al. miRNApath: a database of miRNAs, target genes and metabolic pathways. Genet Mol Res 2007; 6: 859-865.

[53] Putz J, Dupuis B, Sissler M, Florentz C. Mamit-tRNA, a database of mammalian mitochondrial tRNA primary and secondary structures. RNA 2007; 13: 1184-1190.

[54] Yin Y, Zhao Y, Wang J, et al. antiCODE. a natural sense-antisense transcripts database. BMC Bioinformatics 2007; 8: 319.

[55] Griffiths-Jones S. miRBase: the microRNA sequence database. Methods Mol Biol 2006; 342: 129-138.

[56] Kazakov AE, Cipriano MJ, Novichkov PS, et al. RegTransBase--a database of regulatory sequences and interactions in a wide range of prokaryotic genomes. Nucleic Acids Res 2007; 35: D407-412.

[57] Ankeny RA. Sequencing the genome from nematode to human: changing methods, changing science. Endeavour 2003; 27: 87-92.

[58] Gustafson AM, Snitkin ES, Parker SC, DeLisi C, Kasif S. Towards the identification of essential genes using targeted genome sequencing and comparative analysis. BMC Genomics 2006; 7: 265.

[59] Margulies M, Egholm M, Altman WE, et al. Genome sequencing in microfabricated high-density picolitre reactors. Nature 2005; 437: $376-380$

[60] Service RF. Gene sequencing. The race for the $\$ 1000$ genome. Science 2006; 311: 1544-1546.

[61] Venter JC, Smith HO, Hood L. A new strategy for genome sequencing. Nature 1996; 381: 364-366.

[62] McGinnis S, Madden TL. BLAST. at the core of a powerful and diverse set of sequence analysis tools. Nucleic Acids Res 2004; 32 : W20-25.

[63] Kuroda M, Hiramatsu K. Genome sequencing and annotation: an overview. Methods Mol Biol 2004; 266: 29-45.

[64] Besemer J, Borodovsky M. GeneMark: web software for gene finding in prokaryotes, eukaryotes and viruses. Nucleic Acids Res 2005; 33: W451-454.

[65] Cawley SL, Pachter L. HMM sampling and applications to gene finding and alternative splicing. Bioinformatics 2003; 19 Suppl 2: II36-II41.

[66] Chatterji S, Pachter L. Large multiple organism gene finding by collapsed Gibbs sampling. J Comput Biol 2005; 12: 599-608

[67] Eyras E, Reymond A, Castelo R, Bye JM, et al. Gene finding in the chicken genome. BMC Bioinformatics 2005; 6: 131.

[68] Korf I. Gene finding in novel genomes. BMC Bioinformatics 2004; 5: 59.

[69] Noguchi H, Park J, Takagi T. MetaGene: prokaryotic gene finding from environmental genome shotgun sequences. Nucleic Acids Res 2006; 34: 5623-5630.

[70] Wang J, Kraemer E. GFPE. gene-finding program evaluation. Bioinformatics 2003; 19: 1712-1713.

[71] Cuff JA, Coates GM, Cutts TJ, Rae M. The Ensembl computing architecture. Genome Res 2004; 14: 971-975.

[72] Cowan D, Meyer Q, Stafford W, Muyanga S, Cameron R, Wittwer P. Metagenomic gene discovery: past, present and future. Trends Biotechnol 2005; 23: 321-329.

[73] Meyer QC, Burton SG, Cowan DA. Subtractive hybridization magnetic bead capture: a new technique for the recovery of fulllength ORFs from the metagenome. Biotechnol J 2007; 2: 36-40.

[74] Remington KA, Heidelberg K, Venter JC. Taking metagenomic studies in context. Trends Microbiol 2005; 13: 404.

[75] Rusch DB, Halpern AL, Sutton GK, et al. The Sorcerer II Global Ocean Sampling expedition: northwest Atlantic through eastern tropical Pacific. PLoS Biol 2007; 5: e77.

[76] Yooseph S, Sutton G, Rusch DB, et al. The Sorcerer II Global Ocean Sampling expedition: expanding the universe of protein families. PLoS Biol 2007; 5: e16.

[77] Hulo N, Bairoch A, Bulliard V. The PROSITE database. Nucleic Acids Res 2006; 34: D227-230.

[78] Raes J, Korbel JO, Lercher MJ, von Mering C, Bork P. Prediction of effective genome size in metagenomic samples. Genome Biol 2007; 8: R10.

[79] Schneider M, Tognolli M, Bairoch A. The Swiss-Prot protein knowledgebase and ExPASy: providing the plant community with high quality proteomic data and tools. Plant Physiol Biochem 2004; 42: 1013-1021.

[80] Kanehisa M. The KEGG database. Novartis Found Symp 2002; 247: 91-101; discussion 101-103, 119-128, 244-152.
[81] Kanehisa M, Goto S, Hattori M, et al. From genomics to chemical genomics: new developments in KEGG. Nucleic Acids Res 2006; 34: D354-357.

[82] Kanehisa M, Goto S, Kawashima S, Nakaya A. The KEGG databases at GenomeNet. Nucleic Acids Res 2002; 30: 42-46.

[83] Kanehisa M, Goto S, Kawashima S, Okuno Y, Hattori M. The KEGG resource for deciphering the genome. Nucleic Acids Res 2004; 32: D277-280.

[84] Ostell JM, Wheelan SJ, Kans JA. The NCBI data model. Methods Biochem Anal 2001; 43: 19-43.

[85] Guda C. pTARGET. a web server for predicting protein subcellular localization. Nucleic Acids Res 2006; 34: W210-213.

[86] Hoglund A, Donnes P, Blum T, Adolph HW, Kohlbacher O. MultiLoc: prediction of protein subcellular localization using $\mathrm{N}$ terminal targeting sequences, sequence motifs and amino acid composition. Bioinformatics 2006; 22: 1158-1165.

[87] Lee K, Kim DW, Na D, Lee KH, Lee D. PLPD. reliable protein localization prediction from imbalanced and overlapped datasets. Nucleic Acids Res 2006; 34: 4655-4666.

[88] Petsalaki EI, Bagos PG, Litou ZI, Hamodrakas SJ. PredSL. a tool for the N-terminal sequence-based prediction of protein subcellular localization. Genom Prot Bioinfo 2006; 4: 48-55.

[89] Altermann E, Klaenhammer TR. PathwayVoyager: pathway mapping using the Kyoto Encyclopedia of Genes and Genomes (KEGG) database. BMC Genomics 2005; 6: 60 .

[90] Arakawa K, Kono N, Yamada Y, Mori H, Tomita M. KEGG-based pathway visualization tool for complex omics data. In Silico Biol 2005; 5 : 419-423.

[91] Cornwell P. Designing tools for pathway implementation and evaluation. J Burn Care Rehabil 1995; 16: 202-208.

[92] Ekins S, Nikolsky Y, Bugrim A, Kirillov E, Nikolskaya T. Pathway mapping tools for analysis of high content data. Methods Mol Biol 2007; 356: 319-350.

[93] Holford M, Li N, Nadkarni P, Zhao H. VitaPad: visualization tools for the analysis of pathway data. Bioinformatics 2005; 21: 15961602 .

[94] Kacser H. Kinetic models of development and heredity. Symp Soc Exp Biol 1960; 14: 13-27.

[95] Karp PD, Ouzounis CA, Moore-Kochlacs C, et al. Expansion of the BioCyc collection of pathway/genome databases to 160 genomes. Nucleic Acids Res 2005; 33: 6083-6089.

[96] Karp PD, Paley S, Romero P. The Pathway Tools software. Bioinformatics 2002; 18 Suppl 1: S225-232.

[97] Klukas C, Schreiber F. Dynamic exploration and editing of KEGG pathway diagrams. Bioinformatics 2006.

[98] Krummenacker M, Paley S, Mueller L, Yan T, Karp PD. Querying and computing with BioCyc databases. Bioinformatics 2005; 21 : 3454-3455.

[99] Mao X, Cai T, Olyarchuk JG, Wei L. Automated genome annotation and pathway identification using the KEGG Orthology (KO) as a controlled vocabulary. Bioinformatics 2005; 21: 3787-3793.

[100] Paley SM, Karp PD. The Pathway Tools cellular overview diagram and Omics Viewer. Nucleic Acids Res 2006; 34: 3771-3778.

[101] Meier-Kolthoff JP, Auch AF, Huson DH, Goker M. COPYCAT cophylogenetic analysis tool. Bioinformatics 2007; 23: 898-900.

[102] Berezikov E, Guryev V, Cuppen E. Exploring conservation of transcription factor binding sites with CONREAL. Methods Mol Biol 2007; 395: 437-448.

[103] Brown DP, Krishnamurthy N, Sjolander K. Automated protein subfamily identification and classification. PLoS Comput Biol 2007; 3: e160.

[104] Glanville JG, Kirshner D, Krishnamurthy N, Sjolander K. Berkeley Phylogenomics Group web servers: resources for structural phylogenomic analysis. Nucleic Acids Res 2007; 35: W27-32.

[105] Guindon S, Lethiec F, Duroux P, Gascuel O. PHYML Online--a web server for fast maximum likelihood-based phylogenetic inference. Nucleic Acids Res 2005; 33: W557-559.

[106] Loots GG, Ovcharenko I. Mulan: multiple-sequence alignment to predict functional elements in genomic sequences. Methods $\mathrm{Mol}$ Biol 2007; 395: 237-254.

[107] Meinel T, Krause A, Luz H, Vingron M, Staub E. The SYSTERS Protein Family Database in 2005. Nucleic Acids Res 2005; 33: D226-229.

[108] Tarraga J, Medina I, Arbiza L, et al. Phylemon: a suite of web tools for molecular evolution, phylogenetics and phylogenomics. Nucleic Acids Res 2007; 35: W38-42. 
[109] Shah JK, Garner HR, White MA, Shames DS, Minna JD. sIR. siRNA Information Resource, a web-based tool for siRNA sequence design and analysis and an open access siRNA database. BMC Bioinformatics 2007; 8: 178.

[110] Abreu-Goodger C, Merino E. RibEx: a web server for locating riboswitches and other conserved bacterial regulatory elements. Nucleic Acids Res 2005; 33: W690-692.

[111] Bengert P, Dandekar T. Riboswitch finder--a tool for identification of riboswitch RNAs. Nucleic Acids Res 2004; 32: W154-159.

[112] Huang HY, Chien $\mathrm{CH}$, Jen $\mathrm{KH}$, et al. an integrated web server for identifying regulatory RNA motifs and elements. Nucleic Acids Res 2006; 34: W429-434.

[113] Liu CC, Lin CC, Chen WS, Chen HY, Chang PC, Chen JJ, Yang PC. CRSD. a comprehensive web server for composite regulatory signature discovery. Nucleic Acids Res 2006; 34: W571-577.

[114] Tong J, Jiang P, Lu ZH. RISP. A web-based server for prediction of RNA-binding sites in proteins. Comput Methods Programs Biomed 2008.

[115] Zhang Y. miRU. an automated plant miRNA target prediction server. Nucleic Acids Res 2005; 33: W701-704.

[116] Burley SK, Bonanno JB. Structural genomics. Methods Biochem Anal 2003; 44: 591-612.

[117] Goldsmith-Fischman S, Honig B. Structural genomics: computational methods for structure analysis. Protein Sci 2003; 12: 18131821.

[118] Berman HM, Westbrook JD. The impact of structural genomics on the protein data bank. Am J Pharmacogenomics 2004; 4: 247-252.

[119] Berman H, Henrick K, Nakamura H, Markley JL. The worldwide Protein Data Bank (wwPDB): ensuring a single, uniform archive of PDB data. Nucleic Acids Res 2007; 35: D301-303.

[120] Bourgeois D, Royant A. Advances in kinetic protein crystallography. Curr Opin Struct Biol 2005; 15: 538-547.

[121] Esposito L, Vitagliano L, Mazzarella L. Recent advances in atomic resolution protein crystallography. Protein Pept Lett 2002; 9: 95106.

[122] Helliwell JR. Overview and new developments in softer X-ray (2A $<$ lambda < 5A) protein crystallography. J Synchrotron Radiat 2004; 11: 1-3.

[123] Massover WH. Radiation damage to protein specimens from electron beam imaging and diffraction: a mini-review of anti-damage approaches, with special reference to synchrotron X-ray crystallography. J Synchrotron Radiat 2007; 14: 116-127.

[124] Myles DA. Neutron protein crystallography: current status and a brighter future. Curr Opin Struct Biol 2006; 16: 630-637.

[125] Riekel C, Burghammer M, Schertler G. Protein crystallography microdiffraction. Curr Opin Struct Biol 2005; 15: 556-562.

[126] Grishaev A, Llinas M. Protein structure elucidation from minimal NMR data: the CLOUDS approach. Methods Enzymol 2005; 394 : 261-295.

[127] Kay LE. NMR studies of protein structure and dynamics. J Magn Reson 2005; 173: 193-207.

[128] Snyder DA, Bhattacharya A, Huang YJ, Montelione GT. Assessing precision and accuracy of protein structures derived from NMR data. Proteins 2005; 59: 655-661.

[129] Takeuchi K, Wagner G. NMR studies of protein interactions. Curr Opin Struct Biol 2006; 16: 109-117.

[130] Wishart D. NMR spectroscopy and protein structure determination: applications to drug discovery and development. Curr Pharm Biotechnol 2005; 6: 105-120.

[131] Burkhardt K, Schneider B, Ory J. A biocurator perspective: annotation at the Research Collaboratory for Structural Bioinformatics Protein Data Bank. PLoS Comput Biol 2006; 2: e99.

[132] Sussman JL, Abola EE, Lin D, Jiang J, Manning NO, Prilusky J. The protein data bank. Bridging the gap between the sequence and 3D structure world. Genetica 1999; 106: 149-158.

[133] Szabadka Z, Grolmusz V. High throughput processing of the structural information in the protein data bank. J Mol Graph Model 2006.

[134] Bernstein HJ. Recent changes to RasMol, recombining the variants. Trends Biochem Sci 2000; 25: 453-455.

[135] Schwede T, Kopp J, Guex N, Peitsch MC. SWISS-MODEL. An automated protein homology-modeling server. Nucleic Acids Res 2003; 31: 3381-3385.

[136] Dobson PD, Cai YD, Stapley BJ, Doig AJ. Prediction of protein function in the absence of significant sequence similarity. Curr Med Chem 2004; 11: 2135-2142.
[137] Godzik A. Fold recognition methods. Methods Biochem Anal 2003; 44: 525-546.

[138] Bates PA, Kelley LA, MacCallum RM, Sternberg MJ. Enhancement of protein modeling by human intervention in applying the automatic programs 3D-JIGSAW and 3D-PSSM. Proteins 2001; Suppl 5: 39-46.

[139] Bourne PE. CASP and CAFASP experiments and their findings. Methods Biochem Anal 2003; 44: 501-507.

[140] Falcon H, Crosse A, Donaghy J, et al. CASP and CONSORT. Br Dent J 2006; 201: 130; author reply 130-131.

[141] Kryshtafovych A, Venclovas C, Fidelis K, Moult J. Progress over the first decade of CASP experiments. Proteins 2005; 61 Suppl 7: 225-236.

[142] Moult J. A decade of CASP. progress, bottlenecks and prognosis in protein structure prediction. Curr Opin Struct Biol 2005; 15: 285289.

[143] Moult J, Fidelis K, Rost B, Hubbard T, Tramontano A. Critical assessment of methods of protein structure prediction (CASP)-round 6. Proteins 2005; 61 Suppl 7: 3-7.

[144] Valencia A. Protein refinement: a new challenge for CASP in its 10th anniversary. Bioinformatics 2005; 21: 277.

[145] Venclovas C, Zemla A, Fidelis K, Moult J. Assessment of progress over the CASP experiments. Proteins 2003; 53 Suppl 6: 585-595.

[146] Chivian D, Kim DE, Malmstrom L, Schonbrun J, Rohl CA, Baker D. Prediction of CASP6 structures using automated Robetta protocols. Proteins 2005; 61 Suppl 7: 157-166.

[147] Buzko OV, Bishop AC, Shokat KM. Modified AutoDock for accurate docking of protein kinase inhibitors. J Comput Aided Mol Des 2002; 16: 113-127.

[148] Carter P, Lesk VI, Islam SA, Sternberg MJ. Protein-protein docking using 3D-Dock in rounds 3, 4, and 5 of CAPRI. Proteins 2005; 60: 281-288.

[149] Comeau SR, Gatchell DW, Vajda S, Camacho CJ. ClusPro: a fully automated algorithm for protein-protein docking. Nucleic Acids Res 2004; 32: W96-99.

[150] Comeau SR, Gatchell DW, Vajda S, Camacho CJ. ClusPro: an automated docking and discrimination method for the prediction of protein complexes. Bioinformatics 2004; 20: 45-50.

[151] Fahmy A, Wagner G. TreeDock: a tool for protein docking based on minimizing van der Waals energies. J Am Chem Soc 2002; 124 : 1241-1250.

[152] Gao Y, Douguet D, Tovchigrechko A, Vakser IA. DOCKGROUND system of databases for protein recognition studies: unbound structures for docking. Proteins 2007; 69: 845-851.

[153] Goto J, Kataoka R, Hirayama N. Ph4Dock: pharmacophore-based protein-ligand docking. J Med Chem 2004; 47: 6804-6811.

[154] Grosdidier A, Zoete V, Michielin O. EADock: docking of small molecules into protein active sites with a multiobjective evolutionary optimization. Proteins 2007; 67: 1010-1025.

[155] Gupta A, Gandhimathi A, Sharma P, Jayaram B. ParDOCK. an all atom energy based Monte Carlo docking protocol for proteinligand complexes. Protein Pept Lett 2007; 14: 632-646.

[156] Lensink MF, Mendez R, Wodak SJ. Docking and scoring protein complexes: CAPRI 3rd Edition. Proteins 2007; 69: 704-718.

[157] Martin L, Catherinot V, Labesse G. kinDOCK. a tool for comparative docking of protein kinase ligands. Nucleic Acids Res 2006; 34 : W325-329.

[158] May A, Zacharias M. Protein-protein docking in CAPRI using ATTRACT to account for global and local flexibility. Proteins 2007; 69: 774-780.

[159] Pierce B, Weng Z. ZRANK. reranking protein docking predictions with an optimized energy function. Proteins 2007; 67: 1078-1086.

[160] Seifert MH, Schmitt F, Herz T, Kramer B. ProPose: a docking engine based on a fully configurable protein-ligand interaction model. J Mol Model 2004; 10: 342-357.

[161] Tovchigrechko A, Vakser IA. GRAMM-X public web server for protein-protein docking. Nucleic Acids Res 2006; 34: W310-314.

[162] van Dijk M, van Dijk AD, Hsu V, Boelens R, Bonvin AM. Information-driven protein-DNA docking using HADDOCK. it is a matter of flexibility. Nucleic Acids Res 2006; 34: 3317-3325.

[163] Zacharias M. ATTRACT. protein-protein docking in CAPRI using a reduced protein model. Proteins 2005; 60: 252-256.

[164] Ritchie DW. Evaluation of protein docking predictions using Hex 3.1 in CAPRI rounds 1 and 2. Proteins 2003; 52: 98-106. 
[165] Barrett T, Troup DB, Wilhite SE, et al. NCBI GEO. mining tens of millions of expression profiles--database and tools update. Nucleic Acids Res 2007; 35: D760-765.

[166] Kasai Y, Hashimoto S, Yamada T, et al. 5' SAGE -end Serial Analysis of Gene Expression database. Nucleic Acids Res 2005; 33: D550-552.

[167] Parkinson H, Kapushesky M, Shojatalab M, et al. ArrayExpress--a public database of microarray experiments and gene expression profiles. Nucleic Acids Res 2007; 35: D747-750.

[168] Tateno Y, Ikeo K. [International public gene expression database (CIBEX) and data submission]. Tanpakushitsu Kakusan Koso 2004; 49: 2678-2683.

[169] Ikeo K, Ishi-i J, Tamura T, Gojobori T, Tateno Y. CIBEX. center for information biology gene expression database. $C$ R Biol 2003; 326: 1079-1082.

[170] Rocca-Serra P, Brazma A, Parkinson H, Sarkans U, et al. ArrayExpress: a public database of gene expression data at EBI. $C R$ Biol 2003; 326: 1075-1078.

[171] Kodzius R, Matsumura Y, Kasukawa TS, et al. Absolute expression values for mouse transcripts: re-annotation of the READ expression database by the use of CAGE and EST sequence tags. FEBS Lett 2004; 559: 22-26.

[172] Xia Y, Campen A, Rigsby D, et al. DGEM--a microarray gene expression database for primary human disease tissues. Mol Diagn Ther 2007; 11: 145-149.

[173] Zhang Y, Luoh SM, Hon LS, Baertsch R, Wood WI, Zhang Z. GeneHub-GEPIS. digital expression profiling for normal and cancer tissues based on an integrated gene database. Nucleic Acids Res 2007; 35: W152-158.

[174] Smith CM, Finger JH, Hayamizu TF, et al. The mouse Gene Expression Database (GXD): 2007 update. Nucleic Acids Res 2007; 35: D618-623.

[175] Jen CH, Manfield IW, Michalopoulos I, et al. The Arabidopsis coexpression tool (ACT): a WWW-based tool and database for microarray-based gene expression analysis. Plant $J$ 2006; 46: 336348.

[176] Schena M, Shalon D, Davis RW, Brown PO. Quantitative monitoring of gene expression patterns with a complementary DNA microarray. Science 1995; 270: 467-470.

[177] Shalon D, Smith SJ, Brown PO. A DNA microarray system for analyzing complex DNA samples using two-color fluorescent probe hybridization. Genome Res 1996; 6: 639-645.

[178] Nguyen DV, Arpat AB, Wang N, Carroll RJ. DNA microarray experiments: biological and technological aspects. Biometrics 2002; 58: 701-717.

[179] Dai JL. Serial analyses of gene expression (SAGE). Methods Mol Med 2005; 103: 161-174.

[180] Knox DP, Skuce PJ. SAGE and the quantitative analysis of gene expression in parasites. Trends Parasitol 2005; 21: 322-326.

[181] Kodzius R, Kojima M, Nishiyori H, et al. CAGE. cap analysis of gene expression. Nat Methods 2006; 3: 211-222.

[182] Mockler TC, Chan S, Sundaresan A, Chen H, Jacobsen SE, Ecker JR. Applications of DNA tiling arrays for whole-genome analysis. Genomics 2005; 85: 1-15.

[183] Tannenbaum E. An RNA-centered view of eukaryotic cells. Biosystems 2006; 84: 217-224.

[184] Bueno Filho JS, Gilmour SG, Rosa GJ. Design of microarray experiments for genetical genomics studies. Genetics 2006; 174: 945 957.

[185] Imbeaud S, Auffray C. 'The 39 steps' in gene expression profiling: critical issues and proposed best practices for microarray experiments. Drug Discov Today 2005; 10: 1175-1182.

[186] Blalock EM, Chen KC, Stromberg AJ, et al. Harnessing the power of gene microarrays for the study of brain aging and Alzheimer's disease: statistical reliability and functional correlation. Ageing Res Rev 2005; 4: 481-512.

[187] Leung YF, Cavalieri D. Fundamentals of cDNA microarray data analysis. Trends Genet 2003; 19: 649-659.

[188] Olson NE. The microarray data analysis process: from raw data to biological significance. NeuroRx 2006; 3: 373-383.

[189] Pounds S, Cheng C. Statistical development and evaluation of microarray gene expression data filters. J Comput Biol 2005; 12 : 482-495.

[190] Barrett T, Edgar R. Gene expression omnibus: microarray data storage, submission, retrieval, and analysis. Methods Enzymol 2006; 411: 352-369.
[191] Saeed AI, Bhagabati NK, Braisted JC, et al. TM4 microarray software suite. Methods Enzymol 2006; 411: 134-193.

[192] Troein C, Vallon-Christersson J, Saal LH. An introduction to BioArray Software Environment. Methods Enzymol 2006; 411: 99119.

[193] Reimers M, Carey VJ. Bioconductor: an open source framework for bioinformatics and computational biology. Methods Enzymol 2006; 411: 119-134.

[194] Beer I, Barnea E, Admon A. Centralized data analysis of a large interlaboratory proteomics project: a feasibility study. Proteomics 2005; 5: 3491-3496.

[195] Garwood K, Garwood C, Hedeler C, et al. Model-driven user interfaces for bioinformatics data resources: regenerating the wheel as an alternative to reinventing it. BMC Bioinformatics 2006; 7: 532.

[196] Garwood K, McLaughlin T, Garwood C, et al. PEDRo: a database for storing, searching and disseminating experimental proteomics data. BMC Genomics 2004; 5 : 68.

[197] Hill A, Kim H. The UAB Proteomics Database. Bioinformatics 2003; 19: 2149-2151.

[198] Kremer A, Schneider R, Terstappen GC. A bioinformatics perspective on proteomics: data storage, analysis, and integration. Biosci Rep 2005; 25: 95-106.

[199] Martens L, Hermjakob H, Jones P, et al. PRIDE. the proteomics identifications database. Proteomics 2005; 5: 3537-3545.

[200] Martens L, Nesvizhskii AI, Hermjakob H, et al. Do we want our data raw? Including binary mass spectrometry data in public proteomics data repositories. Proteomics 2005; 5: 3501-3505.

[201] Jones P, Cote RG, Martens L, et al. PRIDE. a public repository of protein and peptide identifications for the proteomics community. Nucleic Acids Res 2006; 34: D659-663.

[202] Desiere F, Deutsch EW, King NL, et al. The PeptideAtlas project. Nucleic Acids Res 2006; 34: D655-658.

[203] Beavis RC. Using the global proteome machine for protein identification. Methods Mol Biol 2006; 328: 217-228.

[204] Linding R, Jensen LJ, Pasculescu A, et al. NetworKIN. a resource for exploring cellular phosphorylation networks. Nucleic Acids Res 2008, 36: D695-699.

[205] Proteomics. Nat Biotechnol 2000; 18 Suppl: IT45-46.

[206] Aggarwal K, Choe LH, Lee KH. Shotgun proteomics using the iTRAQ isobaric tags. Brief Funct Genomic Proteomic 2006; 5: 112-120.

[207] Beynon RJ. The dynamics of the proteome: strategies for measuring protein turnover on a proteome-wide scale. Brief Funct Genomic Proteomic 2005; 3: 382-390.

[208] Beynon RJ, Pratt JM. Strategies for measuring dynamics: the temporal component of proteomics. Methods Biochem Anal 2006; 49: 15-25.

[209] Celis JE, Kruhoffer M, Gromova I, et al. Gene expression profiling: monitoring transcription and translation products using DNA microarrays and proteomics. FEBS Lett 2000; 480: 2-16.

[210] DeVoe DL, Lee CS. Microfluidic technologies for MALDI-MS in proteomics. Electrophoresis 2006; 27: 3559-3568.

[211] Elrick MM, Walgren JL, Mitchell MD, Thompson DC. Proteomics: recent applications and new technologies. Basic Clin Pharmacol Toxicol 2006; 98: 432-441.

[212] Gevaert K, Vandekerckhove J. Protein identification methods in proteomics. Electrophoresis 2000; 21: 1145-1154.

[213] Haoudi A, Bensmail H. Bioinformatics and data mining in proteomics. Expert Rev Proteomics 2006; 3: 333-343.

[214] Harry JL, Wilkins MR, Herbert BR, Packer NH, Gooley AA, Williams KL. Proteomics: capacity versus utility. Electrophoresis 2000; 21: 1071-1081.

[215] Hayter JR, Robertson DH, Gaskell SJ, Beynon RJ. Proteome analysis of intact proteins in complex mixtures. Mol Cell Proteomics 2003; 2 : 85-95.

[216] Hogan JM, Higdon R, Kolker E. Experimental standards for highthroughput proteomics. Omics 2006; 10: 152-157.

[217] Jensen ON. Interpreting the protein language using proteomics. Nat Rev Mol Cell Biol 2006; 7: 391-403.

[218] Kellner R. Proteomics. Concepts and perspectives. Fresenius J Anal Chem 2000; 366: 517-524.

[219] Nelson RW, Nedelkov D, Tubbs KA. Biosensor chip mass spectrometry: a chip-based proteomics approach. Electrophoresis 2000; 21: 1155-1163.

[220] Smith JC, Figeys D. Proteomics technology in systems biology. Mol Biosyst 2006; 2: 364-370. 
[221] Suter B, Auerbach D, Stagljar I. Yeast-based functional genomics and proteomics technologies: the first 15 years and beyond. Biotechniques 2006; 40: 625-644.

[222] Topaloglou T. Informatics solutions for high-throughput proteomics. Drug Discov Today 2006; 11: 509-516.

[223] Uttamchandani M, Wang J, Yao SQ. Protein and small molecule microarrays: powerful tools for high-throughput proteomics. $\mathrm{Mol}$ Biosyst 2006; 2: 58-68.

[224] Wasinger V. Holistic biology of microorganisms: genomics, transcriptomics, and proteomics. Methods Biochem Anal 2006; 49: 314.

[225] Wittmann-Liebold B, Graack HR, Pohl T. Two-dimensional gel electrophoresis as tool for proteomics studies in combination with protein identification by mass spectrometry. Proteomics 2006; 6: 4688-4703.

[226] Ram RJ, Verberkmoes NC, Thelen MP, et al. Community proteomics of a natural microbial biofilm. Science 2005; 308: 19151920.

[227] McCarthy FM, Burgess SC, van den Berg BH, Koter MD, Pharr GT. Differential detergent fractionation for non-electrophoretic eukaryote cell proteomics. J Proteome Res 2005; 4: 316-324.

[228] Vener AV, Stralfors P. Vectorial proteomics. IUBMB Life 2005; 57: 433-440.

[229] Whitelegge JP. Mass spectrometry for high throughput quantitative proteomics in plant research: lessons from thylakoid membranes. Plant Physiol Biochem 2004; 42: 919-927.

[230] Doherty MK, McClean L, Edwards I, et al. Protein turnover in chicken skeletal muscle: understanding protein dynamics on a proteome-wide scale. Br Poult Sci 2004; 45 Suppl 1: S27-28.

[231] Doherty MK, Whitehead C, McCormack H, Gaskell SJ, Beynon RJ. Proteome dynamics in complex organisms: using stable isotopes to monitor individual protein turnover rates. Proteomics 2005; 5: 522-533.

[232] Artavanis-Tsakonas K, Misaghi S, Comeaux CA, et al. Identification by functional proteomics of a deubiquitinating/deNeddylating enzyme in Plasmodium falciparum. Mol Microbiol 2006; 61: 11871195.

[233] Camerini S, Polci ML, Bachi A. Proteomics approaches to study the redox state of cysteine-containing proteins. Ann Ist Super Sanita 2005; 41: 451-457.

[234] Gruhler A, Olsen JV, Mohammed S, et al. Quantitative phosphoproteomics applied to the yeast pheromone signaling pathway. Mol Cell Proteomics 2005; 4: 310-327.

[235] Hjerrild M, Gammeltoft S. Phosphoproteomics toolbox: computational biology, protein chemistry and mass spectrometry. FEBS Lett 2006; 580: 4764-4770.

[236] Julka S, Regnier F. Quantification in proteomics through stable isotope coding: a review. J Proteome Res 2004; 3: 350-363.

[237] Kwon SJ, Choi EY, Choi YJ, Ahn JH, Park OK. Proteomics studies of post-translational modifications in plants. J Exp Bot 2006; 57: 1547-1551.

[238] Nielsen ML, Savitski MM, Zubarev RA. Extent of modifications in human proteome samples and their effect on dynamic range of analysis in shotgun proteomics. Mol Cell Proteomics 2006; 5: 2384-2391.

[239] Stern DF. Phosphoproteomics. Exp Mol Pathol 2001; 70: 327-331.

[240] Tannu NS, Hemby SE. Chapter 3 Methods for proteomics in neuroscience. Prog Brain Res 2006; 158: 41-82.

[241] Cui Q, Lewis IA, Hegeman AD, et al. Metabolite identification via the Madison Metabolomics Consortium Database. Nat Biotechnol 2008, 26: 162-164.

[242] Cottingham K. New database for human metabolomics. J Proteome Res 2007; 6: 1243.

[243] Kotera M, McDonald AG, Boyce S, Tipton KF. Functional group and substructure searching as a tool in metabolomics. PLOS ONE 2008, 3: e1537.

[244] Markley JL, Anderson ME, Cui Q, Eghbalnia HR, et al. New bioinformatics resources for metabolomics. Pac Symp Biocomput 2007: 157-168.

[245] Castle AL, Fiehn O, Kaddurah-Daouk R, Lindon JC. Metabolomics Standards Workshop and the development of international standards for reporting metabolomics experimental results. Brief Bioinform 2006; 7: 159-165.

[246] Fiehn O, Kristal B, van Ommen B, et al. Establishing reporting standards for metabolomic and metabonomic studies: a call for participation. Omics 2006; 10: 158-163.
[247] Jenkins H, Hardy N, Beckmann M, et al. A proposed framework for the description of plant metabolomics experiments and their results. Nat Biotechnol 2004; 22: 1601-1606.

[248] Lindon JC, Holmes E, Nicholson JK. So what's the deal with metabonomics? Anal Chem 2003; 75: 384A-391A.

[249] Lindon JC, Nicholson JK, Holmes, et al. Summary recommendations for standardization and reporting of metabolic analyses. Nat Biotechnol 2005; 23: 833-838.

[250] Kell DB. Metabolomics and systems biology: making sense of the soup. Curr Opin Microbiol 2004; 7: 296-307.

[251] Fiehn O. Metabolomics--the link between genotypes and phenotypes. Plant Mol Biol 2002; 48: 155-171.

[252] Nicholson JK, Lindon JC, Holmes E. 'Metabonomics': understanding the metabolic responses of living systems to pathophysiological stimuli via multivariate statistical analysis of biological NMR spectroscopic data. Xenobiotica 1999; 29: 1181-1189.

[253] Brown JA, Sherlock G, Myers CL, et al. Global analysis of gene function in yeast by quantitative phenotypic profiling. Mol Syst Biol 2006; 2: 20060001.

[254] Brown SC, Kruppa G, Dasseux JL. Metabolomics applications of FT-ICR mass spectrometry. Mass Spectrom Rev 2005; 24: 223-231.

[255] Goodacre R, Vaidyanathan S, Dunn WB, Harrigan GG, Kell DB. Metabolomics by numbers: acquiring and understanding global metabolite data. Trends Biotechnol 2004; 22: 245-252.

[256] Griffin JL. The Cinderella story of metabolic profiling: does metabolomics get to go to the functional genomics ball? Philos Trans R Soc Lond B Biol Sci 2006; 361: 147-161.

[257] Grivet JP, Delort AM, Portais JC. NMR and microbiology: from physiology to metabolomics. Biochimie 2003; 85: 823-840.

[258] Hollywood K, Brison DR, Goodacre R. Metabolomics: current technologies and future trends. Proteomics 2006; 6: 4716-4723.

[259] Lee JM, Gianchandani EP, Papin JA. Flux balance analysis in the era of metabolomics. Brief Bioinform 2006; 7: 140-150.

[260] Reo NV. NMR-based metabolomics. Drug Chem Toxicol 2002; 25: 375-382.

[261] Rochfort S. Metabolomics reviewed: a new "omics" platform technology for systems biology and implications for natural products research. J Nat Prod 2005; 68: 1813-1820.

[262] Sanford K, Soucaille P, Whited G, Chotani G. Genomics to fluxomics and physiomics - pathway engineering. Curr Opin Microbiol 2002; 5: 318-322.

[263] Shulaev V. Metabolomics technology and bioinformatics. Brief Bioinform 2006; 7: 128-139.

[264] van der Werf MJ, Jellema RH, Hankemeier T. Microbial metabolomics: replacing trial-and-error by the unbiased selection and ranking of targets. J Ind Microbiol Biotechnol 2005; 32: 234-252.

[265] Wang L, Birol I, Hatzimanikatis V. Metabolic control analysis under uncertainty: framework development and case studies. Biophys $J$ 2004; 87: 3750-3763.

[266] Wang M, Lamers RJ, Korthout HA, et al. Metabolomics in the context of systems biology: bridging traditional Chinese medicine and molecular pharmacology. Phytother Res 2005; 19: 173-182.

[267] Wang QZ, Wu CY, Chen T, Chen X, Zhao XM. Integrating metabolomics into a systems biology framework to exploit metabolic complexity: strategies and applications in microorganisms. Appl Microbiol Biotechnol 2006; 70: 151-161.

[268] Weckwerth W. Metabolomics in systems biology. Annu Rev Plant Biol 2003; 54: 669-689.

[269] Weckwerth W, Morgenthal K. Metabolomics: from pattern recognition to biological interpretation. Drug Discov Today 2005; 10: 1551-1558.

[270] Morgenthal K, Weckwerth W, Steuer R. Metabolomic networks in plants: Transitions from pattern recognition to biological interpretation. Biosystems 2006; 83: 108-117.

[271] Morgenthal K, Wienkoop S, Wolschin F, Weckwerth W. Integrative profiling of metabolites and proteins: improving pattern recognition and biomarker selection for systems level approaches. Methods Mol Biol 2007; 358: 57-75.

[272] Holmes E, Antti H. Chemometric contributions to the evolution of metabonomics: mathematical solutions to characterising and interpreting complex biological NMR spectra. Analyst 2002; 127: 15491557.

[273] Vance W, Arkin A, Ross J. Determination of causal connectivities of species in reaction networks. Proc Natl Acad Sci USA 2002; 99: 5816-5821. 
[274] Marino S, Voit EO. An automated procedure for the extraction of metabolic network information from time series data. J Bioinform Comput Biol 2006; 4: 665-691.

[275] Voit EO, Almeida J, Marino S, et al. Regulation of glycolysis in Lactococcus lactis: an unfinished systems biological case study. Syst Biol (Stevenage) 2006; 153: 286-298.

[276] Chou IC, Martens H, Voit EO. Parameter estimation in biochemical systems models with alternating regression. Theor Biol Med Model 2006; 3 : 25 .

[277] Voit EO, Almeida J. Decoupling dynamical systems for pathway identification from metabolic profiles. Bioinformatics 2004; 20: 1670-1681.

[278] Voit EO, Marino S, Lall R. Challenges for the identification of biological systems from in vivo time series data. In Silico Biol 2005; 5: 83-92.

[279] Gerdes SY, Scholle MD, Campbell JW, et al. Experimental determination and system level analysis of essential genes in Escherichia coli MG1655. J Bacteriol 2003; 185: 5673-5684.

[280] Tong AH, Evangelista M, Parsons AB, et al. Systematic genetic analysis with ordered arrays of yeast deletion mutants. Science 2001; 294: 2364-2368.

[281] Rodriguez-Manzaneque MT, Tamarit J, Belli G, Ros J, Herrero E. Grx 5 is a mitochondrial glutaredoxin required for the activity of iron/sulfur enzymes. Mol Biol Cell 2002; 13: 1109-1121.

[282] Fernandez-Ricaud L, Warringer J, Ericson E, et al. PROPHECY--a database for high-resolution phenomics. Nucleic Acids Res 2005; 33: D369-373.

[283] Buckholz RG, Simmons CA, Stuart JM, Weiner MP. Automation of yeast two-hybrid screening. J Mol Microbiol Biotechnol 1999; 1 : $135-140$.

[284] Ding X, Zhang Y, Song WY. Use of rolling-circle amplification for large-scale yeast two-hybrid analyses. Methods Mol Biol 2006; 354: 85-98.

[285] Fields S. High-throughput two-hybrid analysis. The promise and the peril. FEBS J 2005; 272: 5391-5399.

[286] Parrish JR, Gulyas KD, Finley RL, Jr. Yeast two-hybrid contributions to interactome mapping. Curr Opin Biotechnol 2006; 17: 387 393.

[287] Gavin AC, Bosche M, Krause R, et al. Functional organization of the yeast proteome by systematic analysis of protein complexes. Nature 2002; 415: 141-147.

[288] Ito T, Chiba T, Yoshida M. Exploring the protein interactome using comprehensive two-hybrid projects. Trends Biotechnol 2001; 19: S23-27.

[289] Ito T, Ota K, Kubota H, et al. Roles for the two-hybrid system in exploration of the yeast protein interactome. Mol Cell Proteomics 2002; 1 : 561-566.

[290] Rain JC, Selig L, De Reuse H, et al. The protein-protein interaction map of Helicobacter pylori. Nature 2001; 409: 211-215.

[291] Starling AL, Ortega JM, Gollob KJ, et al. Evaluation of alternative reporter genes for the yeast two-hybrid system. Genet Mol Res 2003; 2 : 124-135.

[292] Stelzl U, Worm U, Lalowski M, et al. A human protein-protein interaction network: a resource for annotating the proteome. Cell 2005; 122: 957-968.

[293] Uetz P, Hughes RE. Systematic and large-scale two-hybrid screens. Curr Opin Microbiol 2000; 3: 303-308.

[294] Walhout AJ, Boulton SJ, Vidal M. Yeast two-hybrid systems and protein interaction mapping projects for yeast and worm. Yeast 2000; 17: 88-94.

[295] Walhout AJ, Sordella R, Lu X, et al. Protein interaction mapping in C. elegans using proteins involved in vulval development. Science 2000; 287: 116-122

[296] Walhout AJ, Vidal M. High-throughput yeast two-hybrid assays for large-scale protein interaction mapping. Methods 2001; 24: 297306.

[297] Ho Y, Gruhler A, Heilbut A, et al. Systematic identification of protein complexes in Saccharomyces cerevisiae by mass spectrometry. Nature 2002; 415: 180-183.

[298] Santonico E, Castagnoli L, Cesareni G. Methods to reveal domain networks. Drug Discov Today 2005; 10: 1111-1117.

[299] Izarzugaza JM, Juan D, Pons C, Ranea JA, Valencia A, Pazos F. TSEMA. interactive prediction of protein pairings between interacting families. Nucleic Acids Res 2006; 34: W315-319.
[300] Juan D, Pazos F, Valencia A. High-confidence prediction of global interactomes based on genome-wide coevolutionary networks. Proc Natl Acad Sci USA 2008, 105: 934-939.

[301] Pazos F, Rausell A, Valencia A. Phylogeny-independent detection of functional residues. Bioinformatics 2006; 22: 1440-1448.

[302] Pazos F, Valencia A. In silico two-hybrid system for the selection of physically interacting protein pairs. Proteins 2002; 47: 219-227.

[303] Gilbert D. Biomolecular interaction network database. Brief Bioinform 2005; 6: 194-198.

[304] Koike A, Takagi T. PRIME. automatically extracted PRotein Interactions and Molecular Information databasE. In Silico Biol 2005; 5 : 9-20.

[305] Pagel P, Kovac S, Oesterheld M, et al. The MIPS mammalian protein-protein interaction database. Bioinformatics 2005; 21: 832834.

[306] Xenarios I, Salwinski L, Duan XJ, Higney P, Kim SM, Eisenberg D. DIP, the Database of Interacting Proteins: a research tool for studying cellular networks of protein interactions. Nucleic Acids Res 2002; 30: 303-305.

[307] Chatr-aryamontri A, Ceol A, Palazzi LM, et al. MINT. the Molecular INTeraction database. Nucleic Acids Res 2007; 35: D572-574.

[308] Misra RV, Horler RS, Reindl W, Goryanin, II, Thomas GH. EchoBASE. an integrated post-genomic database for Escherichia coli. Nucleic Acids Res 2005; 33: D329-333.

[309] Buck MJ, Lieb JD. ChIP-chip: considerations for the design, analysis, and application of genome-wide chromatin immunoprecipitation experiments. Genomics 2004; 83: 349-360.

[310] Wu J, Smith LT, Plass C, Huang TH. ChIP-chip comes of age for genome-wide functional analysis. Cancer Res 2006; 66: 6899. 6902.

[311] Fujii S. Database and structural characterization of intermolecular interactions in nucleic acid and protein complex. Nucleic Acids Symp Ser (Oxf) 2004: 127-128.

[312] Gong S, Yoon G, Jang I, Bolser D, et al. PSIbase: a database of Protein Structural Interactome map (PSIMAP). Bioinformatics 2005; 21 : 2541-2543.

[313] Hoffman MM, Khrapov MA, Cox JC, Yao J, Tong L, Ellington AD. AANT. the Amino Acid-Nucleotide Interaction Database. $\mathrm{Nu}$ cleic Acids Res 2004; 32: D174-181.

[314] Wu T, Wang J, Liu C, Zhang Y, et al. NPInter: the noncoding RNAs and protein related biomacromolecules interaction database. Nucleic Acids Res 2006; 34: D150-152.

[315] Mak HC, Daly M, Gruebel B, Ideker T. CellCircuits: a database of protein network models. Nucleic Acids Res 2007; 35: D538-545.

[316] [IUPAC-IUB Commission on Biochemical Nomenclature (CBN). Nomenclature of multiple enzyme types. Recommendations 1971]. Hoppe Seylers Z Physiol Chem 1972, 353: 852-854.

[317] Sabatti C, Rohlin L, Lange K, Liao JC. Vocabulon: a dictionary model approach for reconstruction and localization of transcription factor binding sites. Bioinformatics 2005; 21: 922-931.

[318] Schomburg I, Chang A, Hofmann O, Ebeling C, Ehrentreich F, Schomburg D. BRENDA. a resource for enzyme data and metabolic information. Trends Biochem Sci 2002; 27: 54-56.

[319] Schomburg I, Chang A, Schomburg D. BRENDA, enzyme data and metabolic information. Nucleic Acids Res 2002; 30: 47-49.

[320] Ji ZL, Chen X, Zhen CJ, et al. KDBI. Kinetic Data of Biomolecular Interactions database. Nucleic Acids Res 2003; 31: 255257.

[321] Nagano N. EzCatDB. the Enzyme Catalytic-mechanism Database. Nucleic Acids Res 2005; 33: D407-412.

[322] Nagano N, Noguchi T, Akiyama Y. Systematic comparison of catalytic mechanisms of hydrolysis and transfer reactions classified in the EzCatDB database. Proteins 2007; 66: 147-159.

[323] Holliday GL, Almonacid DE, Bartlett GJ, O'Boyle N M, Torrance JW, Murray-Rust P, Mitchell JB, Thornton JM. MACiE (Mechanism, Annotation and Classification in Enzymes): novel tools for searching catalytic mechanisms. Nucleic Acids Res 2006.

[324] Holliday GL, Bartlett GJ, Almonacid DE, et al. MACiE. a database of enzyme reaction mechanisms. Bioinformatics 2005; 21: 43154316.

[325] Kumar MD, Bava KA, Gromiha MM, et al. ProTherm and ProNIT. thermodynamic databases for proteins and protein-nucleic acid interactions. Nucleic Acids Res 2006; 34: D204-206.

[326] Rigali S, Schlicht M, Hoskisson P, et al. Extending the classification of bacterial transcription factors beyond the helix-turn-helix 
motif as an alternative approach to discover new cis/trans relationships. Nucleic Acids Res 2004; 32: 3418-3426.

[327] Stegmaier P, Kel AE, Wingender E. Systematic DNA-binding domain classification of transcription factors. Genome Inform 2004; 15 : 276-286.

[328] Chen M, Lin S, Hofestaedt R. STCDB. Signal Transduction Classification Database. Nucleic Acids Res 2004; 32: D456-458.

[329] Saier MH, Jr.: A functional-phylogenetic system for the classification of transport proteins. J Cell Biochem 1999; Suppl 32-33: 8494.

[330] Tamura M, Hendrix DK, Klosterman PS, Schimmelman NR, Brenner SE, Holbrook SR. SCOR. Structural Classification of RNA, version 2.0. Nucleic Acids Res 2004; 32: D182-184.

[331] von Grotthuss M, Koczyk G, Pas J, Wyrwicz LS, Rychlewski L. Ligand.Info small-molecule Meta-Database. Comb Chem High Throughput Screen 2004; 7: 757-761.

[332] Ceroni A, Costa F, Frasconi P. Classification of small molecules by two- and three-dimensional decomposition kernels. Bioinformatics 2007; 23: 2038-2045.

[333] Selkov E, Basmanova S, Gaasterland T, et al. The metabolic pathway collection from EMP. the enzymes and metabolic pathways database. Nucleic Acids Res 1996; 24: 26-28.

[334] Campagne F, Neves S, Chang CW, Skrabanek L, Ram PT, Iyengar $\mathrm{R}$, Weinstein H. Quantitative information management for the biochemical computation of cellular networks. SCi STKE 2004; pl11.

[335] Keseler IM, Collado-Vides J, Gama-Castro S, et al. EcoCyc: a comprehensive database resource for Escherichia coli. Nucleic Acids Res 2005; 33: D334-337.

[336] Le Novere N. Model storage, exchange and integration. BMC Neurosci 2006; 7 Suppl 1: S11.

[337] Le Novere N, Bornstein B, Broicher A, et al. BioModels Database: a free, centralized database of curated, published, quantitative kinetic models of biochemical and cellular systems. Nucleic Acids Res 2006; 34: D689-691.

[338] Le Novere N, Finney A, Hucka M, et al. Minimum information requested in the annotation of biochemical models (MIRIAM). Nat Biotechnol 2005; 23: 1509-1515.

[339] Olivier BG, Snoep JL. Web-based kinetic modelling using JWS Online. Bioinformatics 2004; 20: 2143-2144.

[340] Salgado H, Gama-Castro S, Martinez-Antonio A, et al. RegulonDB (version 4.0): transcriptional regulation, operon organization and growth conditions in Escherichia coli K-12. Nucleic Acids Res 2004; 32: D303-306.

[341] Sivakumaran S, Hariharaputran S, Mishra J, Bhalla US. The Database of Quantitative Cellular Signaling: management and analysis of chemical kinetic models of signaling networks. Bioinformatics 2003; 19: 408-415.

[342] Hucka M, Finney A, Bornstein BJ, et al. Evolving a lingua franca and associated software infrastructure for computational systems biology: the Systems Biology Markup Language (SBML) project. Syst Biol (Stevenage) 2004; 1: 41-53.

[343] Hucka M, Finney A, Sauro HM, et al. The systems biology markup language (SBML): a medium for representation and exchange of biochemical network models. Bioinformatics 2003; 19: 524-531.

[344] Lloyd CM, Halstead MD, Nielsen PF. CellML. its future, present and past. Prog Biophys Mol Biol 2004; 85: 433-450.

[345] Stromback L, Lambrix P. Representations of molecular pathways: an evaluation of SBML, PSI MI and BioPAX. Bioinformatics 2005; 21: 4401-4407.

[346] Cao Y, Gillespie D, Petzold L. Multiscale stochastic simulation algorithm with stochastic partial equilibrium assumption for chemically reacting systems. J Comput Physics 2005; 206: 395411.

[347] Cao Y, Gillespie DT, Petzold LR. Accelerated stochastic simulation of the stiff enzyme-substrate reaction. J Chem Phys 2005; 123 : 144917.

[348] Cao Y, Gillespie DT, Petzold LR. The slow-scale stochastic simulation algorithm. J Chem Phys 2005; 122: 14116.

[349] Cao Y, Li H, Petzold L. Efficient formulation of the stochastic simulation algorithm for chemically reacting systems. J Chem Phys 2004; 121: 4059-4067.

[350] Machne R, Finney A, Muller S, Lu J, Widder S, Flamm C. The SBML ODE Solver Library: a native API for symbolic and fast numerical analysis of reaction networks. Bioinformatics 2006; 22: 1406-1407.
[351] Schmidt H, Jirstrand M. Systems Biology Toolbox for MATLAB. a computational platform for research in systems biology. Bioinformatics 2006; 22: 514-515.

[352] Zi Z, Klipp E. SBML-PET. a Systems Biology Markup Languagebased parameter estimation tool. Bioinformatics 2006; 22: 27042705.

[353] Mulholland AJ. Modelling enzyme reaction mechanisms, specificity and catalysis. Drug Discov Today 2005; 10: 1393-1402.

[354] Urbanc B, Borreguero JM, Cruz L, Stanley HE. Ab initio discrete molecular dynamics approach to protein folding and aggregation. Methods Enzymol 2006; 412: 314-338.

[355] Alvarez-Vasquez F, Sims KJ, Cowart LA, Okamoto Y, Voit EO, Hannun YA. Simulation and validation of modelled sphingolipid metabolism in Saccharomyces cerevisiae. Nature 2005; 433: 425430.

[356] Veflingstad SR, Almeida J, Voit EO. Priming nonlinear searches for pathway identification. Theor Biol Med Model 2004; 1: 8 .

[357] Kaufman M, Thomas R. Model analysis of the bases of multistationarity in the humoral immune response. J Theor Biol 1987, 129: 141-162.

[358] Kaufman M, Thomas R. Emergence of complex behaviour from simple circuit structures. C R Biol 2003; 326: 205-214.

[359] Thieffry D, Thomas R. Dynamical behaviour of biological regulatory networks--II. Immunity control in bacteriophage lambda. Bull Math Biol 1995; 57: 277-297.

[360] Schilling CH, Covert MW, Famili I, Church GM, Edwards JS, Palsson BO. Genome-scale metabolic model of Helicobacter pylori 26695. J Bacteriol 2002; 184: 4582-4593.

[361] Schilling CH, Edwards JS, Letscher D, Palsson BO. Combining pathway analysis with flux balance analysis for the comprehensive study of metabolic systems. Biotechnol Bioeng 2000; 71: 286-306.

[362] Schilling $\mathrm{CH}$, Palsson BO. The underlying pathway structure of biochemical reaction networks. Proc Natl Acad Sci USA 1998; 95: 4193-4198.

[363] Thieffry D, Thomas R. Qualitative analysis of gene networks. Pac Symp Biocomput 1998: 77-88.

[364] Sorribas A, Hernandez-Bermejo B, Vilaprinyo E, Alves R. Cooperativity and saturation in biochemical networks: A saturable formalism using Taylor series approximations. Biotechnol Bioeng 2006.

[365] Frasch HF, Barbero AM. Steady-state flux and lag time in the stratum corneum lipid pathway: results from finite element models. J Pharm Sci 2003; 92: 2196-2207.

[366] Barrett CL, Kim TY, Kim HU, Palsson BO, Lee SY. Systems biology as a foundation for genome-scale synthetic biology. Curr Opin Biotechnol 2006; 17: 488-492.

[367] Becker SA, Feist AM, Mo ML, Hannum G, Palsson BO, Herrgard MJ. Quantitative prediction of cellular metabolism with constraintbased models: the COBRA Toolbox. Nat Protoc 2007; 2: 727-738.

[368] Becker SA, Palsson BO. Genome-scale reconstruction of the metabolic network in Staphylococcus aureus N315: an initial draft to the two-dimensional annotation. BMC Microbiol 2005; 5 : 8.

[369] Becker SA, Price ND, Palsson BO. Metabolite coupling in genomescale metabolic networks. BMC Bioinformatics 2006; 7: 111.

[370] Duarte NC, Becker SA, Jamshidi N, et al. Global reconstruction of the human metabolic network based on genomic and bibliomic data. Proc Natl Acad Sci USA 2007; 104: 1777-1782.

[371] Duarte NC, Herrgard MJ, Palsson BO. Reconstruction and validation of Saccharomyces cerevisiae iND750, a fully compartmentalized genome-scale metabolic model. Genome Res 2004; 14: 12981309.

[372] Duarte NC, Palsson BO, Fu P. Integrated analysis of metabolic phenotypes in Saccharomyces cerevisiae. BMC Genomics 2004; 5: 63.

[373] Herrgard MJ, Covert MW, Palsson BO. Reconciling gene expression data with known genome-scale regulatory network structures. Genome Res 2003; 13: 2423-2434.

[374] Herrgard MJ, Fong SS, Palsson BO. Identification of genome-scale metabolic network models using experimentally measured flux profiles. PLoS Comput Biol 2006; 2: e72.

[375] Herrgard MJ, Lee BS, Portnoy V, Palsson BO. Integrated analysis of regulatory and metabolic networks reveals novel regulatory mechanisms in Saccharomyces cerevisiae. Genome Res 2006; 16 : 627-635.

[376] Joyce AR, Palsson BO. The model organism as a system: integrating 'omics' data sets. Nat Rev Mol Cell Biol 2006; 7: 198-210. 
[377] Joyce AR, Palsson BO. Toward whole cell modeling and simulation: comprehensive functional genomics through the constraintbased approach. Prog Drug Res 2007; 64: 265, 267-309.

[378] Joyce AR, Reed JL, White A, Edwards R, et al. Experimental and computational assessment of conditionally essential genes in Escherichia coli. J Bacteriol 2006; 188: 8259-8271.

[379] Price ND, Papin JA, Schilling CH, Palsson BO. Genome-scale microbial in silico models: the constraints-based approach. Trends Biotechnol 2003; 21: 162-169.

[380] Reed JL, Palsson BO. Genome-scale in silico models of E. coli have multiple equivalent phenotypic states: assessment of correlated reaction subsets that comprise network states. Genome Res 2004; 14: 1797-1805.

[381] Reed JL, Patel TR, Chen KH, et al. Systems approach to refining genome annotation. Proc Natl Acad Sci USA 2006; 103: 1748017484.

[382] Aldridge BB, Burke JM, Lauffenburger DA, Sorger PK. Physicochemical modelling of cell signalling pathways. Nat Cell Biol 2006; 8: 1195-1203.

[383] Jahnke T, Huisinga W. Solving the chemical master equation for monomolecular reaction systems analytically. J Mathematical Biol 2007; 54: 1-26.

[384] Munsky B, Khammash M. The finite state projection algorithm for the solution of the chemical master equation. J Chem Phys 2006; 124: -.

[385] Qian H. Open-system nonequilibrium steady state: Statistical thermodynamics, fluctuations, and chemical oscillations. J Phys Chem B 2006; 110: 15063-15074.

[386] Rao CV, Arkin AP. Stochastic chemical kinetics and the quasisteady-state assumption: Application to the Gillespie algorithm. Journal of Chemical Physics 2003; 118: 4999-5010.

[387] Chance B, Greenstein DS, Higgins J, Yang CC. The mechanism of catalase action. II. Electric analog computer studies. Arch Biochem 1952, 37: 322-339.

[388] Chance B, Greenstein DS, Roughton FJ. The mechanism of catalase action. I. Steady-state analysis. Arch Biochem 1952, 37: 301321.

[389] Michaelis L, Menten M. Die Kinetik der Invertinwirkung. Biochem Z 1913, 49: 333-369.

[390] Savageau MA. Biochemical systems analysis. II. The steady-state solutions for an n-pool system using a power-law approximation. $J$ Theor Biol 1969, 25: 370-379.

[391] Savageau MA. Biochemical systems analysis. I. Some mathematical properties of the rate law for the component enzymatic reactions. J Theor Biol 1969, 25: 365-369.

[392] Savageau MA. Biochemical systems analysis. 3. Dynamic solutions using a power-law approximation. J Theor Biol 1970, 26: 215-226.

[393] Hlavacek WS, Savageau MA. Subunit structure of regulator proteins influences the design of gene circuitry: analysis of perfectly coupled and completely uncoupled circuits. J Mol Biol 1995; 248 : 739-755.

[394] Hlavacek WS, Savageau MA. Rules for coupled expression of regulator and effector genes in inducible circuits. J Mol Biol 1996; 255: 121-139.

[395] Irvine DH, Savageau MA. Network regulation of the immune response: alternative control points for suppressor modulation of effector lymphocytes. J Immunol 1985, 134: 2100-2116.

[396] Irvine DH, Savageau MA. Network regulation of the immune response: modulation of suppressor lymphocytes by alternative signals including contrasuppression. J Immunol 1985, 134: 2117 2130.

[397] Savageau MA. Comparison of classical and autogenous systems of regulation in inducible operons. Nature 1974, 252: 546-549.

[398] Savageau MA. Optimal design of feedback control by inhibition. $J$ Mol Evol 1974, 4: 139-156.

[399] Savageau MA. Optimal design of feedback control by inhibition: dynamic considerations. J Mol Evol 1975, 5: 199-222.

[400] Savageau MA. Mathematics of organizationally complex systems. Biomed Biochim Acta 1985, 44: 839-844.

[401] Savageau MA. A theory of alternative designs for biochemical control systems. Biomed Biochim Acta 1985, 44: 875-880.

[402] Savageau MA. The challenge of reconstruction. New Biol 1991; 3: 101-102.

[403] Savageau MA. Reconstructionist molecular biology. New Biol 1991; 3: 190-197.

[404] Savageau MA. Demand theory of gene regulation. I. Quantitative development of the theory. Genetics 1998; 149: 1665-1676.

[405] Savageau MA. Demand theory of gene regulation. II. Quantitative application to the lactose and maltose operons of Escherichia coli. Genetics 1998; 149: 1677-1691.

[406] Savageau MA. Design principles for elementary gene circuits: Elements, methods, and examples. Chaos 2001; 11: 142-159.

[407] Visser D, Heijnen JJ. The mathematics of metabolic control analysis revisited. Metab Eng 2002; 4: 114-123.

[408] Visser D, Heijnen JJ. Dynamic simulation and metabolic re-design of a branched pathway using linlog kinetics. Metab Eng 2003; 5 : 164-176.

[409] Heijnen JJ. Approximative kinetic formats used in metabolic network modeling. Biotechnol Bioeng 2005; 91: 534-545.

[410] Alves R, Vilaprinyo E, Hernandez-Bermejo B, Sorribas A. Mathematical formalisms based on approximated kinetic representations for modeling genetic and metabolic pathways. Biotechnol Genet Eng Rev 2008, 25: submitted.

[411] Liebermeister W, Klipp E. Bringing metabolic networks to life: convenience rate law and thermodynamic constraints. Theor Biol Med Model 2006; 3: 41. 